\title{
Thermoeconomic Design Optimization of a KRW-Based IGCC Power Plant
}

Final Report

G. Tsatsaronis

L. Lin

J. Pisa

T. Tawfilk

November 1991

Work Performed Under Contract No.: DE-FC21-89MC26019

For

U.S. Department of Energy

Office of Fossil Energy

Morgantown Energy Technology Center

Morgantown, West Virginia

By

Southern Company Services, Inc.

Research and Environmental Affairs

Birmingham, Alabama

and

Tennessee Technological University

Center for Electric Power

Cookeville, Tennessee 


\section{DISCLAIMER}

This report was prepared as an account of work sponsored by an agency of the United States Government. Neither the United States Government nor any agency thereof, nor any of their employees, makes any warranty, express or implied, or assumes any legal liability or responsibility for the accuracy, completeness, or usefulness of any information, apparatus, product, or process disclosed, or represents that its use would not infringe privately owned rights. Reference hercin to any specific commercial product, process, or service by trade name, trademark, manufacturer, or otherwise does not necessarily constitute or imply its endorsement, recommendation, or favoring by the United States Government or any agency thereof. The views and opinions of authors expressed herein do not necessarily state or reflect those of the United States Government or any agency thereof.

This report has been reproduced directly from the best available copy.

Available to DOE and DOE contractors from the Office of Scientific and Technical Information, P.O. Box 62, Oak Ridge, TN 37831; prices available from (615)576-8401,

Available to the public from the National Technical Information Service, U.S. Department of Commerce, 5285 Port Royal Rd., Springfield, VA 22161. 


\title{
Thermoeconomic Design Optimization
} of a KRW-Based IGCC Power Plant

\author{
Final Report
}

G. Tsatsaronis

L. Lin

J. Pisa

T. Tawfik

Work Performed Under Contract No.: DE-FC21-89MC26019

For

U.S. Department of Energy Office of Fossil Energy

Morgantown Energy Technology Center

P.O. Box 880

Morgantown, West Virginia 26507-0880

By

Southern Company Services, Inc.

Research and Environmental Affairs

P.O. Box 2625

Birmingham, Alabama 35202

and

Tennessee Technological University

Center for Electric Power

Cookeville, Tennessee 38505

November 1991 


\begin{abstract}
This report discusses the cost and efficiency optimization of an integrated gasification-combined-cycle (IGCC) power plant design and the effects of important design options and parameters. Advanced thermoeconomic techniques were used to evaluate and optimize a given IGCC concept which uses Illinois No. 6 bituminous coal, air-blown KRW coal gasifiers, a hot gas cleanup system, and GE MS7001F gas turbines.

The study was sponsored by the U.S. Department of Energy Morgantown Energy Technology Center and was conducted by the Tennessee Technological University Center for Electric Power. Southern Company Services, Inc. managed the project. Other participants were The M. W. Kellogg Company and General Electric Company.

Three optimal design concepts are presented and discussed in the report. Two of the concepts are characterized by minimum cost of electricity at two different values of the steam high pressure. The third concept represents the thermodynamic optimum. This study identified several differences between the original design and the design of the optimized cases. Compared with the original concept, significant annual savings are achieved in the cost optimal cases.

Comparisons were made between results obtained using both the old and the new performance data for the MS7001F gas turbine. This report discusses the effects of gasification temperature, steam high pressure, coal moisture, and various design options on the overall plant efficiency and cost of electricity. Cost sensitivity studies were conducted and recommendations for future studies were made.
\end{abstract}




\section{ACKNOWLEDGEMENTS}

Many individuals from several companies helped in the production of this study. Appreciation is extended to the following contributors:

Southern Company Services, Inc.

Rodney E. Sears, Research \& Environmental Affairs (Project Manager)

Robert B. Hinshaw, Power \& Systems Engineering - Mechanical

J. Douglas Maxwell, Research \& Environmental Affairs

Ted W. Wilson, Cost and Scheduling

Southern Electric International, Inc.

David T. Gallaspy (Project Manager until June 1991 while at SCS)

The M. W. Kellogg Company

William M. Campbell

Gopal K. Mathur

General Electric Company

Thomas E. Ekstrom

Industrial Filter \& Pump Manufacturing Company

Paul Eggerstedt

Henry Vogt Machine Company

Paul Eberle

Program Management and Oversight

R. Daniel Brdar, U.S. Department of Energy, Morgantown Energy Technology Center

Gary A. Styles, Southern Company Services, Research \& Environmental Affairs 


\section{CONTENTS}

Page

NOMENCLATURE $\ldots \ldots \ldots \ldots \ldots \ldots \ldots \ldots \ldots \ldots \ldots$

ACRONYMS AND ABBREVIATIONS $\ldots \ldots \ldots \ldots$ viii

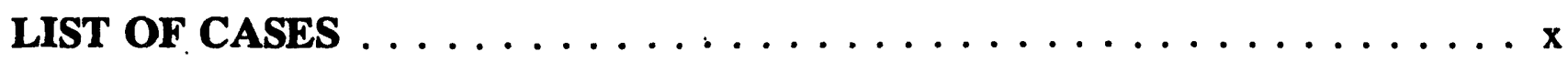

UNITS CONVERSION FACTORS $\ldots \ldots \ldots \ldots \ldots \ldots \ldots \ldots \ldots$

EXECUTIVE SUMMARY $\ldots \ldots \ldots \ldots \ldots \ldots \ldots \ldots$

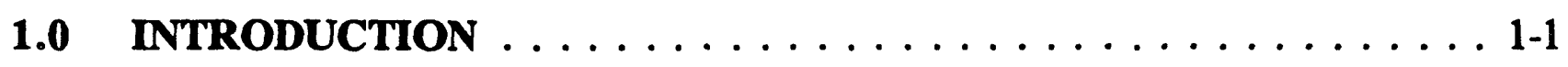

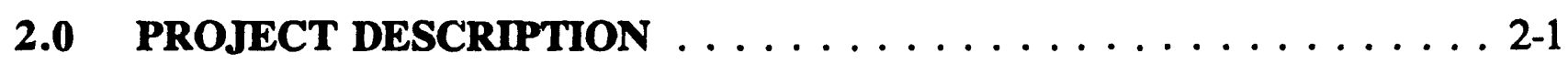

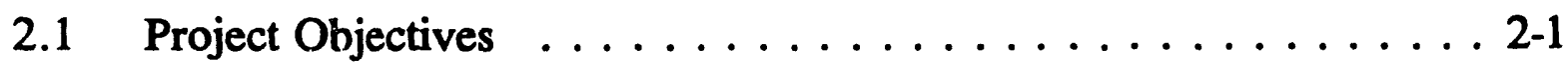

2.2 Project Organization ................ 2-1

2.3 IGCC Plant Description . . . . . . . . . . . . . . . 2-1

2.4 Recommendations from the Previous Thermoeconomic Analysis 2-13

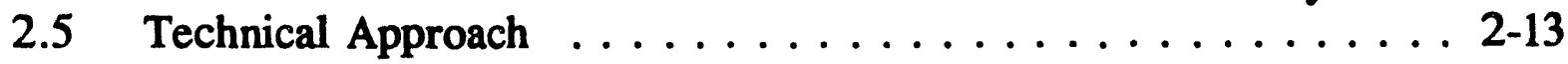

2.6 Organization of the Report $\ldots \ldots \ldots \ldots \ldots \ldots \ldots \ldots \ldots$

3.0 THERMOECONOMIC ANALYSIS AND OPTIMIZATION

OF ENERGY SYSTEMS $\ldots \ldots \ldots \ldots \ldots \ldots \ldots \ldots \ldots \ldots$

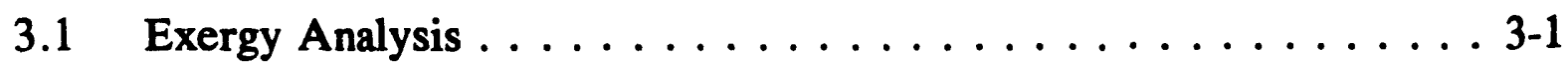

3.2 Thermoeconomic Evaluation . . . . . . . . . . . 3-3

3.3 Thermoeconomic Optimization . . . . . . . . . . . 3-5

3.4 Benefits of Thermoeconomics $\ldots \ldots \ldots \ldots \ldots \ldots \ldots \ldots$ 3-8

4.0 RESULTS OF THE THERMOECONOMIC OPTIMIZATION . . . . . 4-1

4.1 Description of Case $1 \mathrm{CO} 1 \ldots \ldots \ldots \ldots$. . . . . . . . . . . . .

4.2 Description of Case $1 \mathrm{CO} 2 \ldots \ldots \ldots \ldots$. . . . . . . . . . . . . .

4.3 Description of Case $1 \mathrm{TO} \ldots \ldots \ldots$. . . . . . . . . . . . . . . . .

4.4 Discussion of Design Changes . . . . . . . . . . . . . 4-36

4.4.1 Area 250 - Air Booster Compression . . . . . . . . 4-36 


\section{CONTENTS}

Page

4.0 RESULTS OF THE THERMOECONOMIC

OPTIMIZATION (Continued) $\ldots \ldots \ldots \ldots \ldots \ldots$. . . . . . . .

4.4.2 Area 300 - KRW Gas ilcation . . . . . . . . . . 4-37

4.4.3 Area 360/380 - Heat Recovery and Recycle

Gas Compression . . . . . . . . . . . . 4 4-40

4.4.4 Area 400 - Gas Conditioning . . . . . . . . 4-42

4.4.5 Area 500 - External Desulfurization . . . . . . . 4 4-42

4.4.6 Area 600 - Sulfation . . . . . . . . . . . 4-43

4.4.7 Area 900 - Gas Turbine System . . . . . . . . . 4-43

4.4.8 Area 1000 - HRSG System . . . . . . . . . . . 4-44

4.4.9 Area 1100 - Steam Turbine System . . . . . . . . . 4-45

4.5 Comparison of Cases $1,1 \mathrm{CO} 1,1 \mathrm{CO} 2$ and $1 \mathrm{TO} 1 \ldots \ldots$. . . 4-45

5.0 PARAMETRIC STUDIES $\ldots \ldots \ldots \ldots \ldots \ldots \ldots \ldots$ 5-1

5.1 The Effect of Gasification Temperature . . . . . . . . . 5-1

5.2 The Effect of Coal Moisture . . . . . . . . . . . 5-1

5.3 The Effect of HP Steam Pressure . . . . . . . . . . 5-1

5.4 The Effect of Gas Turbine Performance . . . . . . . . . 5-5

5.5 Cost of Electricity Sensitivity Studies . . . . . . . . . . . . 5-7

6.0 CONCLUSIONS AND RECOMMENDATIONS . . . . . . . . . 6-1

7.0 REFERENCES $\ldots \ldots \ldots \ldots \ldots \ldots \ldots \ldots \ldots \ldots \ldots$ 7-1

\section{APPENDIX}




\section{NOMENCLATURE}

Symbol

c

d

D

$\dot{\boldsymbol{E}}$

f

F

g

$\dot{\mathbf{H}}$

$\Delta \mathbf{h}^{0}$

I

m

n

$\mathrm{P}$

Q

\section{Meaning [units]}

cost per exergy unit [\$/GJ or $\$ / M M B t u]$

relative cost difference between average cost per exergy unit of product and average cost per exergy unit of fuel

cost of exergy destruction [\$]

exergy flow rate $[M W$ or $M M B t u / h r]$

thermoeconomic factor denoting the contribution of the capital costs, $Z$, to the relative cost difference, $d$, between fuel and product in a plant component

variable expressing the criterion of thermosconomic similarity, Equations 3-12 and 3-17

constant in Equations 3-1C and 3-13 expressing the dependence of total net investment for a plant component on the efficiency and capacity of the component

enthalpy flow rate [MW or MMBiu/hr]

higher heating value $[\mathrm{kJ} / \mathrm{kg}$ or $\mathrm{Btu} / \mathrm{lbm}]$

investment cost [\$]

mass $[\mathrm{kg}$ or $\mathrm{lbm}]$

exponent in cost Equations 3-10 and 3-13

pressure [bar or psia]

heat [MJ or MBtu] 


\section{Symbol}

$\mathbf{r}$

$\dot{\mathbf{S}}$

T

$\dot{\mathbf{W}}$

$\mathbf{X}$

Z

Greek letters:

$\gamma$

$\epsilon$

$\zeta$

$\eta$

$\theta$

$\tau$

Subscripts:

D

F

\section{Meaning [units]}

ratio of capital costs to product exergy in a heat exchanger [\$/MJ or $\$ / \mathrm{MBtu}]$

entropy flow rate $[\mathrm{kW} / \mathrm{K}$ or $\mathrm{MBtu} / \mathrm{hr} \cdot \mathrm{R}]$

temperature $\left[{ }^{*} \mathrm{C}\right.$ or $\left.{ }^{*} \mathrm{~F}\right]$

power $[\mathrm{MW}]$

mole fraction [\%]

capital costs associated with a plant component and considered in cost equations [\$]

coefficient expressing the part of the fixed operating and maintenance costs which depends on the net investment expenditure for a plant component [\%]

capital recovery factor [\%]

exergetic efficiency [\%]

thermal efficiency [\%]

exergy destruction ratio [\%]

annual number of hours of plant operation at the nominal capacity [hr]

exergy destruction

fuel (according to the definition of exergetic efficiency) 


$\begin{array}{ll}\text { Symbol } & \text { Meaning [units] } \\ \text { i } & \text { stream } \\ \text { in } & \text { input } \\ \text { j } & \text { output stream } \\ \text { k } & \text { plant component } \\ \text { L } & \text { exergy losses } \\ \text { LOSS } & \text { heat losses } \\ \text { P } & \text { product (according to the definition of exergetic efficiency) } \\ \text { tot } & \text { total plant } \\ \text { Superscripts: } & \\ \text { OPT } & \text { optimum } \\ \text { - } & \text { time rate of the corresponding variable }\end{array}$




\section{LIST OF ACRONYMS AND ABBREVIATIONS}

$\begin{array}{ll}\text { ACRS } & \text { Accelerated Cost Recovery System } \\ \text { AFDC } & \text { Allowance for Funds During Construction } \\ \text { ASPEN } & \text { Computer Simulation Software } \\ \text { BFW } & \text { Boiler Feedwater } \\ \text { BLDWN } & \text { Blowdown } \\ \text { CM } & \text { Coal Moisture at the Gasifier Inlet } \\ \text { COE } & \text { Cost of Electricity } \\ \text { CT } & \text { Combustion Turbine } \\ \text { CTG } & \text { Combustion Turbine Generator } \\ \text { DOE } & \text { U.S. Department of Energy } \\ \text { DOE/METC } & \text { U.S. Department of Energy/Morgantown Energy Technology Center } \\ \text { EPRI } & \text { Electric Power Research Institute } \\ \text { EXD } & \text { Exergy Destruction } \\ \text { FGD } & \text { Flue Gas Desulfurization } \\ \text { FWH } & \text { Feedwater Heater } \\ \text { GE } & \text { General Electric Company } \\ \text { GI } & \text { Gasification Island } \\ \text { GPC } & \text { Georgia Power Company } \\ \text { GSC } & \text { Gland Seal Condenser } \\ \text { GT } & \text { Gasification Temperature } \\ \text { HHV } & \text { Higher Heating Value } \\ \text { HP } & \text { High Pressure } \\ \text { HRSD } & \text { Heat Recovery Steam Drum } \\ \text { HRSG } & \text { Heat Recovery Steam Generat r } \\ \text { IGCC } & \text { Integrated Gasification Combined Cycle } \\ \text { IP } & \text { Intermediate Pressure } \\ \end{array}$




\section{LIST OF ACRONYMS AND ABBREVIATIONS (Continued)}

KRW

KRW Energy Systems

LASH Limestone-Containing Ash

LHV Lower Heating Value

LP Low Pressure

MWK The M. W. Kellogg Company

O\&M Operation and Maintenance

PC Pulverized-Coal

PH Preheater

PI Power Island

PPC Process Plant Cost

PROMOD Computer Simulation Model

RAM Reliability Availability Maintainability

RGC Recycle Gas Cooler

SCS Southern Company Services, Inc.

SHP Steam High Pressure

SN Stream Number

SSR $\quad$ Steam Seal Regulator

STG Steam Turbine-Generator

TAG Technology Assessment Guide (EPRI)

TCR Total Capital Requirement

THESIS Thermodynamic and Economic Simulation System (computer software)

TPC Total Plant Cost

TPI Total Plant Investment

TTU Tennessee Technological University

UNIRAM Software Application for Reliability, Availability, and Maintainability 


\section{LIST OF CASES MENTIONED IN THIS REPORT}

Case Explanation

1 Uriginal Case 1 (see section 2.3). This case is identical with Case 1 in Reference [1] (GT $=1900^{\circ} \mathrm{F} ; \mathrm{CM}=4.98 \%$; SHP $=1600$ psia)

1A Same design configuration as in the original Case $1 . \quad\left(G T=1800^{\circ} \mathrm{F}\right.$;

$\mathrm{CM}=4.98 \%$; SHP $=1600$ psia)

1B Same design configuration as in the original Case 1. (GT=2000 $\mathrm{F}$;

$\mathrm{CM}=4.98 \%$; $\mathrm{SHP}=1600$ psia)

1C Same design configuration in the gasification island as in the cost optimal Cases $1 \mathrm{CO} 1$ and $1 \mathrm{CO} 2$. (GT $=1800^{\circ} \mathrm{F} ; \mathrm{CM}=11.12 \%$; SHP $=1815$ psia)

$1 \mathrm{CO}$ Cost Optimal Case 1 (see section 4.1) at a relatively high steam pressure. (GT $\left.=1920^{\circ} \mathrm{F} ; \mathrm{CM}=11.12 \% ; \mathrm{SHP}=2055 \mathrm{psia}\right)$

$1 \mathrm{CO} 2$ Cost Optimal Case 1 (see section 4.2) at a steam pressure value close to the original Case 1 value. Same design configuration in the gasification island as in the Case 1CO1. (GT $=1920^{\circ} \mathrm{F} ; \mathrm{CM}=11.12 \%$; $\mathrm{SHP}=1515$ psia)

1 TO1 Thermodynamically optimal case 1 (see section 4.3$)$. (GT $=1800^{\circ} \mathrm{F}$; $\mathrm{CM}=11.12 \%$; SHP $=2200$ psia)

Abbreviations

GT Gasification temperature

CM Coal moisture at the gasifier inlet (weight percent)

SHP Steam high pressure 


\section{UNITS CONVERSION FACTORS}

Temperature

$\mathrm{T}[\cdot \mathrm{F}]=\frac{9}{5} \mathrm{~T}[\cdot \mathrm{C}]+32$

Pressure

$1 \mathrm{bar}=14.504 \mathrm{psia}$

1 bar $=29.530$ inches $\mathrm{Hg}$

$1 \mathrm{bar}=0.1 \mathrm{MPa}$

Mass

$1 \mathrm{~kg}=2.2046 \mathrm{lbm}$

Mass flow rate

$1 \mathrm{~kg} / \mathrm{s}=7936.6 \mathrm{lbm} / \mathrm{hr}$

Energy (or Exergy)

$1 \mathrm{kv} / \mathrm{h}=3.6 \mathrm{MJ}$

$1 \mathrm{MJ}=10^{6} \mathrm{~J}=0.9478 \mathrm{MBtu}$

$1 \mathrm{GJ}=10^{\circ} \mathrm{J}=0.9478 \mathrm{MMBtu}$

Specific energy (or exergy) $1 \frac{\mathrm{MJ}}{\mathrm{kg}}=0.4299 \frac{\mathrm{MBtu}}{\mathrm{lbm}}$

Power (energy flow rate) $\quad 1 \mathrm{MW}=10^{6} \mathrm{~W}=3.412 \frac{\mathrm{MMBtu}}{\mathrm{hr}}$

Eniropy flow rate

$$
1 \frac{\mathrm{MW}}{\mathrm{K}}=1.8956 \frac{\mathrm{MMBtu}}{\mathrm{hr} \cdot{ }^{\circ} \mathrm{F}}
$$

Cost per exergy unit

$$
1 \frac{\$}{\mathrm{GJ}}=1.0551 \frac{\$}{\mathrm{MMBtu}}
$$

Meaning of Prefixes

SI System of Units

$$
\mathrm{G}=10^{9} ; \mathrm{k}=10^{3} ; \mathrm{M}=10^{6}
$$

English System of Units

$$
\mathrm{M}=10^{3} ; \mathrm{MM}=10^{6}
$$




\section{EXECUTIVE SUMMARY}

Several integrated gasification-combined-cycle (IGCC) power plants are currently under development to provide a clean, efficient and cost effective option for generating electric power from coal. Through a joint site-specific project with the U.S. Department of Energy (DOE) Morgantown Energy Technology Center (METC), Southern Company Services, Inc. (SCS) conducted a comprehensive study to determine the characteristics of IGCC power plants with respect to thermal and environmental performance, capital costs and electricity costs. The results of that study are summarized in Reference [1].

Among the power plant configurations developed and compared in that study, the so-called Case 1 design configuration was found to be an attractive IGCC power plant configuration. This plant uses four air-blown KRW coal gasifiers, a hot gas cleanup system, and two GE MS7001F gas turbines. However, no attempt was made to minimize the cost of electricity (COE) in the results presented in Reference [1]. Indeed, final conclusions from the comparison of different IGCC design configurations should only be drawn after these configurations have been optimized from the economic viewpoint, or at least after the potential for further cost and efficiency improvements has been estimated.

To optimize the design of Case 1 using advanced thermoeconomic optimization techniques, SCS entered into a supplementary project with DOE/METC. The simulation and optimization studies reported here were conducted by the Tennessee Technological University (TTU) Center for Electric Power under a subcontract to SCS. SCS was responsible for overall project management and cost estimates in the power island. The M. W. Kellogg Company provided TTU with material and energy balances in addition to cost estimates for the gasification island. Some other companies (General Electric, Industrial Filter and Pump Manufacturing, and the Henry Vogt Machine Company) provided performance and cost data for specific equipment items.

The major objectives of this supplementary project were to:

- Study the effect of various design options on the plant efficiency and the cost of electricity generated by an IGCC power plant using Illinois No. 6 bituminous coal, air-blown KRW coal gasifiers, a hot gas cleanup system, and industrial gas turbines.

- Develop an IGCC power plant concept characterized by minimum cost of electricity. 
Severai design concepts were developed and evaluated on the same basis as those in Reference [1]. For each case, a process design was developed; capital costs, O\&M costs and cost of electricity were estimated; det : led thermoeconomic analyses were conducted; and suggestions for improving the cost effectiveness were developed. In addition to the original Case 1, three optimal cases were selected for presentation and discussion in this report. Two of the cases (1CO1 and 1CO2) are cost optimal cases while the third case (1TO1) represents the thermodynamic optimum. Figures 1 and 2 show the simplified flow diagram of Case $1 \mathrm{CO} 1$ as an example of the design configurations optimized in the present study.

The major differences among the cases discussed here refer to the

- gasification temperature

- coal moisture at the gasifier inlet

- $\quad$ steam high pressure

- $\quad$ use of the heat of the flue gas from the sulfation area

- design of the heat recovery steam generator, product gas cooler, recycle gas cooler, exit gas cooler, and feedwater preheaters

- design of the HP section of the steam turbine, and

- $\quad$ steam extractions from the steam turbine.

Table 1 compares the primary features and performance of the cases addressed in this study. The cost optimal cases $1 \mathrm{CO} 1$ and $1 \mathrm{CO} 2$ have identical configurations of the gasification island. The major difference between these cases is in the value of the steam high pressure which is 2055 psia in Case $1 C O 1$ and 1515 psia in Case 1CO2. Case 1 TO1 represents the thermodynamically optimal case and demonstrates the potential for improving the overall plant efficiency.

The differences in the cold gas efficiency of the gasification island in Table 1 can Le explained by the differences in the gasification temperature and the coal moisture at the gasifier inlet. The sulfur removal in the gasifier is 91.4 percent for the three optimized cases and 86.5 percent for the original Case 1. The sulfur removal in the gasification island is the same, 99.4 percent, for all four cases.

The net power output varies between 458.4 MW (original Case 1) and 482.5 MW (Case 1CO1). As expected, Case 1TO1 possesses the lowest net plant heat rate $(8,181$ $\mathrm{Btu} / \mathrm{kWh})$. Case $1 \mathrm{CO} 1$ is the next lowest $(8,351 \mathrm{Btu} / \mathrm{kWh})$, while the original Case 1 has the highest net plant heat rate $(8,595 \mathrm{Btu} / \mathrm{kWh})$. The efficiency difference between Cases $1 \mathrm{CO} 1$ and $1 \mathrm{CO} 2$ is mainly caused by the difference in the steam high pressure value. 


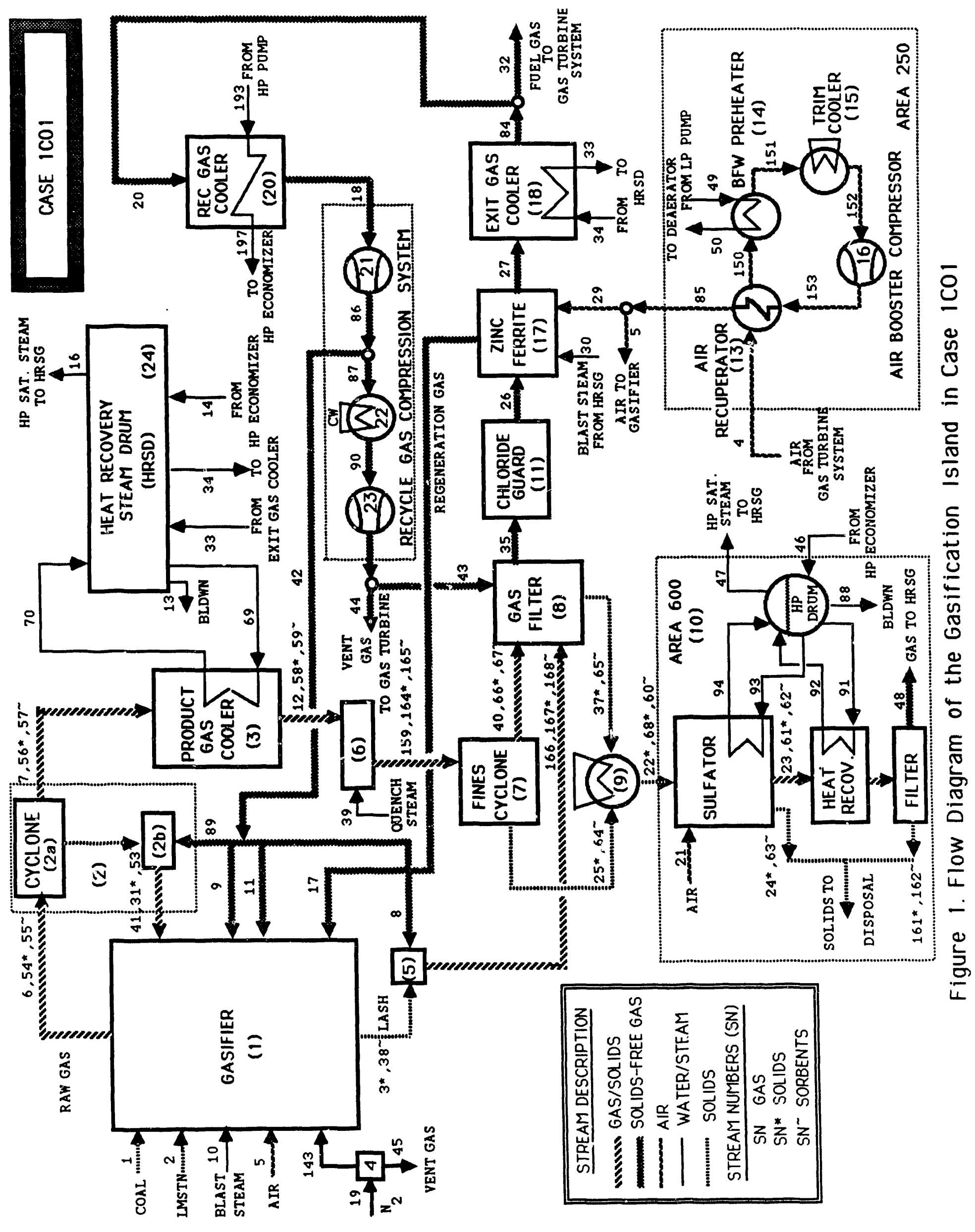




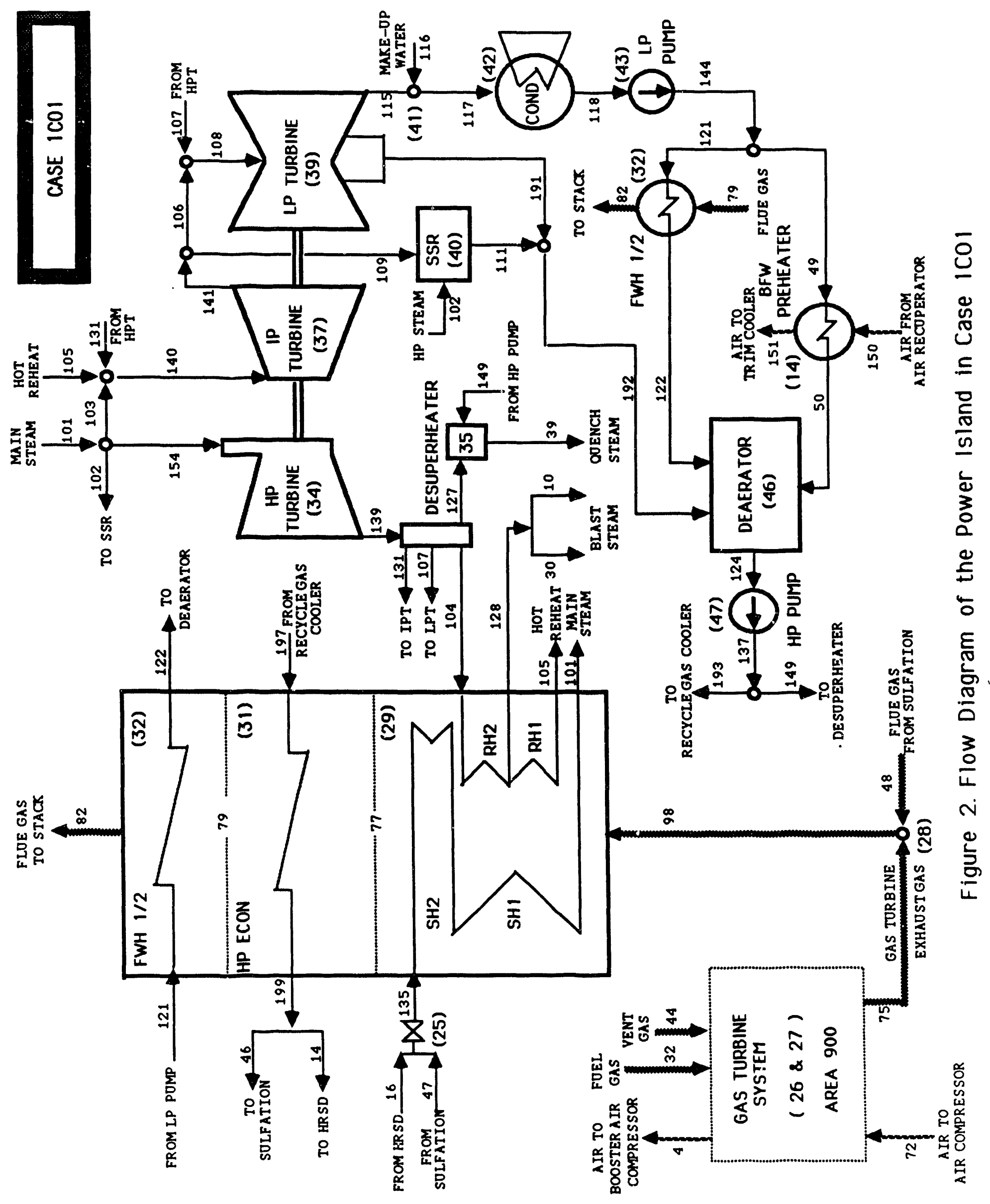


TABLE 1

Summary of Gasification Power Plant Performance

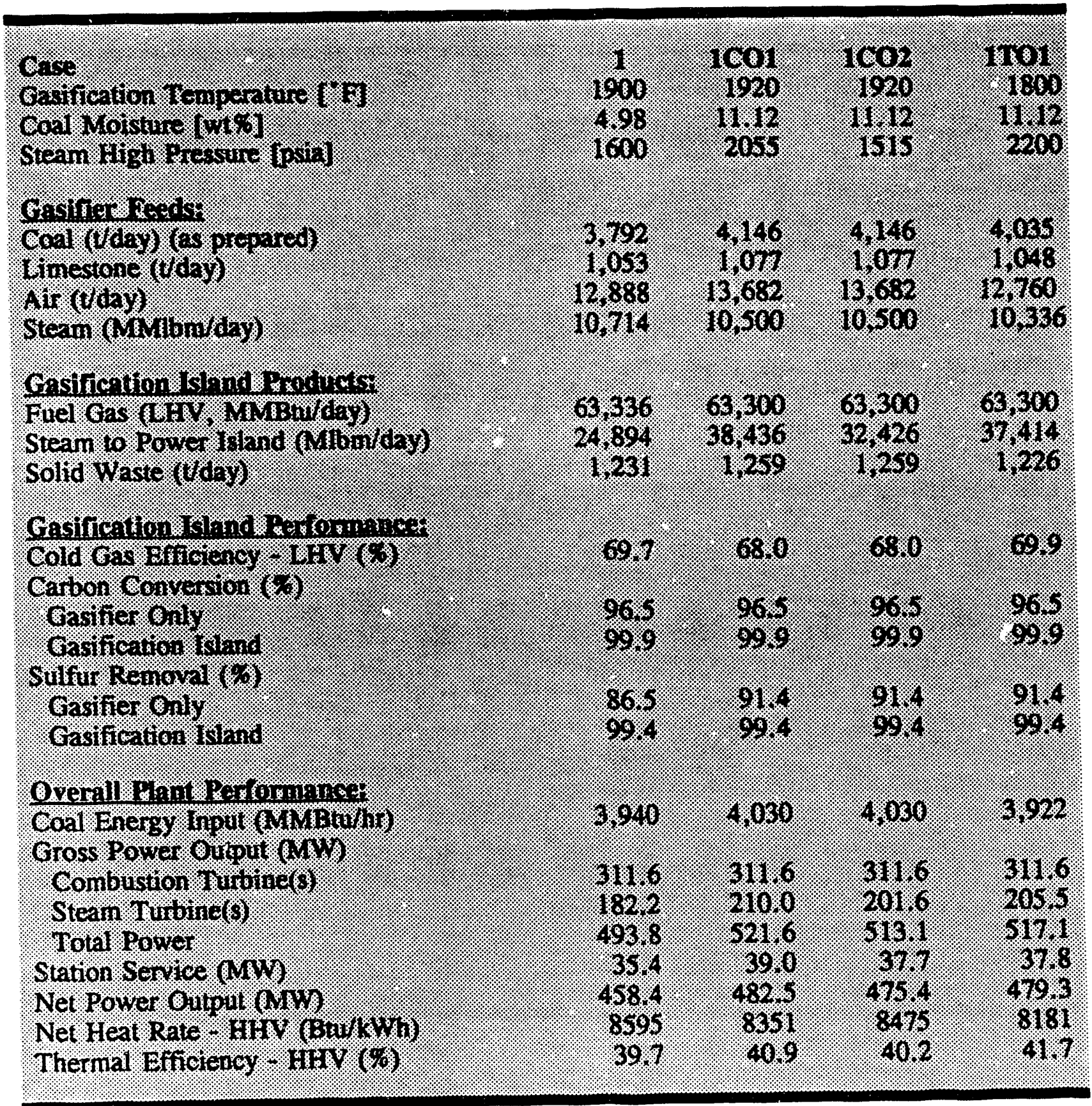


TABLE 2

Summary of Gasification Power Plant Costs

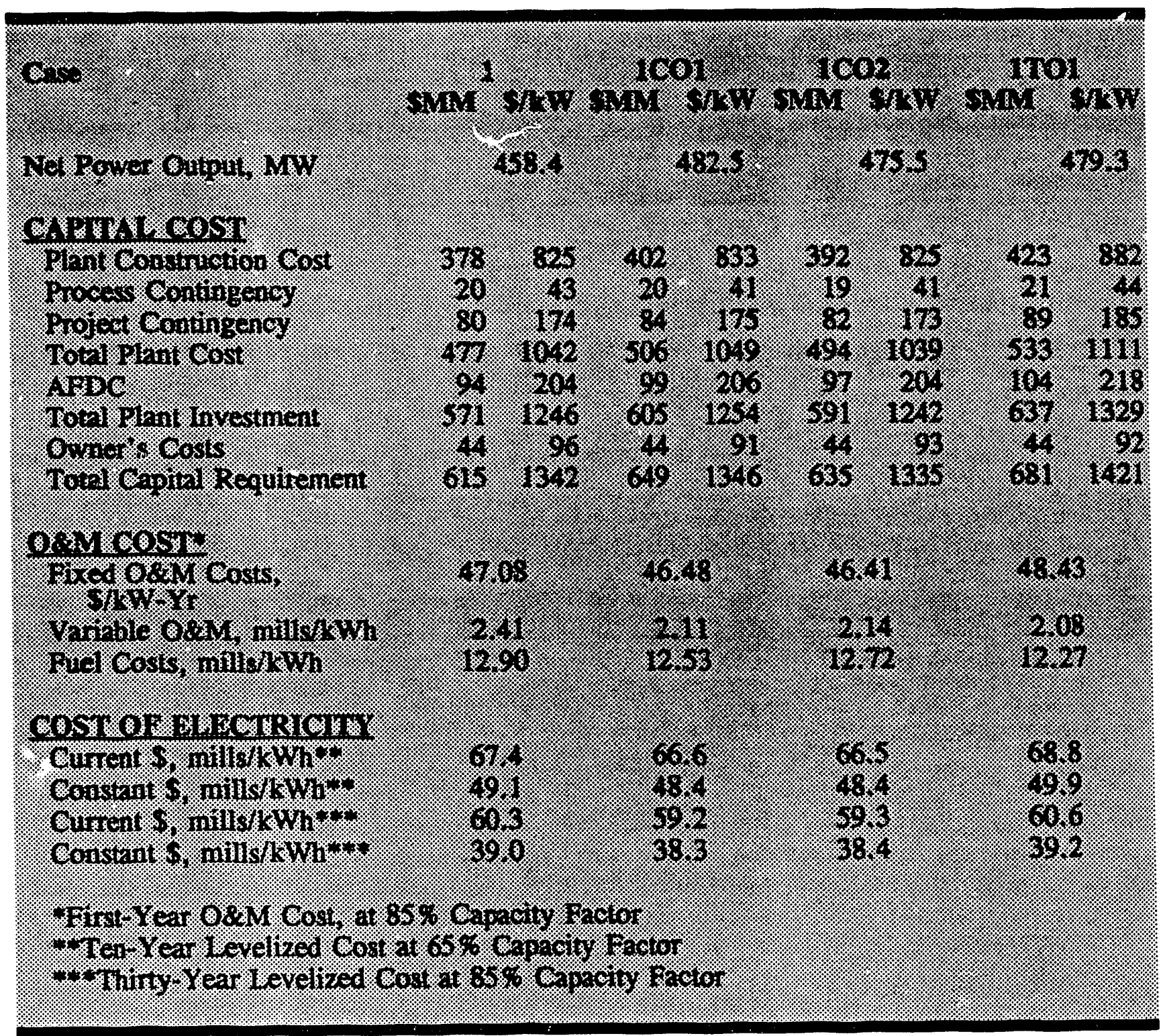


Table 2 provides a cost summary. The differences in the total capital requirement among the Cases 1, 1CO1 and 1CO2 (1335-1346 \$/kW) are less than one percent. The highest total capital requirement is for Case $1 \mathrm{TO}$ at $1421 \$ / \mathrm{kW}$, primarily the result of the optimization according to efficiency criteria.

Case $1 \mathrm{CO} 1$ possesses the lowest cost of electricity (COE) with $38.3 \mathrm{mills} / \mathrm{kWh}$ in constant dollars, 1.83 percent lower than the COE of the original Case 1(39.0 mills $/ \mathrm{kWh}$ ). Case $1 \mathrm{CO} 2$ is the next lowest with a COE of $38.4 \mathrm{mills} / \mathrm{kWh}$, which is 1.61 percent lower than the COE of the original Case 1. The highest COE is for Case 1TO1 at 39.2 mills $/ \mathrm{kWh}, 2.30$ percent greater than for Case $1 \mathrm{CO}$, but only 0.44 percent greater than the COE for the original Case 1.

The difference in COE between Case $1 \mathrm{CO} 1(1 \mathrm{CO} 2)$ and the original Case 1 results in savings of over 2.4 (2.2) million constant (mid-1990) dollars per year of plant operation. Compared with the original Case 1, the 30-year pre-tax present value of the cost savings in Cases $1 \mathrm{CO} 1$ and $1 \mathrm{CO} 2$ are 30.0 and 27.7 million constant mid-1990 dollars, respectively.

This study identified several design changes which improve the cost effectiveness of the Case 1 IGCC concept. These changes include the following:

- The coal should be supplied to the gasifier with the "as received" moisture of 11.12 weight percent, or with the highest moisture content allowed by the reliability of the coal feeding process.

- The gasification temperature and the steam high pressure should be optimized using the thermoeconomic variables discussed in section 3 . This optimization refers to the interaction between gasification island and power island.

- The heat of the flue gas from the sulfation area should be used in the HRSG.

- The mass flow rate of the quench steam should be decreased and its temperature increased through adjustments in the steam turbine and elimination of the desuperheating process.

- The BFW preheater in area 250 (air booster compression) and the recycle gas cooler should preheat LP (or low-temperature) instead of HP (or hightemperature) feedwater. 
- The recycle gas should be extracted from the clean gas after the exit gas cooler instead of after the zinc-ferrite unit.

- The size of the product gas cooler and the exit gas cooler should be increased to accommodate some of the above changes.

- The design of the HP steam turbine should be adjusted to the new steam high pressure values.

- The deaerator should be operated at the lowest possible pressure.

- At least one LP steam extraction should be used to preheat feedwater.

These recommendations refer only to the design of Case 1 and should not be used automatically in conjunction with other IGCC concepts. The cost optimal Cases 1CO1 and 1CO2 are certainly not unique. Other design configurations can be found with comparable cost of electricity values.

General Electric supplied new performance data for the MS7001F gas turbine. These data have significant impact on the overall efficiency and the cost of electricity. Use of the new data results in (a) an increase in thermal efficiency by 0.7-0.8 percentage points in the optimized cases, and (b) a decrease in the cost of electricity by more than 2.5 percent.

The parametric study conducted to investigate the impact of major design parameters on the efficiency and cost of electricity established the importance of the steam high pressure and the gasification temperature for the cost optimization process. The cost sensitivity studies confirmed that the plant capacity factor is the most important variable for cost-effective plant operation.

The thermoeconomic analysis and optimization techniques were very useful tools in conducting this study. Some optimization techniques were refined during the investigations and will be applied to future design optimizations of IGCC plants and other energy systems.

Future studies should include investigation of the economic feasibility of design options aimed at eliminating or modifying the external desulfurization step and the gas recycling process. Significant performance and cost benefits should be expected from the elimination or modification of these processes. 


\section{Reference}

1. Southern Company Services, "Assessment of Coal Gasification/Hot Gas Cleanup Based Advanced Gas Turbine Systems," Final Report prepared for the U.S. Department of Energy, Morgantown Energy Technology Center, Contract No. DE-FC21-89MC26019 December 1990. 


\subsection{INTRODUCTION}

Several studies of Integrated Gasification-Combined-Cycle (IGCC) power plants have indicated that these plants have the potential for providing performance and cost improvements over conventional coal-fired steam power plants with flue gas desulfurization, assuming equal plant capacity factors. Generally, IGCC power plants have a higher energy-conversion efficienc';, require less water, conform with existing environmental standards at lower cost, and are expected to convert coal to electricity at lower costs than coal-fired steam power plants.

Most IGCC power plant designs currently under development require cooling of the hot gas from the coal gasifier to near-ambient temperatures to facilitate cleanup of sulfur, particulates, and other contaminants. The gas must then be reheated before being burned in a combustion turbine. The volume of gas which must be cleaned is reduced by using oxygen from an air separation plant as the primary fuel oxidant in the gasifier. However, the requirements of gas cooling/reheating and air separation result in capital cost and thermal efficiency penalties which adversely affect the economics of IGCC power plant designs using an oxygen-blown gasifier and a cold gas cleanup process.

Hot gas cleanup, in which sulfur and particulates are removed from a gas stream at high temperatures, has the potential to increase the cost competitiveness of IGCC plants. Using air as the coal oxidant rather than oxygen may yield further cost advantages.

Southern Company Services (SCS), Inc., under a cooperative agreement with the U.S. Department of Energy, Morgantown Energy Technology Center (DOE/METC), conducted a study entitled "Assessment of Coal Gasification/Hot Gas Cleanup Based Advanced Gas Turbine Systems" [1]. The objective of that study was to compare the estimated costs, performance, and reliability of several Kellogg-Rust-Westinghouse (KRW)-based IGCC power plant configurations. The power plants were assumed to be located at the Plant Wansley site of Georgia Power Company. The project team consisted of SCS, the engineering and research subsidiary of The Southern Company, the M. W. Kellogg Company (MWK), the Tennessee Technological University (TTU) Center for Electric Power, and General Electric Company (GE).

Among the power plant configurations compared in that study [1], the so-called Case 1 configuration was found to be an attractive alternative for generating electricity from coal. This configuration uses four air-blown KRW coal gasifiers, a hot gas cleanup system, and two GE MS7001F gas turbines to generate $458.4 \mathrm{MW}$ electric power at a net heat rate of $8,595 \mathrm{Btu} / \mathrm{kWh}$. The Higher-Heating-Value (HHV)-based net thermal 
efficiency is 39.70 percent. Assuming ten-year levelized costs at 65 percent average plant capacity factor, the estimated levelized cost of electricity is $67.4 \mathrm{mills} / \mathrm{kWh}$ in current dollars, or $49.1 \mathrm{mills} / \mathrm{kWh}$ in constant mid-1990 dollars.

For the results reported in Reference [1], no attempt was made to minimize the Cost of Electricity (COE) generated in each IGCC power plant. Thus, we should expect that the potential for improving the efficiency and cost effectiveness of each IGCC configuration studied in Reference [1] is different. Reference [1] discusses the comparison of Case 1 with the Reference Case (oxygen-blown KRW gasifier and cold gas cleanup). This comparison indicates that significant differences in the potential for improving each case exist. Final conclusions from the comparison of different configurations, however, should be drawn after these configurations have been optimized from the economic viewpoint, or after at least the potential for further improvements has been estimated. The second law analysis and the thermoeconomic analysis of Case 1 reported in Reference [1] identified a number of design changes that could potentially improve the performance and reduce the Cost of Electricity (COE).

To study various design options for Case 1 and determine the effect of the most important plant parameters on performance and COE, SCS entered into a supplementary project with the U.S. DOE/METC. The focus of the study was to optimize the design of Case 1 using advanced thermoeconomic evaluation and optimization techniques. The present report summarizes the results of this study. As in the previous study [1], the IGCC power plant was assumed to be located at the Plant Wansley site of Georgia Power Company, an operating subsidiary of The Southern Company. Every effort was made to put the results of the present study on the same basis as those reported in References [1], [2] and [3]. 


\subsection{PROJECT DESCRIPTION}

\subsection{PROJECT OBJECTIVES}

The major objectives of this project are to:

- Study the effect of various design options on the efficiency and the cost of electricity generated by an IGCC power plant using air-blown KRW coal gasifiers, a hot gas cleanup system, and industrial gas turbines.

- Develop a power plant design characterized by minimum cost of electricity.

For this purpose, several design configurations were evaluated. This report discusses the most interesting features of each attractive configuration.

\subsection{PROJECT ORGANIZATION}

The simulation, evaluation, and optimization studies were conducted at Tennessee Technological University (TTU) Center for Electric Power under a subcontract to Southern Company Services (SCS). Input data were provided by several companies. SCS Research and Environmental Affairs was responsible for overall project management and cost estimates in the power island. The M. W. Kellogg Company was responsible for developing gasification island designs and costs according to TTU specifications. Some other companies (General Electric, Industrial Filter and Pump Manufacturing and the Henry Vogt Machine Company) provided performance and cost data for specific equipment items.

\subsection{IGCC PLANT DESCRIPTION}

The IGCC power plant configuration for Case 1, as reported in Reference [1], is the base case for the studies discussed in this report. In the following we will refer to this case as original Case 1. This section briefly describes this case. Additional details may be found in Reference [1].

Figures 2-1 and 2-2 show simplified flow diagrams of the gasification island and the power island, respectively. The gasification island converts coal to a clean combustible gas that fuels a combustion turbine. The combustion turbine exhaust heat is used in a heat recovery steam generator (HRSG) to produce steam which drives a turbine generator. The integration between the gasification island and the steam cycle mainly involves (a) generation of saturated steam in the gasification island and use of this steam in the steam cycle, and (b) supply of steam at various temperature and pressure 
levels by the steam cycle to cover the demands of the gasification island. Case 1 has four separate processing trains for the gasification island (two trains for the Area 250-Booster Air Compression) with two combustion turbines and heat recovery steam generators and one steam turbine for the power island. In the following, the numbers given in parentheses refer to the material streams shown in Figures 2-1 and 2-2.

The coal receiving, handling, and preparation system (Area 100) includes an unloading sysiem, twenty-eight vibrating feeders, a magnetic separator, four coal storage silos and four fluid-bed roller mills. Flue gas from the sulfator (48) provides the heat to dry the coal, which is fed inio the gasifier with a moisture content of 4.98 weight percent.

The limestone receiving, handling and preparation system includes a rail car receiving hopper, a car shaker, two belt feeders, a conveyor, two reclaim hoppers, three storage silos, and two pulverizers, where limestone is dried with the heat supplied by an oil-fired heater. After preparation, the coal and limestone are transported to separate bunkers and then fed with weigh feeders into bins where the two are mixed. Four pneumatic conveying svstems (one spare) are then used to transport the coal/limestone mixture io surge bins in the gasifiers. An air compressor provides pressurization of the gasifier lockhoppers.

The air booster compression system (Area 250) supplies the air necessary for the gasifier operation (5) and for the regeneration of the zinc-ferrite desulfurizer (29). Air for this system is obtained by extraction from the compressor of the gas turbine (4). The air booster compression system includes an air recuperator, a boiler feedwater (BFW) preheater, a trim cooler, and an air compressor.

The coal is gasified in a KRW pressurized fluidized bed gasifier (Area 300). Hydrogen sulfide, produced from the sulfur in the coal, is removed from the gas phase by reacting with calcium oxide which is obtained through the decomposition of limestone. The limestone in the gasifier serves as the bulk desulfurization step in the plant. The product gas from the gasifier (6) enters a cyclone which separates most of the fine particulates that escape the gasifier bed and returns them to the bed.

The gas exiting the cyclone (7) is partially cooled in the product gas cooler where HP steam is generated. Additional cooling is provided by quenching with steam (39). The amount of quench steam is determined by the desired moisture content of the gas ( $30 \%$ by volume) in order to achieve a satisfactory operation of the zinc ferrite unit.

The product gas (159), now around $1015^{\circ} \mathrm{F}$, then passes through a non-recycle cyclone and a ceramic candle gas filter where all of the remaining particulates are 
removed from the gas. The collected solids are transferred to a depressurization lockhopper from which the solids, now at atmospheric pressure, are sent through a watercooled conveyor to the sulfation area.

Since chlorides can severely affect the structural integrity of the zinc ferrite sorbent, a chloride guard is used to remove chlorides from the fuel gas (35). This guard consists of two parallel fixed beds of calcined nahcolite sorbent. When a bed becomes loaded as indicated by outlet gas (26) analysis, it will be isolated; the sorbent will be replaced and the bed will be available for the next duty cycle.

Zinc ferrite was selected as the external bed sorbent for high-temperature coal gas desulfurization because of its effectiveness and capability for sulfur absorption combined with its regenerative characteristics. In a similar manner to the chloride guard drums, the two zinc ferrite reactors, where final product gas desulfurization is achieved, are operated in a parallel arrangement. In the design of the original case $1,86.5 \%$ of the coal sulfur is removed in the gasifier. After the additional removal in the zinc ferrite reactors, the total sulfur removal in the gasification island is $99.4 \%$.

The zinc ferrite is regenerated through oxidation of the zinc and iron sulfides with air. This process begins with steam pressurization to a level above that of the gasifier. The flow of steam and air to the reactor is controlled to maintain the bed temperature of the oxidation front below $1500^{\circ} \mathrm{F}$ to avoid sintering and destroying the sorbent. The minimum temperature is $1100^{\circ} \mathrm{F}$ since lower temperatures will promote the formation of zinc sulfate. The regeneration gas (17) is recycled to the gasifier and the sulfur dioxide in the gas is captured by the limestone in the gasifier bed. The major part of the desulfurized product gas (84) enters the exit-gas cooler where the temperature is controlled at the maximum fuel-supply valve temperature $\left(1000^{\circ} \mathrm{F}\right)$ for supply to the gas turbine. This temperature is controlled by varying the flow rate $\left(\dot{m}_{34}\right)$ of the highpressure saturated steam produced in the exit-gas cooler.

A small portion of the clean product gas (20) is cooled in the recycle gas cooler, compressed, and, recycled back to the gasifier (42) and the gas filter (15). The outlet gas temperature of the recycle gas cooler is controlled by the flow of boiler feedwater to the cooler (36).

The mixture of spent (sulfided) limestone, ash and fines (22) is prepared for disposal in the fluidized-bed sulfator. This system is used to oxidize the calcium sulfide to calcium sulfate, a chemical compound similar to gypsum, which can be readily disposed of in a dry landfill. The calcium sulfide oxidation is highly exothermic. At temperatures below $1600^{\circ} \mathrm{F}$, little sulfur dioxide is formed. During this process, any residual carbon remaining in the fines is combusted. The heat is recovered by in-bed heat 
exchanger tubes that keep the bed temperature less than $1600^{\circ} \mathrm{F}$ without the need for high excess air. The gas from the combustor is cooled by an additional heat exchanger to approximately $1400^{\circ} \mathrm{F}$ before being routed to the coal preparation section of the plant for coal drying.

Two General Electric MS7001F combustion gas turbines were assumed in the combined cycle. These advanced combustion turbines will have a firing temperature of about $2300^{\circ} \mathrm{F}$. Fuel gas (32) is introduced to the gas turbine combustor along with air (73) supplied by the compressor, which is driven by the gas turbine expander. The hot gas exiting the combustor (74) is supplied to the hot gas expander which in turn drives the gas turbine generator.

The exhaust gas from each combustion turbine (75) enters a heat recovery steam generator which provides steam generation and superheating of high-pressure (HP) and intermediate-pressure (IP) steam, reheating of IP steam, and feedwater preheating. The combined-cycle steam turbine consists of a high-pressure, intermediate-pressure and lowpressure sections. The HP section accepts the 1,500 psia/1000 $\mathrm{F}$ steam (101) from the two HRSGs. The exhaust steam (104) from the HP turbine is reheated to $1000^{\circ} \mathrm{F}$ by the HRSGs and returns to the IP turbine (105). The IP exhaust steam (141) is then routed to the LP turbine from which it is condensed $9 t$ a design backpressure of $3.5^{n} \mathbf{H g}$.

Condensate from the conderiser (118) enters two vertical motor driven condensate pumps and subsequently passes through the gland seal condenser. Steam for this heating is provided by the steam seal regulator (SSR). Subsequently, the condensate (121) is heated in the low-pressure feedwater heater (FWH2) before it enters (122) the two deaerators, which are an integral part of each HRSG. Finally, the electric motor driven HRSG feed pumps supply the feedwater (124) to its HRSG feedwater inlets $(125,129)$ and to the gasification process $(36,46,49)$.

Tables 2-1, 2-2 and 2-3 summarize the results of the simulation and the exergy analysis for the original Case 1. Some small deviations between the numbers shown in these tables and the corresponding tables of Reference [1] are due to improvements in the simulation procedure. All results presented for the various cases in this report were obtained using identical assumptions for the simulation, exergy analysis, and thermoeconomic analysis.

In addition to the original Case 1 (gasification temperature - $1900^{\circ} \mathrm{F}$ ), Reference [1] contains performance and cost data obtained for the Cases $1 \mathrm{~A}$ and $1 \mathrm{~B}$, which refer to the same flow diagram as the original Case 1 but gasification temperatures of $1800^{\circ} \mathrm{F}$ and $2000^{\circ} \mathrm{F}$, respectively. All these data were considered in the thermoeconomic optimization of Case 1. 


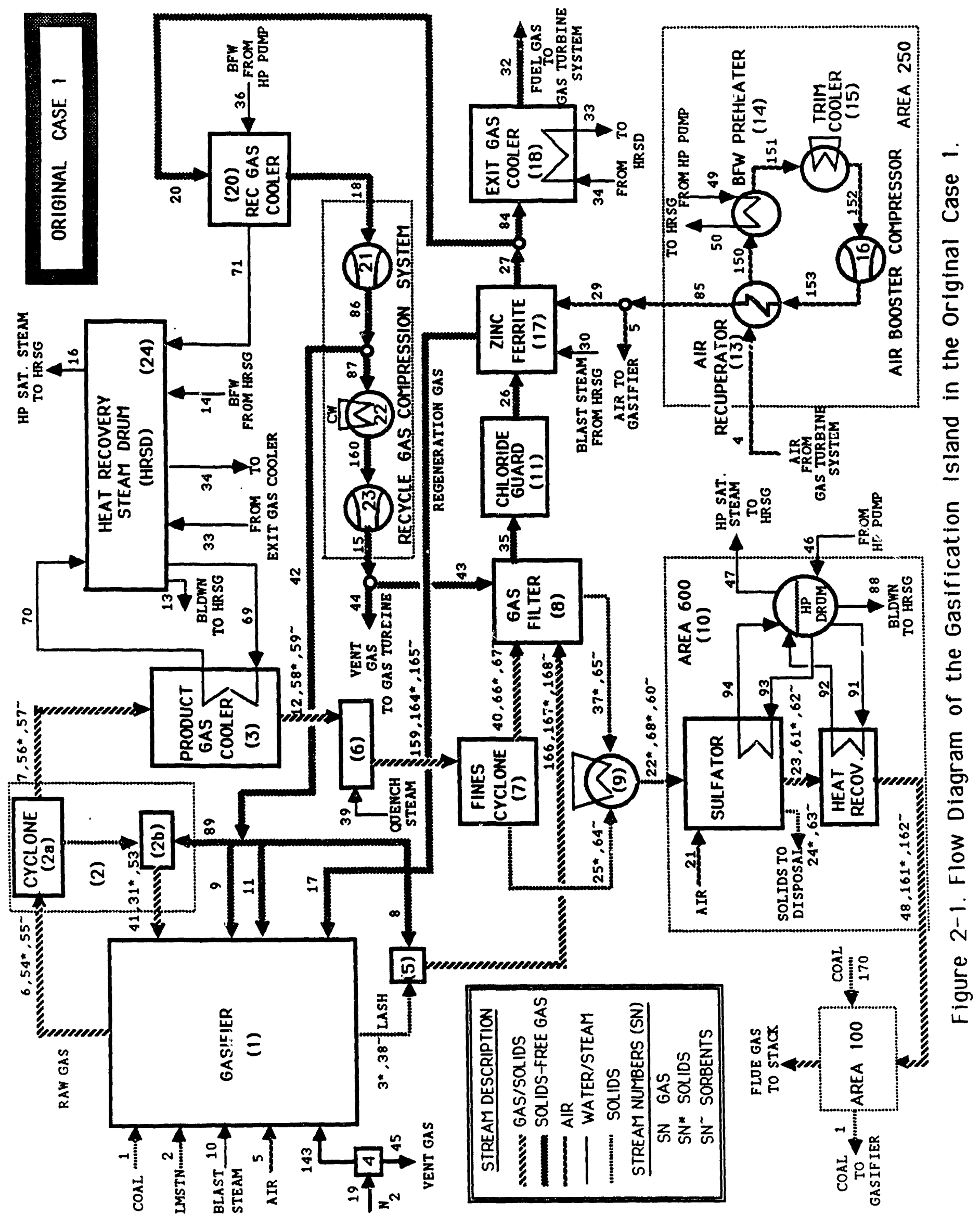




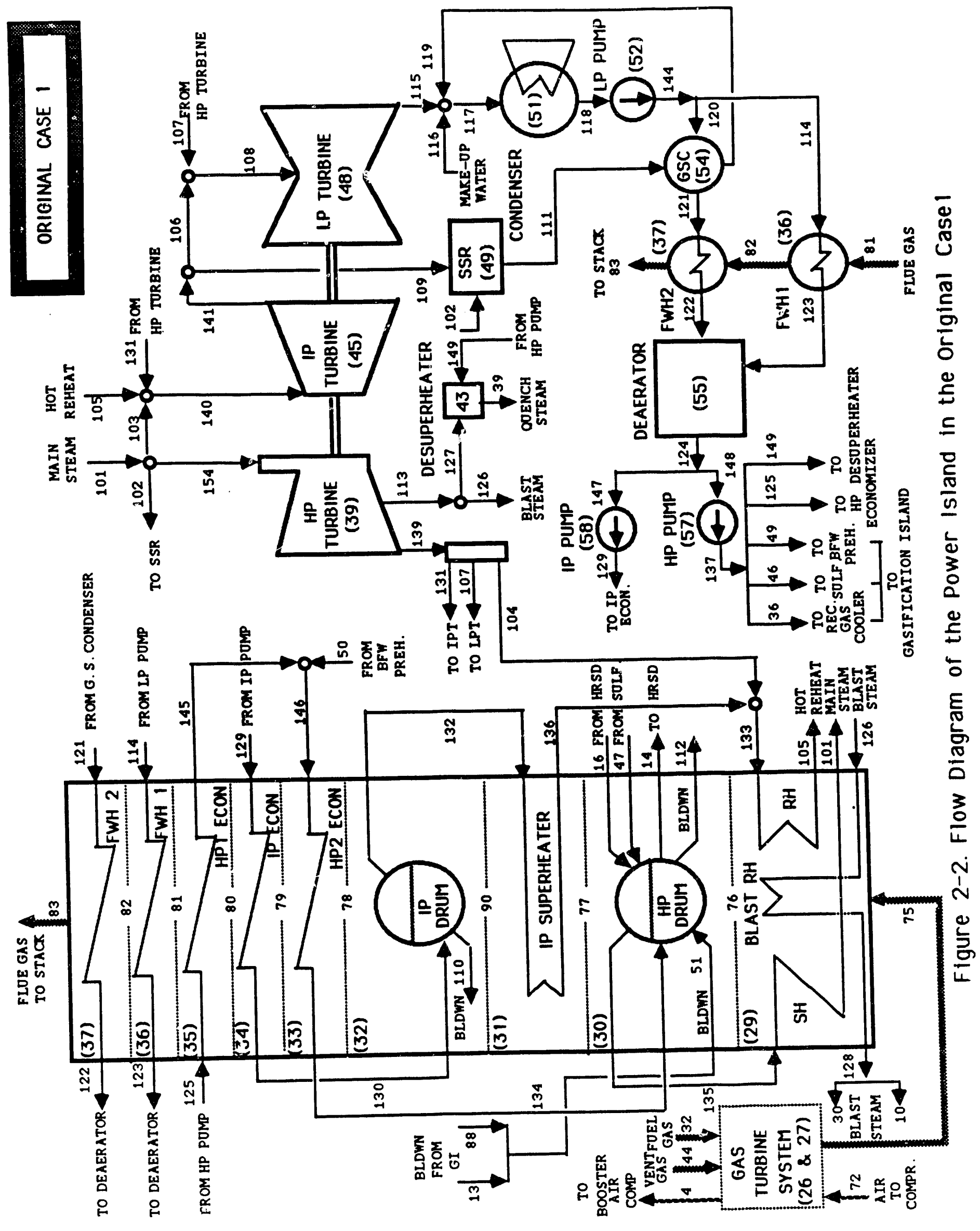


TABLE 2-1

Mass Flow Rate, Temperature, Pressure and Flow Rates of Enthalpy, Entropy and Exergy for Each Stream of the Original Case 1 (Cont'd)

\begin{tabular}{|c|c|c|c|c|c|c|}
\hline $\begin{array}{l}\text { Stream } \\
\text { No. }\end{array}$ & $\underset{[\mathbf{l} / \mathbf{m} \mathbf{h}]}{\dot{m}}$ & $\underset{[F]}{T}$ & $\underset{[p s i a]}{\mathbf{P}}$ & $\stackrel{\stackrel{\text { H }}{\text { [MMBtu/hr] }}}{\text { [MMB }}$ & $\stackrel{\text { S }}{\text { [MBtu/hrR] }}$ & $\underset{[\mathbf{M W}]}{\boldsymbol{E}}$ \\
\hline 83 & 6736999 & 279.8 & 14.7 & -6160.28 & 12046.16 & 33.51 \\
\hline 84 & 1830903 & 1196.3 & 305.0 & -3145.77 & 3943.58 & 920.24 \\
\hline 85 & 1073962 & 650.0 & 450.0 & 152.20 & 1701.13 & 54.40 \\
\hline 86 & 104465 & 411.0 & 450.0 & -209.15 & 197.31 & 48.28 \\
\hline 87 & 16342 & 411.0 & 450.0 & -32.72 & 30.87 & 7.55 \\
\hline 88 & 1779 & 604.9 & 1600.0 & -11.13 & 2.95 & 0.09 \\
\hline 89 & 7021 & 411.0 & 430.0 & -14.07 & 13.29 & 3.23 \\
\hline 90 & 6736999 & 627.1 & 14.9 & -5529.11 & 12739.35 & 106.82 \\
\hline 91 & 19343 & 604.9 & 1600.0 & -121.05 & 32.13 & 1.01 \\
\hline 92 & 19343 & 604.9 & 1600.0 & -110.59 & 41.94 & 2.49 \\
\hline 93 & 295659 & 604.9 & 1600.0 & -1850.31 & 491.07 & 15.45 \\
\hline 94 & 295659 & 604.9 & 1600.0 & -1690.47 & 641.13 & 38.12 \\
\hline 101 & 1344245 & 1000.0 & 1450.0 & -7247.08 & 3288.01 & 241.82 \\
\hline 102 & 568 & 1000.0 & 1450.0 & -3.06 & 1.39 & 0.10 \\
\hline 103 & 2313 & 1000.0 & 1450.0 & -12.47 & 5.66 & 0.42 \\
\hline 104 & 925235 & 644.7 & 350.0 & -5131.89 & 2286.91 & 120.47 \\
\hline 105 & 1025829 & 1000.0 & 329.0 & -5495.88 & 2694.74 & 164.77 \\
\hline 106 & 1043212 & 802.5 & 150.0 & -5689.66 & 2755.43 & 135.64 \\
\hline 107 & 1687 & 644.7 & 350.0 & -9.36 & 4.17 & 0.22 \\
\hline 108 & 1044899 & 802.2 & 150.0 & -5699.02 & 2759.76 & 135.84 \\
\hline 109 & 641 & 802.5 & 150.0 & -3.50 & 1.69 & 0.08 \\
\hline 110 & 1005 & 431.7 & 350.0 & -6.51 & 1.45 & 0.02 \\
\hline 111 & 1209 & 860.3 & 150.0 & -6.56 & 3.22 & 0.16 \\
\hline 112 & 13442 & 604.9 & 1600.0 & -84.13 & 22.33 & 0.70 \\
\hline 113 & 398731 & 727.3 & 500.0 & -2196.97 & 983.42 & 56.55 \\
\hline 114 & 110543 & 120.4 & 25.0 & -751.07 & 111.25 & 0.06 \\
\hline 115 & 1044899 & 120.6 & 1.7 & -6039.28 & 2878.78 & 16.95 \\
\hline 116 & 460852 & 80.0 & 14.7 & -3149.81 & 430.58 & 0.16 \\
\hline 117 & 1506960 & 120.6 & 1.7 & -9197.19 & 3311.97 & 16.91 \\
\hline 118 & 1506960 & 120.4 & 1.7 & -10238.99 & 1516.52 & 0.83 \\
\hline 119 & 1209 & 211.4 & 14.7 & -8.10 & 1.39 & 0.00 \\
\hline 120 & 1396417 & 120.4 & 25.0 & -9487.77 & 1405.34 & 0.79 \\
\hline 121 & 1396417 & 121.7 & 25.0 & -9486.00 & 1408.38 & 0.82 \\
\hline 122 & 1396417 & 160.9 & 24.5 & -9431.26 & 1499.50 & 2.19 \\
\hline 123 & 110543 & 240.1 & 24.5 & -632.53 & 282.73 & 7.18 \\
\hline 124 & 1506960 & 236.2 & 24.5 & -10063.80 & 1791.66 & 7.85 \\
\hline 125 & 853728 & 240.0 & 1650.0 & -5695.19 & 1017.67 & 5.83 \\
\hline 126 & 56698 & 727.3 & 500.0 & -312.40 & 139.84 & 8.04 \\
\hline 127 & 342034 & 727.3 & 500.0 & -1884.57 & 843.58 & 48.51 \\
\hline
\end{tabular}


TABLE 2-1

Mass Flow Rate, Temperature, Pressure and Flow Rates of Enthalpy, Entropy and Exergy for Each Stream of the Original Case 1 (Cont'd)

\begin{tabular}{|c|c|c|c|c|c|c|}
\hline $\begin{array}{l}\text { Stream } \\
\text { No. }\end{array}$ & $\stackrel{\dot{\mathbf{m}}}{[\mathbf{l b} / \mathbf{h r}]}$ & $\begin{array}{c}\mathbf{T} \\
{[\mathbf{F}]}\end{array}$ & $\underset{\text { [psia] }}{\mathbf{P}}$ & $\stackrel{\dot{\mathbf{H}}}{[\mathbf{M M B t u} / \mathbf{h r} \mathbf{]}}$ & $\begin{array}{c}\dot{\mathbf{S}} \\
\text { [MBtu/hrR] }\end{array}$ & $\stackrel{\dot{E}}{\text { [MW] }}$ \\
\hline 128 & 56698 & 950.0 & 450.0 & -305.48 & 145.82 & 9.11 \\
\hline 129 & 101600 & 237.0 & 350.0 & -678.36 & 120.86 & 0.56 \\
\hline 130 & 101600 & 391.0 & 350.0 & -662.15 & 141.85 & 1.93 \\
\hline 131 & 15711 & 644.7 & 350.0 & -87.14 & 38.83 & 2.05 \\
\hline 132 & 100594 & 431.7 & 350.0 & -571.26 & 235.18 & 11.37 \\
\hline 133 & 1025829 & 640.0 & 329.3 & -5691.07 & 2541.02 & 132.33 \\
\hline 134 & 1100379 & 568.0 & 1600.0 & -6944.54 & 1772.42 & 49.37 \\
\hline 135 & 1344245 & 604.9 & 1600.0 & -7685.90 & 2914.98 & 173.31 \\
\hline 136 & 100594 & 620.0 & 329.3 & -559.18 & 248.16 & 12.82 \\
\hline 137 & 1405360 & 240.0 & 1650.0 & -9375.12 & 1675.24 & 9.60 \\
\hline 138 & 1341364 & 992.3 & 1305.0 & -7231.54 & 3295.54 & 238.95 \\
\hline 139 & 942633 & 644.7 & 350.0 & -5228.39 & 2329.91 & 122.74 \\
\hline 140 & 1043853 & 994.5 & 329.0 & -5595.49 & 2739.99 & 167.11 \\
\hline 141 & 1043853 & 802.5 & 150.0 & .5693 .16 & 2757.12 & 135.73 \\
\hline 142 & 1030113 & 604.9 & 1600.0 & -5889.81 & 2233.79 & 132.81 \\
\hline 143 & 3761 & 500.0 & 450.0 & 0.40 & 5.80 & 0.18 \\
\hline 144 & 1506960 & 120.4 & 25.0 & -10238.83 & 1516.59 & 0.86 \\
\hline 145 & 853728 & 433.0 & 1625.2 & -5524.08 & 1233.40 & 21.22 \\
\hline 146 & 1100379 & 431.9 & 1600.0 & -7121.40 & 1588.34 & 27.19 \\
\hline 147 & 101600 & 236.2 & 24.5 & -678.50 & 120.79 & 0.53 \\
\hline 148 & 1405360 & 236.2 & 24.5 & -9385.29 & 1670.87 & 7.32 \\
\hline 149 & 47673 & 240.0 & 1650.0 & -318.02 & 56.83 & 0.33 \\
\hline 150 & 1073962 & 450.1 & 199.0 & 98.21 & 1707.59 & 37.54 \\
\hline 151 & 1073962 & 266.3 & 198.0 & 49.41 & 1648.05 & 32.82 \\
\hline 152 & 1073962 & 127.7 & 176.0 & 13.18 & 1601.36 & 29.73 \\
\hline 153 & 1073962 & 341.9 & 453.0 & 69.39 & 1613.29 & 44.28 \\
\hline 154 & 1341364 & 1000.0 & 1450.0 & -7231.54 & 3280.96 & 241.30 \\
\hline 159 & 1904715 & 1015.0 & 385.0 & -3260.61 & 4036.74 & 973.68 \\
\hline 160 & 16342 & 365.6 & 450.0 & -32.98 & 30.56 & 7.53 \\
\hline 161 & 67 & 1400.0 & 14.7 & -0.32 & 0.04 & 0.01 \\
\hline 162 & 134 & 1400.0 & 14.7 & -0.59 & 0.06 & 0.01 \\
\hline 164 & 13524 & 1015.0 & 385.0 & -27.14 & 8.29 & 35.96 \\
\hline 165 & 2115 & 1015.0 & 385.0 & -8.53 & 0.79 & 0.05 \\
\hline 166 & 15991 & 479.6 & 375.0 & -31.62 & 30.89 & 7.40 \\
\hline 167 & 28438 & 479.6 & 375.0 & -139.95 & 9.67 & 7.09 \\
\hline 168 & 49583 & 479.6 & 375.0 & -205.42 & 13.91 & 0.27 \\
\hline 170 & 337788 & 90.0 & 14.7 & .343 .01 & 111.15 & 1176.96 \\
\hline
\end{tabular}




\section{TABLE 2-2}

Exergy Flow Rates of Fuel $\left(\dot{E}_{p}\right)$, Product $\left(\hat{E}_{\mathrm{p}}\right)$, and Exergy Destruction $\left(\hat{E}_{\mathrm{p}}\right)_{2}$ Exergy Destruction Ratio $(\theta)$, Exergy Destruction to Total Exergy Input Ratio $(\theta)$ and Exergetic Efficiency $(\zeta)$ for Each Area and the Total Plant in the Original Case 1

Area

Area 250: Booster Air Compressor Area 300: KRW Gasification Area 380: Recycle Gas Compression Area 400: Gas Conditioning Area 500: External Desulfurization Area 600: Sulfation

Area 900: Gas Turbine System Area 1000: HRSG

Area 1100: Steam Cycle

Total Plant Exergy Losses

Service Station Power

Total'Plant

$$
\text { [MW] }
$$

21.99 1252.90

54.22

196.15

940.25

33.88

636.13

225.13

233.20

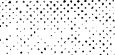

1179.50

$$
\text { [MW] }
$$

13.91
1009.09

52.02

174.75

922.93

21.71

360.89

190.87

182.20

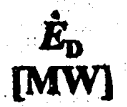

8.08

243.82

2.20

21.39

17.33

12.17

275.23

34.27

51.00

45.01

10.58

$\mathbf{4 5 8 . 4 2}$
[\%]

1.12

33.81

0.31

2.97

2.40

1.69

38.17

4.75

7.07

6.24

1.47

100.00

\section{[\%]}

0.69

20.67

0.19

1.81

1.47

1.03

23.33

2.91

4.32

3.82

0.90

61.13
5

63.25

80.54

95.94

89.09

98.16

64.07

56.73

84.78

78.13

38.87 


\section{TABLE 2-3}

Heat Loss, Power Supplied (Generated), Exergy Destruction Flow Rate, Exergy Destruction Ratio $(\theta)$, Exergy Destruction to Total Exergy Input Ratio $\left(\theta^{\circ}\right)$ and Exergetic Efriciency ( $)$ for Plant Components in the Original Case 1

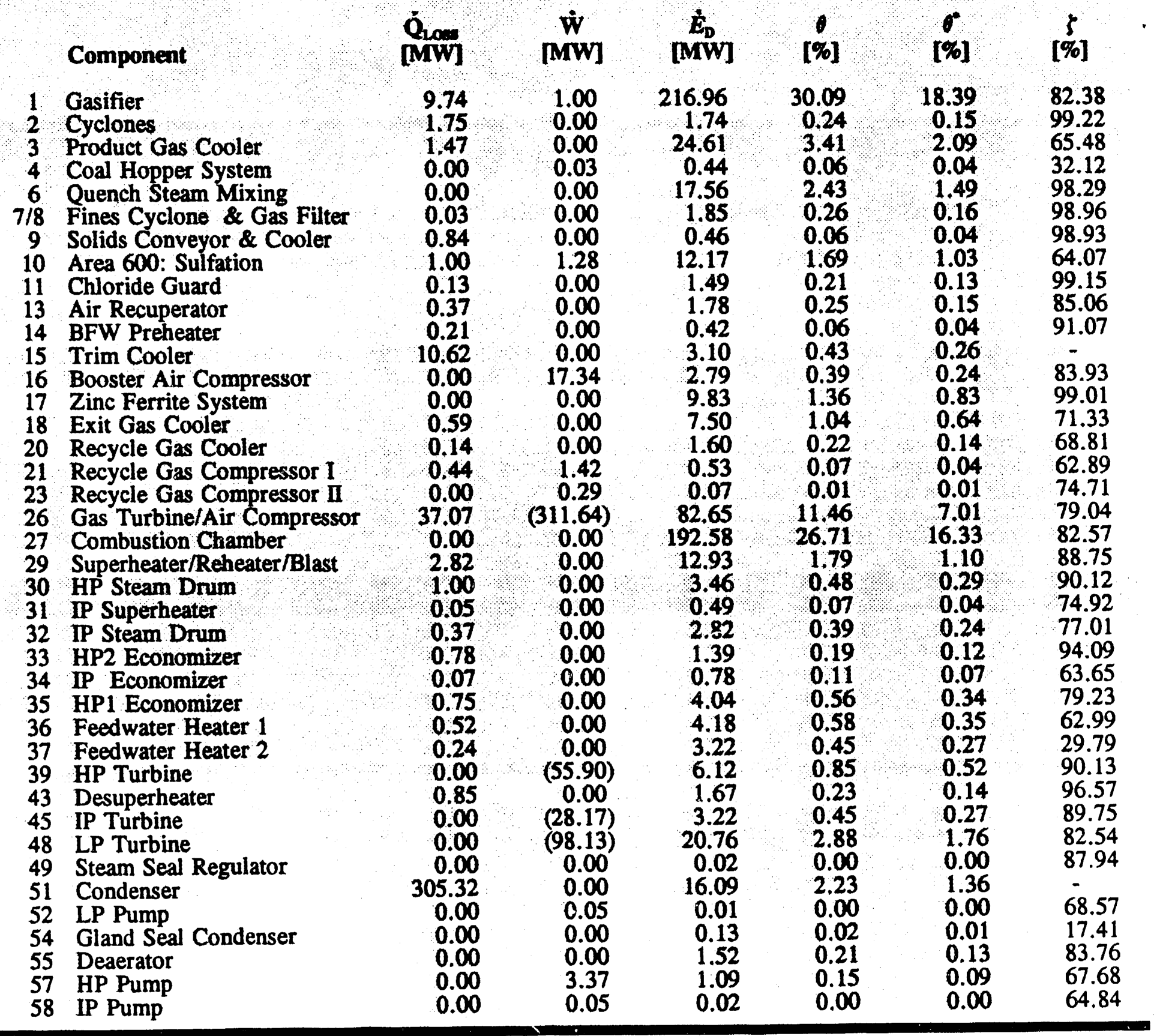




\subsection{RECOMMENDATIONS FROM THE PREVIOUS THERMOECONOMIC ANALYSIS}

The thermoeconomic analysis reported in Reference [1] identified the following possible design changes to cost effectively improve the thermal efficiency.

- Supply the coal with the original moisture of 11.12 weight percent to the gasifier instead of the original design specification of 4.98 weight percent.

- Operate the gasifier in the temperature range of $1850^{\circ} \mathrm{F}$ to $1870^{\circ} \mathrm{F}$ versus $1900^{\circ} \mathrm{F}$ as designed.

- Redesign the recycle gas cooler, IP economizer, and IP drum to avoid heat transfer across the pinch point.

- Cool the gas at the outlet of the product gas cooler to a temperature lower than in the original Case 1 prior to adding steam to the gas.

- Further explore the option of using heat recovered in the sulfation area for steam generation rather than coal drying.

- Study the economic feasibility of developing and using a gas turbine system with a reheat stage.

All of the above recommendations, with the exception of the last one, were considered in the optimization studies reported here. It should be noted that each recommendation considered alone would improve the cost effectiveness of the original Case 1 power plant design. In general, however, when more than one recommendation is considered, some others may become less attractive or the recommended values might change.

\subsection{TECHNICAL APPROACH}

Several design options for the IGCC power plant shown in Figures 2-1 and 2-2 were studied. All of the design configurations developed and analyzed use

- an air-blown KRW gasifier with a constant carbon conversion ratio (96.5 percent),

- the same processes for gas conditioning, external desulfurization and sulfation, and 
- the same combustion gas turbines receiving the fuel gas (constant energy flow rate based on heating value) always at $1000^{\circ} \mathrm{F}$.

The major design changes studied refer to the

- total plant heat exchanger network (product gas cooler, heat recovery in sulfation and in booster air compression, recycle gas cooler, exit gas cooler, HRSG and feedwater preheaters),

- gasification temperature,

- coal drying process, and

- $\quad$ steam turbine.

The size of all plant components was kept variable.

To facilitate the comparison of results, the cases addressed in the present study employ the same basis as the cases developed in previous studies sponsored by DOE [1] and EPRI [2,3]. The design approach, costing methodology, and economic evaluations are on a common basis.

Despite the fact that certain plant systems are not yet commercially available, technological maturity was assumed in the plant designs. In other words, each design is for an "n-th" plant, with several commercial plants assumed to have preceded the plant under consideration. The cost estimates do not, however, reflect widespread penetration of the technology in the utility market. All design configurations were based on the Plant Wansley site of Georgia Power Company.

For each design configuration, the detailed plant operation was simulated, the capital and O\&M costs were estimated, a thermoeconomic analysis at the component level was conducted, and, finally, the cost of electricity was calculated. The latest results available from research projects and studies were used to estimate performance and costs.

The total plant performance was simulated using the THESIS (Thermodynamic and Economic Simulation System) software package [4, 5]. Simulation of the gasifier was based on data supplied by MWK and obtained using MWK's proprietary computer programs. The ASPEN-based material and energy balances provided by MWK for the gasification-island sections downstream of the gasifier were used to adjust the THESIS predictions. In addition, MWK furnished the data required to estimate the capital costs of the major components in the gasification island. 
GE supplied the performance and cost data for the combustion gas turbines. The cost estimates for the HRSG and the steam cycle, as well as the economic evaluations and the calculation of the levelized COE, were done according to data and procedures provided by SCS.

The thermodynamic evaluation and comparison of the various design configurations were based on the exergy method. This method calculates the exergy destruction and exergetic efficiency of each plant component, as well as the exergy losses associated with material streams rejected to the environment. The exergy method provides an objective basis for detailed performance comparisons from the thermodynamic viewpoint and for estimating the potential to increase the overall plant thermal efficiency.

The thermoeconomic evaluation assesses the performance of a component or group of components from a combined thermodynamic and economic vievpoint and estimates the potential for improving the overall plant cost effectiveness through design changes. The procedures used for the thermoeconomic analysis and optimization are highly specialized and are still undergoing development. These procedures are discussed in greater detail in Section 3 of the report.

\subsection{ORGANIZATION OF THE REPORT}

The Contents of the report provide a detailed outline of the report material. Sections 1,2 and 3 of the report contain background material. The optimal design configurations developed in this study are discussed and compared in Section 4. Section 5 presents the effect of important design and cost parameters on the overall thermal efficiency and the COE. Design configurations are described in Sections 2 and 4. Detailed results of the thermodynamic and thermoeconomic evaluations are presented in Sections 2 and 4 and in the Appendix. 


\subsection{THERMOECONOMIC EVALUATION AND OPTIMIZATION OF ENERGY SYSTEMS}

This section contains a very brief introduction to the exergy analysis and the thermoeconomic evaluation and optimization of energy systems. These techniques are somewhat specialized and will not be described in detail in this section but will be summarized is the level necessary to discuss some of the final results and key conclusions. More details on the methodology are given in References [5] through [8].

\subsection{EXERGY ANALYSIS}

The second law of thermodynamics complements and enhances an energy balance by enabling calculation of both the real thermodynamic value of an energy carrier, and the real inefficiencies and losses from processes or systems. The concept of exergy (thermodynamic availability) is extremely useful for this purpose since an energy analysis generally fails to identify energy waste or the effective use of fuels and energy resources.

Exergy $(E)$ is the maximum useful work attainable from an energy carrier under the conditions imposed by a given environment. Exergy is a thermodynamic property that depends on both the state of the carrier being considered and the state of the environment. It expresses the maximum capability of the energy carrier to cause changes. In most cases we can think of exergy as the useful part of energy, i.e., the part of energy that can theoretically be transformed into any other form of energy.

Unlike total energy, a part of the total exergy supplied to a system is irreversibly destroyed in all real processes. The exergy destruction $\left(E_{\mathrm{p}}\right)$ usually represents the largest part of what the layman calls "energy waste." The other part of "energy waste" is the exergy loss $\left(E_{\mathrm{L}}\right)$, i.e., the exergy transfer out of a system associated with a stream rejected to the environment. The term "destruction" is used to identify the unrecoverable loss of exergy within the system, as distinct from the loss of exergy in an output stream. Both exergy destruction and exergy loss are identified through an exergy analysis.

In addition, an exergy analysis calculates the exergetic efficiency (second-law efficiency) of each plant component. The exergetic efficiency evaluates the true component performance from the thermodynamic viewpoint and is very useful in overall plant design evaluations. The definition of the exergetic efficiency must be consistent with the purpose of using the system or component being considered.

To understand the term exergetic efficiency, it is helpful to think of each component as having a "product," which represents the desired result from the component, and a "fuel," which represents the driving force for the process, or the 
resources used to obtain the "product." In the following, the terms "fuel" and "product" for a component are used without quotation marks. Using this terminology, the exergetic efficiency $\left(\zeta_{k}\right)$ of the component is defined as the ratio of the exergy in the product $\left(\dot{E}_{\mathrm{p}, \mathrm{k}}\right)$ to the exergy in the fuel $\left(\dot{E}_{\mathrm{F}, \mathrm{k}}\right)$

$$
\zeta_{k}=\frac{\dot{\boldsymbol{E}}_{\mathrm{P}, \mathrm{k}}}{\dot{\boldsymbol{E}}_{\mathrm{F}, \mathrm{k}}}
$$

The exergy balance shows that the difference between exergy in the fuel and exergy in the product is the sum of exergy destruction and exergy loss in the component being considered:

$$
\dot{E}_{\mathrm{F}, \mathrm{k}}-\dot{\boldsymbol{E}}_{\mathrm{P}, \mathrm{k}}=\dot{\boldsymbol{E}}_{\mathrm{D}, \mathbf{k}}+\dot{\boldsymbol{E}}_{\mathrm{L}, \mathrm{k}}
$$

The greater the percentage of the fuel exergy reiained in the product, and, thus, the lower the extent of exergy destruction and exergy loss, the higher the exergetic efficiency of the component.

The objectives of an exergy analysis are:

- To identify the real thermodynamic losses (exergy destruction and exergy losses) in an energy system and to understand the effects causing the losses (chemical reactions, heat transfer, mixing, friction, etc.)

- To facilitate feasibility and optimization studies during the preliminary design phase of a project, as well as process improvement studies for an existing system

- To assist decision-making concerning plant operation and maintenance and allocation of research funds

In an exergy analysis we calculate, among others, the exergy flow rate of each stream $\left(\dot{E}_{\mathrm{i}}\right)$, the flow rate of exergy destruction $\left(\dot{E}_{\mathrm{D}_{\mathrm{k}}}\right)$, and the exergetic efficiency $\left(\zeta_{k}\right)$ of each plant component. The thermodynamic evaluation of each plant component is also based on the ratios $(\theta)$ of exergy destruction in a plant component to (a) the total plant exergy destruction $\left(\sum_{\mathbf{r}} \dot{E}_{\mathrm{D}, \mathrm{k}}\right)$, Equation 3-3, and (b) the total exergy input to the plant $\left(\dot{\boldsymbol{E}}_{\mathrm{tot}, \mathrm{in}}\right)$, Equation 3-4: 


$$
\begin{aligned}
& \theta_{\mathrm{k}}=\frac{\dot{E}_{\mathrm{D}, \mathrm{k}}}{\sum_{\mathbf{k}} \dot{E}_{\mathrm{D}, \mathrm{k}}} \\
& \theta_{\mathrm{k}}^{*}=\frac{\dot{E}_{\mathrm{D}, \mathrm{k}}}{\dot{E}_{\mathrm{lot,in}}}
\end{aligned}
$$

These exergy destruction ratios can be used for comparisons among various components of the same plant and among similar components of different plants which use the same fuels as energy input to the total plant.

\subsection{THERMOECONOMIC EVALUATION}

Exergy is not only a measure of the true thermodynamic value of an energy carrier but is also closely related to the economic value of the carrier since users pay only for the useful part of energy. A thermoeconomic analysis combines an exergy analysis with an economic analysis at the component level. The objectives of a detailed thermoeconomic analysis include all the previously mentioned objectives of an exergy analysis in addition to the following:

- To shed light on the cost formation process, and, thus, facilitate studies to effectively reduce the product costs in an energy system.

- To estimate economically optimal operating conditions for a given design configuration.

- To understand the interactions between the thermodynamic performance of each plant component and the cost of the final plant product(s).

- To calculate the production costs of various products generated in the same process.

- To enable cost minimization studies in very complex energy systems.

In addition to mass, energy, and exergy balances, cost balances are formulated for each system component by assigning a cost value to the exergy (not the energy) of each stream entering or exiting the component. This procedure, exergy costing, is based on the finding that exergy is the only rational basis for assigning costs to streams as well as to "energy waste" (exergy destruction and exergy losses). With the aid of cost balances and some auxiliary assumptions, the cost per unit of exergy for each stream is calculated. Subsequently, we determine the average cost of (a) providing a unit of fuel exergy to the $k$-th plant component $\left(c_{F, k}\right)$, (b) generating a un of product exergy in the $k$-th plant 
component $\left(c_{P, k}\right)$, and (c) the exergy destruction rate in the $k$-th plant component $\left(\dot{D}_{k}\right)$. Using this terminology, the cost balance is written as follows:

$$
\mathrm{c}_{\mathrm{F}, \mathrm{k}} \dot{\boldsymbol{E}}_{\mathrm{F}, \mathrm{k}}+\dot{\mathrm{Z}}_{\mathrm{k}}=\mathrm{c}_{\mathrm{P}, \mathrm{K}} \dot{\boldsymbol{E}}_{\mathrm{P}, \mathrm{k}}+\mathrm{c}_{\mathrm{F}, \mathrm{K}} \dot{\boldsymbol{E}}_{\mathrm{L}, \mathrm{k}}
$$

Here, $\dot{\mathrm{Z}}_{\mathrm{k}}$ expresses the contribution of the investment costs and the operating (excluding fuel) and maintenance (O\&M) costs associated with the $\mathrm{k}$-th component to the product cost $c_{\mathrm{P}, \mathrm{k}}$. In the discussion below, these costs are called "capital costs" in order to distinguish them from the exergy costs ("fuel costs") for a plant component.

In the following discussion of the thermoeconomic evaluation we assume that the variables $\mathrm{c}_{\mathrm{F}, \mathrm{k}}$ and $\dot{E}_{\mathrm{P}, \mathrm{k}}$ remain constant. In addition to the variables discussed in section 3.1 , the following parameters are used for evaluating the performance of the $k$-th component or group of components from the thermoeconomic viewpoint.

1. The cost of exergy destruction in the k-th system is calculated in this study from the following relationship:

$$
\dot{\mathrm{D}}_{\mathbf{k}}=\mathrm{C}_{\mathrm{F}, \mathrm{k}} \dot{\mathrm{E}}_{\mathrm{D}, \mathbf{k}}
$$

This is the cost of the fuel used to cover the exergy destruction in the system.

2. The relative cost difference $\left(d_{k}\right)$ between average cost per exergy unit of product and average cost per exergy unit of fuel:

$$
\mathrm{d}_{\mathrm{k}}=\frac{\mathrm{c}_{\mathrm{P}, \mathrm{k}}-\mathrm{c}_{\mathrm{F}, \mathrm{k}}}{\mathrm{c}_{\mathrm{F}, \mathrm{k}}}=\frac{\dot{\mathrm{D}}_{\mathrm{k}}+\dot{\mathrm{Z}}_{\mathrm{k}}}{\mathrm{c}_{\mathrm{F}, \mathbb{E}} \dot{\boldsymbol{E}}_{\mathrm{P}, \mathrm{k}}}=\frac{1-\zeta_{\mathrm{k}}}{\zeta_{\mathrm{k}}}+\frac{\dot{\mathrm{Z}}_{\mathrm{k}}}{\mathrm{c}_{\mathrm{F}, \mathrm{k}} \dot{\boldsymbol{E}}_{\mathrm{P}, \mathrm{k}}}
$$

This equation reveals the real cost sources in the $k$-th system, which are (a) the capital costs $\left(\dot{Z}_{k}\right)$, and (b) the exergy destruction in the system, as expressed by the first term on the equation right side. In general, the higher the relative cost difference $d_{k}$, the more attention should be paid to the $k$-th system.

3. The thermoeconomic factor $f_{k}$ :

$$
f_{k}=\frac{\dot{Z}_{k}}{\dot{Z}_{k}+\dot{D}_{k}}
$$

which expresses the contribution of the capital costs to the relative cost difference $d_{k}$. 
4. For the thermoeconomic evaluation of heat exchangers we use, in addition to those discussed above, the variable $r_{k}$ defined by:

$$
\mathbf{r}_{\mathbf{k}}=\frac{\dot{\mathbf{Z}}_{\mathbf{k}}}{\dot{\boldsymbol{E}}_{\mathrm{P}, \mathrm{k}}}
$$

This variable states the capital costs required to transfer a unit of exergy to the cold stream of the heat exchanger.

All these variables are used in the thermoeconomic evaluation to determine what changes in the plant structure or in a variable (temperature, pressure, etc.) could lead to a decrease in the cost of electricity.

\subsection{THERMOECONOMIC OPTIMIZATION}

Cost optimization for a complex energy-conversion system such as the IGCC power plant presented in section 2.3 is usually expensive and requires knowledge of engineering, science, and business. The goal of optimization is to find the design configuration and the values of the system variables (the temperature, pressure, and chemical composition of flow streams, equipment size, materials, etc.) that minimize the cost of electricity. This usually involves a trade-off between capital and fuel costs for the entire system. Typical problems in the design and operation of energy systems have many workable solutions - sometimes an infinite number. Selecting the best solution requires engineering judgment, intuition, and critical analysis.

In many cases a rigorous cost optimization for a complex energy system is not possible because some of the cost functions that are needed to express the capital cost of a component as a function of thermodynamic variables (temperatures, pressures, etc.) are either unavailable or inaccurate. But even in cases in which all the information is available and acceptably accurate, it is expensive and time-consuming to formulate and solve an optimization problem with an extremely large number of equations, constraints, and highly interdependent variables.

Traditionally, design optimization includes the following steps. First, a detailed system configuration is developed; material and energy balances are conducted for this configuration. Then, product costs are estimated through an economic analysis. The third step includes development of a modified/new configuration that accounts for the corresponding material and energy balances. Subsequently the product costs for the new configuration are calculated. The last two steps are repeated several times.

Development of new process configurations is based, among other factors, on the experience and intuition of design engineers. Several decisions must be made with 
respect to thermodynamic variables. The final selection criterion, however, is economic. It is apparent that judiciously combining the thermodynan ic and economic analyses, as in the thermoeconomic analysis, is advantageous to the of :mization proces3.

Assuming well-designed total system configurations, the contribution of the capital costs to the final product costs decreases with decreasing thermodynamic efficiency (increasing exergy destruction), whereas the fuel cost increases with decreasing efficiency (see Figure 3-1).

Conventional optimization techniques seek the best trade-off between capital costs and fuel costs for the entire system. In thermoeconomics, a fuel is defined for each plant component. Thus the search for an optimum is simplified since these trade-offs can be made at the component level. If the relationship between investment costs and thermodynamic efficiency of the k-th component is known (e.g., Equation 3-10), then the optimal thermodynamic efficiency from the cost viewpoint can be calculated, Equation 3-11.

$$
\begin{gathered}
I_{k}=I_{0, k}+g_{k}\left[\frac{\zeta_{k}}{1-\zeta_{k}}\right]^{n_{k}} E_{P, k} \\
\zeta_{k}^{O P T}=\frac{1}{1+\sqrt[7+1]{F_{k}}}
\end{gathered}
$$

with

$$
F_{k}=\frac{\left(\epsilon_{k}+\gamma_{k}\right) n_{k} g_{k}}{\tau c_{F, k}}
$$

In these equations, $I_{o, k}$ represents the part of investment costs $\left(I_{k}\right)$, which is independent of the component efficiency and capacity, $\epsilon_{\mathrm{k}}$ is the capital recovery factor, $\gamma_{k}$ represents a coefficient which indicates what part of the fixed O\&M costs depends on the investment cost $I_{k}, \tau$ is the annual time of plant operation at the nominal capacity and $\mathrm{g}_{\mathrm{k}}$ and $\mathrm{n}_{\mathrm{k}}$ are constants which depend on the component being considered. The variable $F_{k}$ is called the thermoeconomic similarity number of the $k$-th component.

The cost data provided for this project did not always support a relationship according to Equation 3-10. In those cases, the following relationship between investment costs and exergy destruction was used:

$$
I_{k}=\frac{g_{k}^{*}}{E_{\mathrm{D}, k}^{\mathrm{a}_{\mathrm{k}}}} E_{\mathrm{P}, \mathrm{k}}
$$




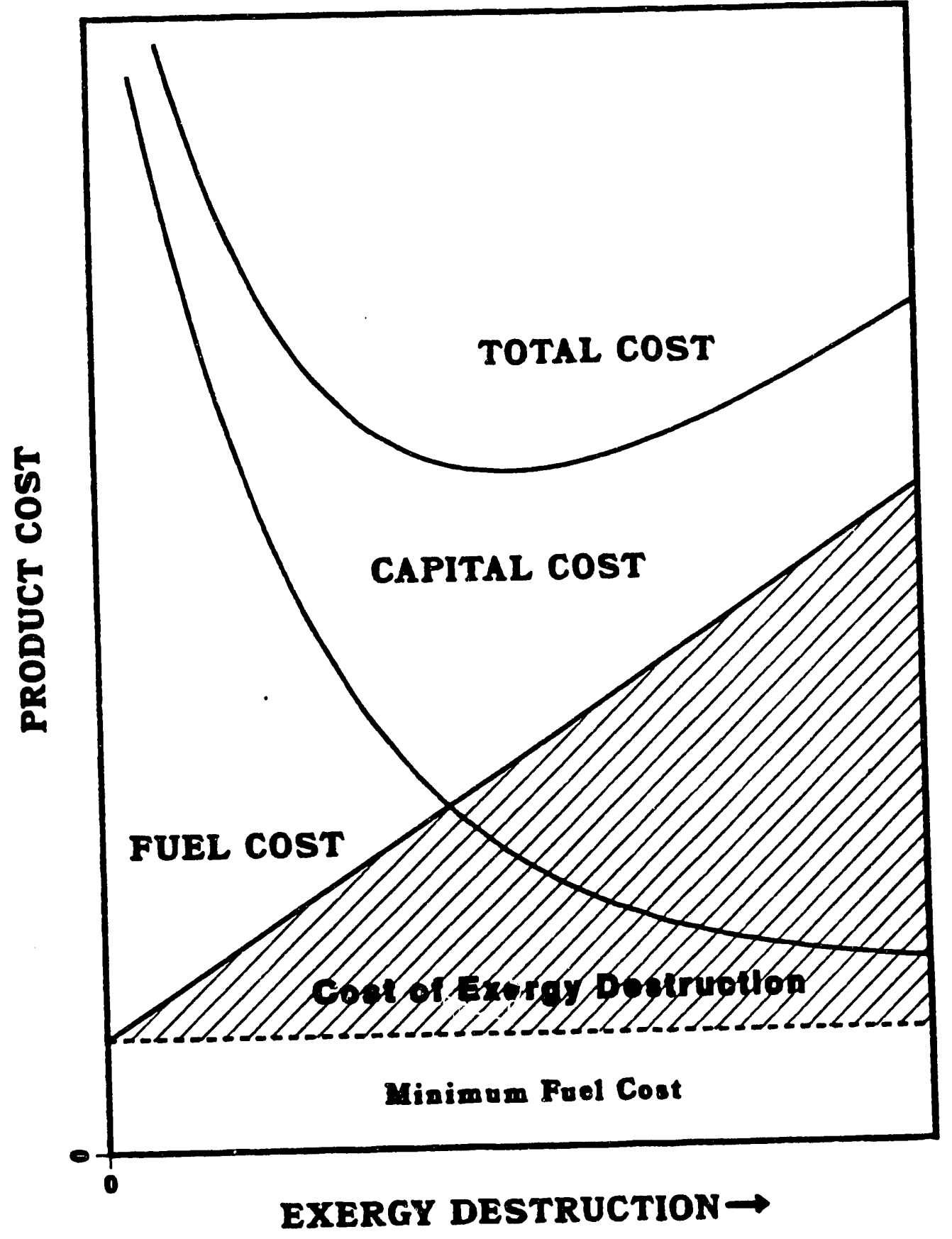

$100 \% \leftarrow$ THERMODYNAMIC EFFICIENCY

Figure 3-1. Contribution of Fuel and Capital Costs to the Product Cost as a Function of the Thermodynamic (Exergetic) Efficiency. 
It is apparent that the numerical values of the constants $g_{k}$ and $g_{k}^{*}$ in Equations 3-10 and 3-13 are different. The same symbol is used in both equations to indicate the similarities between the equations. When Equation 3-13 is used, the thermoeconomically optimal exergetic efficiency, exergy destruction, and investment cost are given by

$$
\begin{gathered}
\zeta_{\mathrm{k}}^{\mathrm{OPT}}=\frac{1}{1+\sqrt[\mathrm{n}^{+1}]{\mathrm{F}_{\mathrm{k}}^{*} / E_{\mathrm{P}, \mathrm{k}}^{\mathrm{n}_{\mathrm{k}}}}} \\
E_{\mathrm{D}, \mathrm{k}}^{\mathrm{OPT}}=\sqrt[n_{\mathrm{k}}+1]{\mathrm{F}_{\mathrm{k}}^{*} E_{\mathrm{P}, \mathrm{k}}} \\
\mathrm{I}_{\mathrm{k}}^{\mathrm{OPT}}=\mathrm{g}_{\mathrm{k}}^{*} \sqrt[\mathrm{n}_{\mathrm{k}}+1]{E_{\mathrm{P}, \mathrm{k}} /\left(\mathrm{F}_{\mathrm{k}}^{*}\right)^{\mathrm{n}_{\mathrm{k}}}}
\end{gathered}
$$

with

$$
F_{k}^{*}=\frac{\left(\epsilon_{k}+\gamma_{k}\right) n_{k} g_{k}^{*}}{\tau c_{F, k}}
$$

The thermoeconomic similarity number, Equation $3-12$ or 3-17, plays a significant role in optimizing the component performance from the thermoeconomic viewpoint using either Equations 3-10 and 3-11 or Equations 3-13 through 3-16.

All of the above optimization results have been obtained by assuming $E_{\mathrm{P}, \mathrm{k}}=$ constant and $c_{F, k}=$ constant. These assumptions are fulfilled when a single plant component is optimized. It is apparent, however, that these assumptions are not valid when the total plant is optimized and several design changes (including changes in the design structure) are considered simultaneously. In this case, an iterative procedure is required to optimize the total plant. The thermoeconomic variables discussed in section 3.2 are used in the iteration to achieve a fast convergence.

\subsection{BENEFITS OF THERMOECONOMICS}

The discussion in this section is more general than the scope of the present project dictates. This is done because thermoeconomics is a significantly younger discipline than exergy analysis and the benefits are not obvious to many energy engineers.

Today the field of thermoeconomics has matured to the point where it is a valuable 
analytical tool for the design, operation, and maintenance of energy systems; it is not yet, however, a fully developed discipline. Thus, studies involving further development of the basic aspects of thermoeconomics are currently being carried out in parallel with applications of this field to practical problems.

The :ffectiveness of reducing costs in the design or operation of an energy system increases when we understand the real causes and sources of costs. A thermoeconomic analysis identifies these sources and indicates the changes required to reduce product costs. This information, complemented by the engineer's intuition and judgment, assists in the effective reduction of the product costs in energy systems on a relatively short time scale compared with traditional approaches. Decisions about the design, operation, and repair or replacement of equipment are facilitated.

In addition, thermoeconomics provides an objective cost allocation to more than one product of the same process. For instance, a thermoeconomic analysis of a cogeneration plant (which produces electricity and process steam) will provide the cost of steam and the cost of electricity separately. The cost ratio of steam to electricity calculated by the analysis does not necessarily have to be reflected in their selling prices, but the plant operators should know the real cost of generating each form of energy. In this project, thermoeconomics calculates the cost at which the electric power is generated in the combustion turbine generator and the steam turbine generator separately.

The thermoeconomic analysis also shows how much raw fuel is required to produce each stream in the system. Finally, thermoeconomics helps managers decide how to allocate research and development funds to improve plant components that contribute most significantly to the product costs.

It is true that many conclusions obtained by a thermoeconomic optimization could also be obtained through a large number of conventional energy and economic analyses. The advantage of thermoeconomics is that it replaces an expensive and subjective search for cost reduction with an objective, well-informed, systematic, and, therefore, shorter seárch in which all of the cost sources are properly identified and evaluated. The savings in both engineering and computer time are significant. Application of thermoeconomic analysis to new energy system concepts and complex installations (particularly those with several chemical reactions) results in significant savings. 


\subsection{RESULTS OF THE THERMOECONOMIC OPTIMIZATION}

This section discusses the results obtained from the thermoeconomic optimization of the IGCC power plant described in section 2.3. Based on the recommendations from the previous thermoeconomic analysis [1] conducted for case 1 (see also section 2.4), the optimization efforts focused on the gasifier (mainly in determining the optimum coal moisture and gasification temperature), the steam turbines, and the total plant heat exchanger network. The latter includes the product gas cooler and heat recovery steam drum, heat recovery in sulfation and HP drum, recycle gas cooler, exit gas cooler, heat recovery in booster air compression, HRSG, and feedwater preheaters.

In addition to the factors considered in this study, a complete Case 1 design optimization should consider various options for hot gas cleanup and an optimization of the in-bed sulfur removal per pass in the gasifier. These studies exceed the scope of the present project.

All performance and cost calculations were conducted using exactly the same assumptions presented and discussed in sections 4,7 , and 8 of Reference [1]. The only change was made in the value of the plant capacity factor used to minimize the cost of electricity. In all base case evaluations reported in Reference [1] a capacity factor of 65 percent was assumed to facilitate comparisons with other DOE-sponsored studies. However, the plant availability analysis, conducted with the aid of the UNIRAM software, indicated that the plant would be available 85 percent of the time [1]. In the Southern Company, the average plant availabilty is currently about 90 percent. Since the Case 1 IGCC power plant would be dispatched as a baseload plant, its capacity factor could approach the equivalent availability factor. Therefore, it was decided to use a plant capacity factor of 85 percent in the optimization. Tables 4-1 through 4-4 summarize the most important assumptions made to calculate the total plant facilities investment, the operating and maintenance costs, and the cost of electricity.

The final criterion used to evaluate the optimization results was the 30-year levelized cost of electricity. This cost was calculated in both current and constant dollars. Calculations on a constant dollar basis assume a zero inflation rate during plant construction and operation. The calculation procedure used to calculate the levelized cost of electricity emulates the DOE cost of electricity computer program, as developed at the Morgantown Energy Technology Center. This program is generally consistent with the EPRI Technical Assessment Guide (TAG) [9] and has a number of built-in costing assumptions based on experience and utility costing approaches. 


\begin{tabular}{|c|c|c|}
\hline \multicolumn{3}{|c|}{$\begin{array}{l}\text { TABLE 4-1 } \\
\text { Process Contingency Factors and Maintenance Material Cost as a Percentage of } \\
\text { Process Plant Cost (PPC) for each IGCC Plant Area }\end{array}$} \\
\hline Area & $\begin{array}{l}\text { Process } \\
\text { Contingency } \\
\text { Factor [\%] }\end{array}$ & $\begin{array}{c}\text { Maintenance } \\
\text { Material Costs } \\
{[\% \text { of PPC }]} \\
\end{array}$ \\
\hline Booster Air Compression & 0 & 2.4 \\
\hline Coal Receiving and Handling & 0 & 1.2 \\
\hline Limestone Receiving and Handling & 0 & 1.2 \\
\hline Coal Pressurization/Feeding & 5 & 2.4 \\
\hline Ash Depressurization/LASH Transport & 10 & 2.4 \\
\hline Ash and Fines Handling and Disposal & 0 & 1.2 \\
\hline Gasification/Fines Recycle & 15 & 2.4 \\
\hline Heat Recovery & 5 & 2.4 \\
\hline Fines Removal/Depressurization & 15 & 2.4 \\
\hline Gas Cooling & 0 & 2.4 \\
\hline Recycle Gas System & 10 & 2.4 \\
\hline Resaturation/Startup Heater & 0 & 2.4 \\
\hline Sulfation & 15 & 2.4 \\
\hline Chloride Removal & 10 & 2.4 \\
\hline Zinc Ferrite Sulfur Removal & 10 & 2.4 \\
\hline Balance of Gasification Island & 0 & 2.4 \\
\hline Gas Turbine System & 5 & 0.9 \\
\hline Heat Recovery Steam Generation & 5 & 0.9 \\
\hline Steam Turbine System & 0 & 0.9 \\
\hline General Facilities & 0 & 0.9 \\
\hline \multicolumn{3}{|c|}{$\begin{array}{l}\text { *These percentages are applied to the sum of each area process plant cost and the prorated } \\
\text { engineering fees (excluding contingencies) to yield a total weighted average percent. The resulting } \\
\text { value is multiplied by TPC to produce maintenance material costs. Maintenance labor costs are } \\
\text { estimated based on plant staffing plans. }\end{array}$} \\
\hline
\end{tabular}




\section{TABLE 4-2}

\section{Expenditure Schedule During Construction Period}

(4.5 Years)

$\begin{array}{cr}\text { Year } & \text { Expendit } \\ 1 & 5 \% \\ 2 & 15 \% \\ 3 & 30 \% \\ 4 & 35 \% \\ 5 & 15 \%\end{array}$

TABLE 4-3

\section{Unit Costs for Calculating the Annual O\&M Costs (Mid-1990 Dollars)}

Cost Item

Fuel, Illinois No. 6 coal

Limestone

Nahcolite

Zinc Ferrite

Miscellaneous

Ash and sorbent disposal Average O\&M labor
Cost

$\$ 35.00 /$ ton

$\$ 11.20 /$ ton

$\$ 261.25 /$ ton

$\$ 6,270.00 /$ ton

$\$ 1.00 /$ ton

$\$ 2.94 /$ ton

$\$ 21.80 / \mathrm{hr}$ 


\section{TABLE 4-4}

Economic Assumptions for Cost of Electricity Calculation

Project life

Book life

Tax life

Federal and state income tax rate (composite) Investment tax credit

Tax depreciation method

Annual inflation rate

Real annual escalation rates (over inflation)

Fuel

Operating \& maintenance

Plant facilities

Year dollar basis

Capacity factor
30 years

30 years

30 years

$37.7 \%$

$0 \%$

ACRS

$4.5 \%$

$0.5 \%$

$0 \%$

0\%

mid-1990

$85 \%$

Financial Structure

$\%$ of Cost in Cost in

Type of Security Total Current Dollars [\%] Constant Dollars [\%]

Debt

45

10.3

5.6

Preferred stock

10

45

9.8

13.8

5.1

Common stock

13.8

8.9

Discount rate, [\%]

(cost of capital)

11.8

7.0 
In the following, three optimized cases are presented. Subsequently, the changes and options considered in the optimization are discussed separately for each IGCC plant area. Case $1 \mathrm{CO} 1$ is the cost optimal IGCC plant design when a relatively high value for the steam high pressure is used. Case $1 \mathrm{CO} 2$ represents a cost optimal IGCC plant design with a value for the steam high pressure comparable with the value used in the original Case 1. Finally, Case 1TO1 represents a thermodynamically optimized case which demonstrates the potential for improving the overall plant thermal efficiency.

\subsection{DESCRIPTION OF CASE 1CO1}

Figures 4-1 and 4-2 show simplified flow diagrams of the gasification island and the power island. Tables 4-5, 4-6 and 4-7 summarize the results of the simulation and thermodynamic analysis for this case. Detailed results of the thermoeconomic analysis are given in the Appendix. Compared with the original Case 1, the following design changes were identified for the thermoeconomically optimal IGCC power plant design of Case $1 \mathrm{CO}$. The corresponding design options and values used in the original Case 1 (Figures 2-1 and 2-2; Tables 2-1, 2-2 and 2-3) are given in parentheses.

1. The coal moisture at the gasifier inlet is 11.12 weight percent (4.98 weight percent).

2. The gasification temperature is $1920^{\circ} \mathrm{F}\left(1900^{\circ} \mathrm{F}\right)$.

3. The raw gas is cooled in the product gas cooler to $T_{12}=1168^{\circ} \mathrm{F}\left(T_{12}=1252^{\circ} \mathrm{F}\right)$.

4. The pressure of the HP steam generated in the gasification island is $P_{16}=2055$ psia $\left(\mathrm{P}_{16}=1600 \mathrm{psia}\right)$.

5. The temperature and mass flow rate of the quench steam, which is mixed with the gas at the exit of the product gas cooler, are $\mathrm{T}_{39}=663^{\circ} \mathrm{F}\left(\mathrm{T}_{39}=500^{\circ} \mathrm{F}\right)$ and $\dot{\mathrm{m}}_{39}=401,759 \mathrm{lbm} / \mathrm{hr}\left(\dot{\mathrm{m}}_{39}=389,707 \mathrm{lbm} / \mathrm{hr}\right)$, respectively. The ratio $\dot{\mathrm{m}}_{39} / \dot{\mathrm{m}}_{1}$ is smaller in Case 1CO1 than in the original Case 1. Note that the temperature and moisture content of the gas after quenching, stream 159, remained constant during the optimization studies.

6. The combustion gas exiting the sulfator at $T_{48}=1098^{\circ} \mathrm{F}$ is filtered, mixed with the gas turbine exhaust, and supplied to the HRSG. (In the original Case 1, the combustion gas exited the sulfator at $\mathrm{T}_{48}=1400^{\circ} \mathrm{F}$ and was used for coal drying.) As a result of this change, more HP saturated steam is generated in the sulfation area in Case 1CO1 than in the Original Case 1. 
7. The boiler feedwater (BFW) preheater in the air booster compression area preheats low-pressure (high-pressure) feedwater. The heat rejection in the subsequent trim cooler is $2.95 \mathrm{MMBtu} / \mathrm{hr}$ (36.23 MMBtu/hr).

8. The recycle gas, stream 20 , is extracted from the main gas stream at the outlet of the exit gas cooler (at the outlet of the zinc ferrite system).

9. The recycle gas cooler is used to preheat low-temperature (high-temperature) feedwater.

10. The steam cycle of Case $1 \mathrm{CO} 1$ does not generate or use any intermediate-pressure (IP) steam.

11. The HRSG of Case $1 \mathrm{CO}$ does not contain any steam drums. The heat supplied to the HRSG is used for superheating and reheating steam and for feedwater preheating but not for steam generation. HP steam generation in Case 1CO1 occurs exclusively in the gasification island.

12. The main steam pressure at the HP turbine inlet is $P_{101}=1849$ psia $\left(P_{101}=1,450\right.$ psia) and at the HP turbine outlet $P_{139}=500$ psia $\left(P_{139}=350\right.$ psia). Thus, no extraction from the HP turbine is required in Case 1CO1. The blast steam and quench steam are taken at the HP turbinie exhaust.

13. The steam required for the deaerator operation is extracted from the LP turbine in Case 1CO1 whereas it is generated in the FWH1 of the HRSG in the original Case 1. The deaerator operating pressure is 20 psia ( 24.5 psia).

14. No desuperheating of the quench steam is required in Case 1CO1. The desuperheater is shown in Figure 4-2 but the design mass flow rate of stream 149 is zero.

The justification for the above changes and the effects of the changes on the plant performance and costs are discussed in section 4.4. Section 4.5 compares Case $1 \mathrm{CO}$ with the original Case 1 and the other optimized cases. 


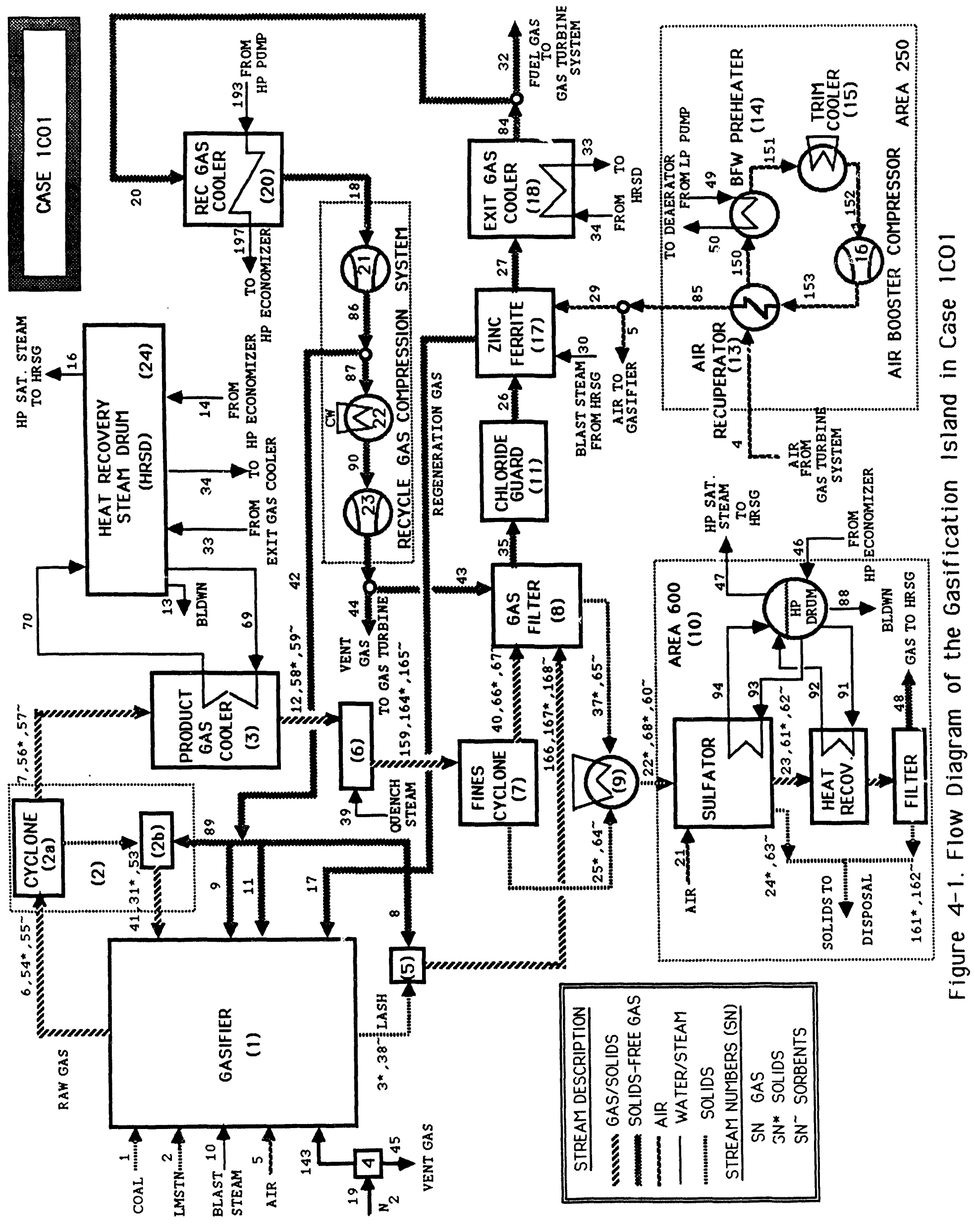




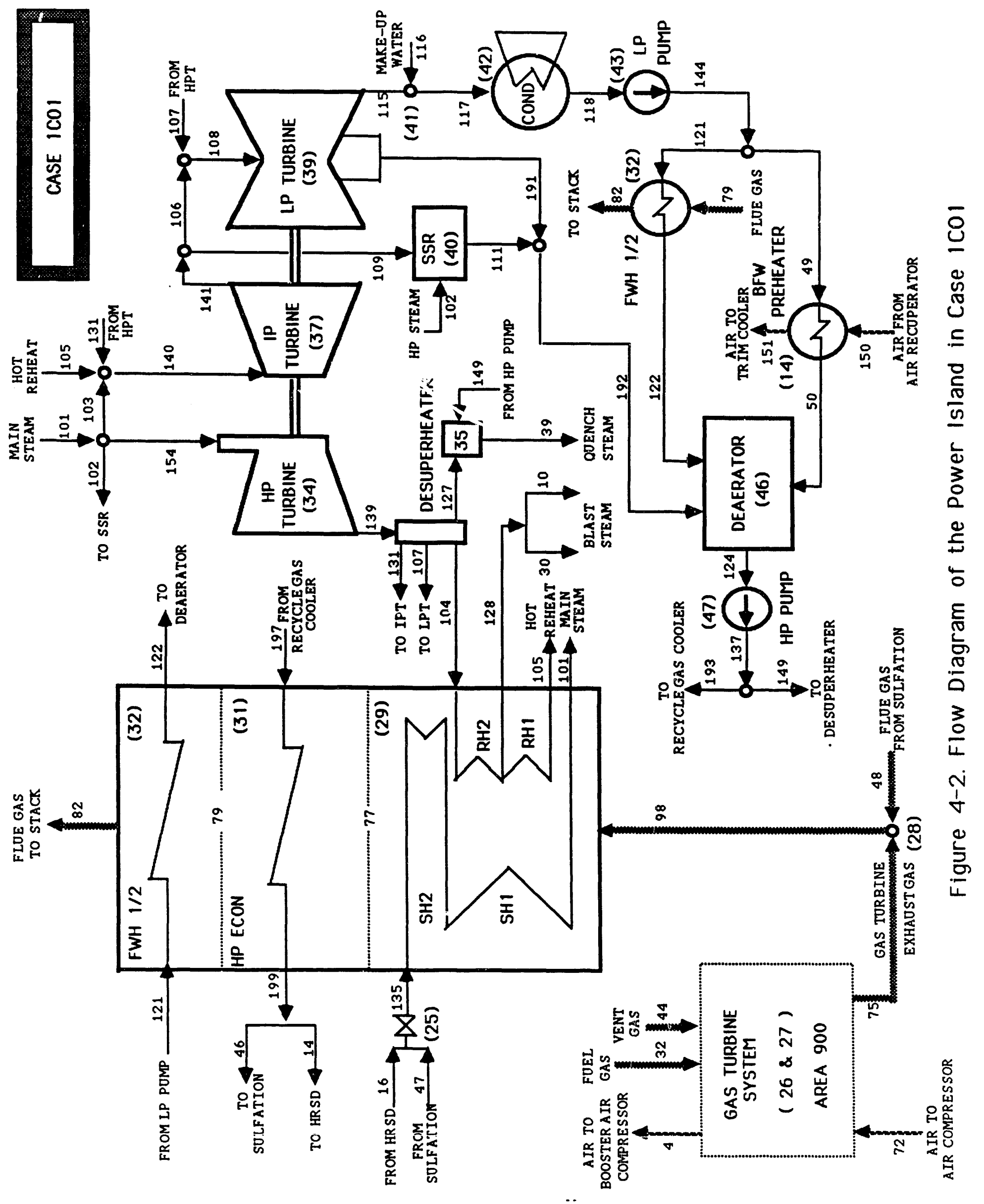


TABLE 4-5

Mass Flow Rate, Temperature, Pressure and Flow Rates of Enthalpy, Entropy and Exergy for Each Stream of Case 1 CO1

\begin{tabular}{|c|c|c|c|c|c|c|}
\hline $\begin{array}{l}\text { Stream } \\
\text { No }\end{array}$ & $\stackrel{\dot{\mathbf{m}}}{[\mathbf{l b} / \mathbf{h r}]}$ & $\begin{array}{c}\mathbf{T} \\
{[\mathbf{F}]}\end{array}$ & $\begin{array}{c}\mathbf{P} \\
\text { [psia] }\end{array}$ & $\begin{array}{c}\dot{\mathbf{H}} \\
\text { [MMBtu/hr] }\end{array}$ & $\stackrel{\dot{\mathbf{S}}}{\text { [MBtu/hrR] }}$ & $\begin{array}{c}\dot{\boldsymbol{E}} \\
\text { [MW] }\end{array}$ \\
\hline 1 & 345485 & 90.0 & 14.7 & -503.74 & 134.72 & 1203.80 \\
\hline 2 & 87703 & 90.0 & 14.7 & -456.19 & 18.75 & 0.00 \\
\hline 3 & 28031 & 500.0 & 425.0 & -138.03 & 9.72 & 6.77 \\
\hline 4 & 1140136 & 760.0 & 200.0 & 193.52 & 1896.78 & 52.48 \\
\hline 5 & 1135222 & 650.0 & 450.0 & 160.88 & 1798.16 & 57.50 \\
\hline 6 & 1611124 & 1920.0 & 400.0 & -817.73 & 3361.49 & 1034.86 \\
\hline 7 & 1611124 & 1920.0 & 395.0 & -817.72 & 3363.10 & 1034.60 \\
\hline 8 & 16115 & 411.0 & 430.0 & -32.16 & 30.35 & 7.14 \\
\hline 9 & 36896 & 411.0 & 430.0 & -73.64 & 69.49 & 16.35 \\
\hline 10 & 6897 & 950.0 & 450.0 & -37.16 & 17.74 & 1.11 \\
\hline 11 & 49374 & 411.0 & 430.0 & -98.55 & 92.98 & 21.88 \\
\hline 12 & 1611124 & 1168.1 & 385.0 & -1220.41 & 3163.34 & 948.76 \\
\hline 13 & 11857 & 639.7 & 2055.0 & -73.55 & 20.27 & 0.72 \\
\hline 14 & 1197697 & 639.7 & 2055.0 & -7429.38 & 2047.10 & 72.64 \\
\hline 15 & 16502 & 523.9 & 750.0 & -32.30 & 30.98 & 7.51 \\
\hline 16 & 1185840 & 639.7 & 2055.0 & -6812.91 & 2518.30 & 151.86 \\
\hline 17 & 34075 & 1200.0 & 430.0 & -153.30 & 86.02 & 6.37 \\
\hline 18 & 126280 & 330.0 & 285.3 & -255.48 & 238.07 & 54.89 \\
\hline 19 & 13094 & 500.0 & 450.0 & 1.40 & 20.20 & 0.64 \\
\hline 20 & 126280 & 1000.0 & 295.0 & -225.58 & 265.05 & 59.31 \\
\hline 21 & 197485 & 160.0 & 20.0 & 3.96 & 326.47 & 0.76 \\
\hline 22 & 29504 & 500.0 & 14.7 & -141.46 & 10.34 & 10.52 \\
\hline 23 & 190224 & 1600.0 & 19.8 & -49.48 & 369.53 & 13.10 \\
\hline 24 & 34428 & 150.0 & 14.7 & -181.30 & 7.08 & 0.88 \\
\hline 25 & 13260 & 1015.0 & 14.7 & -29.36 & 8.02 & 32.86 \\
\hline 26 & 2043491 & 1007.2 & 345.0 & -3506.43 & 4320.67 & 998.50 \\
\hline 27 & 2043144 & 1187.6 & 305.0 & -3508.32 & 4373.67 & 987.31 \\
\hline 29 & 4914 & 650.0 & 450.0 & 0.70 & 7.78 & 0.25 \\
\hline 30 & 28935 & 950.0 & 450.0 & -155.89 & 74.42 & 4.65 \\
\hline 31 & 279919 & 1862.0 & 430.0 & -482.45 & 242.08 & 722.28 \\
\hline 32 & 1916864 & 1000.0 & 295.0 & -3424.20 & 4023.26 & 900.29 \\
\hline 33 & 304344 & 639.7 & 2055.0 & -1748.52 & 646.32 & 38.98 \\
\hline 34 & 304344 & 639.7 & 2055.0 & -1887.86 & 520.18 & 18.46 \\
\hline 35 & 2043353 & 1007.2 & 365.0 & -3505.94 & 4310.51 & 1000.06 \\
\hline 37 & 29504 & 494.0 & 14.7 & -141.52 & 10.27 & 10.51 \\
\hline 38 & 50587 & 500.0 & 425.0 & -209.37 & 14.41 & 0.30 \\
\hline 39 & 401759 & 663.1 & 450.0 & -2226.89 & 983.83 & 54.23 \\
\hline 40 & 2012883 & 1015.0 & 385.0 & -3446.07 & 4241.17 & 988.21 \\
\hline 41 & 7393 & 1862.0 & 430.0 & -10.'.8 & 16.58 & 4.01 \\
\hline
\end{tabular}


TABLE 4-5

Mass Flow Rate, Temperature, Pressure and Flow Rates of Enthalpy, Entropy and Exergy for Each Stream of Case 1CO1 (Cont'd)

\begin{tabular}{|c|c|c|c|c|c|c|}
\hline $\begin{array}{l}\text { Stream } \\
\text { No }\end{array}$ & $\begin{array}{c}\dot{\mathbf{m}} \\
{[\mathbf{l b} / \mathbf{h r}]}\end{array}$ & $\begin{array}{l}\mathbf{T} \\
{[\mathbf{F}]}\end{array}$ & $\underset{\text { [psia] }}{\mathbf{P}}$ & $\stackrel{\dot{\mathbf{H}}}{[\mathrm{MMBtu} / \mathrm{hr}]}$ & $\begin{array}{c}\dot{\mathbf{S}} \\
\text { [MBtu/hrR] }\end{array}$ & $\underset{[\mathbf{M W}]}{\dot{E}}$ \\
\hline 42 & 109778 & 411.0 & 450.0 & -219.12 & 206.30 & 48.70 \\
\hline 43 & 14355 & 524.0 & 750.0 & -28.10 & 26.95 & 6.54 \\
\hline 44 & 2147 & 524.0 & 750.0 & -4.20 & 4.03 & 0.98 \\
\hline 45 & 9215 & 90.0 & 14.7 & 0.03 & 15.15 & 0.02 \\
\hline 46 & 419823 & 639.7 & 2055.0 & -2604.18 & 717.56 & 25.46 \\
\hline 47 & 415666 & 639.7 & 2055.0 & -2388.09 & 882.73 & 53.23 \\
\hline 48 & 190224 & 1098.0 & 19.6 & -76.01 & 354.91 & 7.68 \\
\hline 49 & 797647 & 120.4 & 23.0 & -5419.51 & 802.74 & 0.45 \\
\hline 50 & 797647 & 228.0 & 20.0 & -5333.51 & 938.73 & 3.75 \\
\hline 53 & 113266 & 1862.0 & 430.0 & -435.63 & 53.56 & 6.95 \\
\hline 54 & 294652 & 1920.0 & 400.0 & -496.46 & 259.67 & 762.85 \\
\hline 55 & 115575 & 1920.0 & 400.0 & -442.97 & 55.31 & 7.44 \\
\hline 56 & 14733 & 1920.0 & 395.0 & -24.82 & 12.98 & 38.14 \\
\hline 57 & 2310 & 1920.0 & 395.0 & -8.85 & 1.11 & 0.15 \\
\hline 58 & 14733 & 1168.1 & 385.0 & -31.48 & 9.65 & 36.73 \\
\hline 59 & 2310 & 1168.1 & 385.0 & -9.24 & 0.91 & 0.07 \\
\hline 60 & 52897 & 500.0 & 14.7 & -218.93 & 15.07 & 0.31 \\
\hline 61 & 68 & 1600.0 & 19.8 & -0.32 & 0.04 & 0.01 \\
\hline 62 & 137 & 1600.0 & 19.8 & -0.59 & 0.07 & 0.01 \\
\hline 63 & 68454 & 150.0 & 14.7 & -320.11 & 13.80 & 0.01 \\
\hline 64 & 2079 & 1015.0 & 14.7 & -8.38 & 0.78 & 0.05 \\
\hline 65 & 50818 & 494.0 & 14.7 & -210.39 & 14.41 & 0.29 \\
\hline 66 & 1473 & 1015.0 & 385.0 & -3.26 & 0.89 & 3.65 \\
\hline 67 & 231 & 1015.0 & 385.0 & -0.93 & 0.09 & 0.01 \\
\hline 68 & 13260 & 500.0 & 14.7 & -32.36 & 5.54 & 32.38 \\
\hline 69 & 881496 & 639.7 & 2055.0 & -5467.97 & 1506.65 & 53.46 \\
\hline 70 & 881496 & 639.7 & 2055.0 & -5064.39 & 1871.98 & 112.89 \\
\hline 72 & 5958123 & 90.0 & 14.7 & 18.91 & 9803.01 & 0.99 \\
\hline 75 & 6736999 & 1098.0 & 15.0 & -4801.56 & 13433.59 & 260.86 \\
\hline 77 & 6927222 & 703.2 & 14.9 & -5651.89 & 13222.50 & 132.81 \\
\hline 79 & 6927222 & 305.1 & 14.9 & $-64 C 0.78$ & 12436.36 & 39.97 \\
\hline 82 & 6927222 & 279.8 & 14.9 & -6447.12 & 12375.72 & 36.16 \\
\hline 84 & 2043144 & 1000.0 & 295.0 & -3649.78 & 4288.31 & 959.60 \\
\hline 85 & 1140136 & 650.0 & 450.0 & 161.57 & 1805.94 & 57.75 \\
\hline 86 & 126280 & 411.0 & 450.0 & -252.04 & 237.31 & 56.02 \\
\hline 87 & 16502 & 411.0 & 450.0 & -32.94 & 31.01 & 7.32 \\
\hline 88 & 4156 & 639.7 & 2055.0 & -25.78 & 7.10 & 0.25 \\
\hline 89 & 7393 & 411.0 & 430.0 & -14.75 & 13.92 & 3. \\
\hline 90 & 16502 & 365.7 & 450.0 & -33.20 & 30.70 & 7. \\
\hline
\end{tabular}


TABLE 4-5

Mass Flow Rate, Temperature, Pressure and Flow Rates of Enthalpy, Entropy and Exergy for Each Stream of Case 1CO1 (Cont'd)

\begin{tabular}{|c|c|c|c|c|c|c|}
\hline $\begin{array}{l}\text { Stream } \\
\text { No }\end{array}$ & 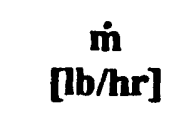 & $\frac{\mathbf{T}}{[\mathbf{F}]}$ & $\underset{\text { [psia] }}{\mathbf{P}}$ & $\stackrel{\stackrel{\dot{H}}{\text { [MMBtu/hr] }}}{\text { [MM }}$ & $\begin{array}{c}\dot{\mathbf{S}} \\
\text { [MBtu/hrR] }\end{array}$ & $\frac{\dot{E}}{[\mathbf{M W}]}$ \\
\hline 91 & 57149 & 639.7 & 2055.0 & -354.50 & 97.68 & 3.47 \\
\hline 92 & 57149 & 639.7 & 2055.0 & -328.33 & 121.36 & 7.32 \\
\hline 93 & 358517 & 639.7 & 2055.0 & -2223.90 & 612.78 & 21.74 \\
\hline 94 & 358517 & 639.7 & 2055.0 & -2059.76 & 761.36 & 45.91 \\
\hline 98 & 6927222 & 1098.0 & 15.0 & -4877.58 & 13793.28 & 267.79 \\
\hline 101 & 1601506 & 1000.0 & 1848.6 & -8654.23 & 3863.81 & 290.79 \\
\hline 102 & 677 & 1000.0 & 1848.6 & -3.66 & 1.63 & 0.12 \\
\hline 103 & 2756 & 1000.0 & 1848.6 & -14.89 & 6.65 & 0.50 \\
\hline 104 & 1175588 & 663.1 & 500.0 & -6519.94 & 2862.55 & 160.18 \\
\hline 105 & 1139756 & 1000.0 & 470.0 & -6110.95 & 2946.79 & 189.30 \\
\hline 106 & 1160466 & 720.0 & 150.0 & -6377.71 & 3025.37 & 143.07 \\
\hline 107 & 2010 & 663.1 & 500.0 & -11.15 & 4.89 & 0.27 \\
\hline 108 & 1162476 & 719.9 & 150.0 & -6388.85 & 3030.52 & 143.30 \\
\hline 109 & 764 & 720.0 & 150.0 & -4.20 & 1.99 & 0.09 \\
\hline 111 & 1440 & 805.2 & 150.0 & -7.85 & 3.81 & 0.19 \\
\hline 115 & 1126619 & 120.6 & 1.7 & -6534.34 & 3064.73 & 17.92 \\
\hline 116 & 453603 & 80.0 & 14.5 & -3100.26 & 423.80 & 0.16 \\
\hline 117 & 1580222 & 120.6 & 1.7 & -9634.60 & 3489.73 & 17.89 \\
\hline 118 & 1580222 & 120.4 & 1.7 & -10736.76 & 1590.24 & 0.87 \\
\hline 121 & 782576 & 120.4 & 23.0 & -5317.11 & 787.57 & 0.44 \\
\hline 122 & 782576 & 178.7 & 20.0 & -5271.47 & 862.55 & 1.74 \\
\hline 124 & 1617520 & 228.0 & 20.0 & -10815.64 & 1903.62 & 7.60 \\
\hline 127 & 401759 & 663.1 & 450.0 & -2226.89 & 983.83 & 54.23 \\
\hline 128 & 35831 & 950.0 & 450.0 & -193.05 & $\$ 2.15$ & 5.75 \\
\hline 131 & 18718 & 663.1 & 500.0 & -103.81 & 45.58 & 2.55 \\
\hline 135 & 1601506 & 638.6 & 2039.9 & -9201.01 & 3402.00 & 204.94 \\
\hline 137 & 1617520 & 232.7 & 2105.0 & -10800.68 & 1910.12 & 10.94 \\
\hline 139 & 1598074 & 663.1 & 500.0 & -8863.10 & 3891.30 & 217.75 \\
\hline 140 & 1161230 & 994.3 & 470.0 & -6229.65 & 2999.86 & 192.22 \\
\hline 141 & 1161230 & 720.0 & 150.0 & -6381.90 & 3027.36 & 143.17 \\
\hline 143 & 3879 & 500.0 & 450.0 & 0.41 & 5.98 & 0.19 \\
\hline 144 & 1580222 & 120.4 & 23.0 & -10736.62 & 1590.32 & 0.90 \\
\hline 149 & 0 & - & - & - & - & - \\
\hline 150 & 1140136 & 450.0 & 199.0 & 104.24 & 1812.78 & 39.85 \\
\hline 151 & 1140136 & 138.4 & 198.0 & 16.93 & 1695.79 & 33.10 \\
\hline 152 & 1140136 & 127.7 & 176.0 & 13.98 & 1700.01 & 31.56 \\
\hline 153 & 1140136 & 341.9 & 453.0 & 73.64 & 1712.66 & 47.01 \\
\hline 154 & 1598074 & 1000.0 & 1848.6 & -8635.68 & 3855.53 & 290.17 \\
\hline 159 & 2012883 & 1015.0 & 385.0 & -3446.07 & 4241.17 & 988.21 \\
\hline
\end{tabular}


TABLE 4-5

Mass Flow Rate, Temperature, Pressure and Flow Rates of Enthalpy, Entropy and Exergy for Each Stream of Case 1 CO1 (Cont'd)

\begin{tabular}{|c|c|c|c|c|c|c|}
\hline $\begin{array}{l}\text { Stream } \\
\text { No }\end{array}$ & $\underset{[\mathbf{m b} / \mathbf{h r}]}{\dot{\mathbf{m}}}$ & $\begin{array}{c}T \\
{[\mathbf{F}]}\end{array}$ & $\underset{\text { [psia] }}{\mathbf{P}}$ & $\underset{\text { [MMBtu/hr] }}{\dot{\mathbf{H}}}$ & $\begin{array}{c}\dot{\mathbf{S}} \\
\text { [MBtu/hrR] }\end{array}$ & $\stackrel{\dot{E}}{[M W]}$ \\
\hline 161 & 68 & 1098.0 & 19.6 & -0.34 & 0.04 & 0.00 \\
\hline 162 & 137 & 1098.0 & 19.6 & -0.61 & 0.06 & 0.00 \\
\hline 164 & 14733 & 1015.0 & 385.0 & -32.63 & 8.91 & 36.51 \\
\hline 165 & 2310 & 1015.0 & 385.0 & -9.31 & 0.86 & 0.05 \\
\hline 166 & 16115 & 479.7 & 375.0 & -31.78 & 30.97 & 7.15 \\
\hline 167 & 28031 & 479.7 & 375.0 & -138.22 & 9.52 & 6.74 \\
\hline 168 & 50587 & 479.7 & 375.0 & -209.58 & 14.19 & 0.27 \\
\hline 170 & 345485 & 90.0 & 14.7 & -503.74 & 134.72 & 1203.80 \\
\hline 176 & 6927222 & 1054.1 & 15.0 & -4965.28 & 13736.65 & 251.21 \\
\hline 190 & 1601506 & 950.0 & 1938.0 & -8709.86 & 3817.48 & 281.95 \\
\hline 191 & 35857 & 374.8 & 22.0 & -202.81 & 95.23 & 2.46 \\
\hline 192 & 37298 & 391.3 & 22.0 & -210.66 & 99.40 & 2.59 \\
\hline 193 & 1617520 & 232.7 & 2105.0 & -10800.68 & 1910.12 & 10.94 \\
\hline 197 & 1617520 & 250.8 & 2083.9 & -10771.22 & 1952.27 & 12.78 \\
\hline 199 & 1617520 & 639.7 & 2055.0 & -10033.56 & 2764.66 & 98.10 \\
\hline
\end{tabular}




\section{TABLE 46}

Exergy Flow Rates of Fuel $\left(\dot{\boldsymbol{E}}_{\mathrm{p}}\right)$, Product $\left(\dot{\boldsymbol{E}}_{\mathrm{p}}\right)$, and Exergy Destruction $\left(\dot{\boldsymbol{B}}_{\mathrm{p}}\right)$, Exergy Destruction Ratio $(\theta)$, Exergy Destruction to Total Exergy Input Ratio $\left(\theta^{*}\right)$ and Exergetic Efriciency ( $\zeta$ ) for Each Area and the Total Plant in Case $1 \mathrm{CO1}$

\section{Area}

Area 250: Booster Air Compressor Area 300: KRW Gasification Area 380: Recycle Gas Compression Area 400: Gas Conditioning Area 500: External Desulfurization Area 600: Sulfation Area 900: Gas Turbine System Area 1000: HRSG Area 1100: Steam Cycle

Total Plant Exergy Losses Service Station Power Steam Transport Losses

\section{[MW]}

23.35 1288.93

61.44 201.59 1003.40 36.70 641.21 232.38 264.40 [MW] 13.51 1028.71 182.77 986.49 363.93 207.34

1206.35 58.06 28.02 209.95

482.55

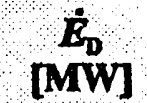

\subsection{4}

260.23

3.38

18.82

16.91

8.68

277.28

25.04

54.45

37.87

11.15

0.16

$\theta$

[\%]

\subsection{6}

35.95

0.47

2.60

2.34

1.20

38.31

3.47

7.52

5.23

1.54

0.02

723.81

100.00
5 [\%]

57.86

79.81

94.50

90.66

98.31

76.35

56.76

89.22

79.41

3.14

0.92

0.01

60.00

40.00 
TABLE 4-7

Heat Loss, Power Supplied (Generated), Exergy Destruction Flow Rate, Exergy Destruction Ratio $(\theta)$, Exergy Destruction to Total Exergy Input Ratio $\left(\theta^{*}\right)$ and Exergetic Efriciency $(\zeta)$ for Plant Components in Case $1 \mathrm{CO1}$

\begin{tabular}{ll} 
Component \\
1 Gasifier \\
2 & Cyclones \\
3 & Product Gas Cooler \\
4 & Coal Hopper System \\
6 & Quench Steam Mixing \\
$7 / 8$ & Fines Cyclone \& Gas Filter \\
9 & Solids Conveyor \& Cooler \\
10 & Area 600: Sulfation \\
11 & Chloride Guard \\
13 & Air Recuperator \\
14 & BFW Preheater \\
15 & Trim Cooler \\
16 & Booster Air Compressor \\
17 & Zinc Ferrite System \\
18 & Exit Gas Cooler \\
20 & Recycle Gas Cooler \\
21 & Recycle Gas Compressor 1 \\
23 & Recycle Gas Compressor II \\
25 & Steam Transport Losses \\
26 & Gas Turbine/Air Compressor \\
27 & Combustion Chamber \\
29 & Superheater \& Reheater \\
31 & HP Economizer \\
32 & Feedwater Heater 1/2 \\
34 & HP Turbine \\
37 & IP Turbine \\
39 & LP Turbine \\
40 & Steam Seal Regulator \\
42 & Condenser \\
43 & LP Pump \\
46 & Deaerator \\
47 & HP Pump \\
& \\
\hline 1
\end{tabular}

\section{Component}

Gasifier

Cyclones

Coal Hopper System

18 Fines Cyclone \& Gas Filter

9 Solids Conveyor \& Cooler

11 Chloride Guard

13 Air Recuperator

16

\section{for Pant Components in Case 1 CO1}




\subsection{DESCRIPTION OF CASE 1CO2}

This case represents an economically optimal design of Case 1 at a steam highpressure value $\left(\mathrm{P}_{\mathrm{HP}}=1515\right.$ psia) comparable with the value in the original case $1\left(\mathrm{P}_{\mathrm{HP}}\right.$ $=1600$ psia). The simplified flow diagrams for this case are presented in Figures 4-3 and 4-4. The results of the simulation and thermodynamic analyses are shown in Tables 4-8, 4-9 and 4-10. The structure of the gasification island is identical in the optimal Cases $1 \mathrm{CO} 1$ and $1 \mathrm{CO} 2$. Both cases have the same gasification temperature $\left(1920^{\circ} \mathrm{F}\right)$ and the same coal moisture at the gasifier inlet (11.12 weight percent). The major differences between these two cases are

- in the steam high-pressure value $\left(\mathrm{P}_{\mathrm{HP}}=\mathrm{P}_{16}=\mathrm{P}_{47}=1515\right.$ psia in Case $1 \mathrm{CO} 2$ versus $P_{\mathrm{HP}}=2055$ psia in Case $1 \mathrm{CO}$ ).

- in the HRSG design as it is apparent from a comparison of Figures 4-2 and 4-4 and the values shown in Tables 4-5 through 4-10 (e.g., in addition to the components included in the HRSG of Case 1CO1, the HRSG of Case $1 \mathrm{CO} 2$ has an HP steam drum, a blast steam reheater and a second feedwater heater),

- in the steam turbine (pressure ratio and steam extractions), and

- in the design of the LP feedwater preheating process (Case 1CO2 has two more feedwater heaters than Case 1CO1; the steam extraction from the LP turbine is used in the FWH1 in Case $1 \mathrm{CO} 2$ versus the deaerator in Case 1CO1).

The design of Case 1CO2 is closer than the design of Case 1CO1 to the design of the original Case 1. The differences in performance and costs between the two optimized Cases $1 \mathrm{CO} 1$ and $1 \mathrm{CO} 2$ are discussed in section 4.5. 


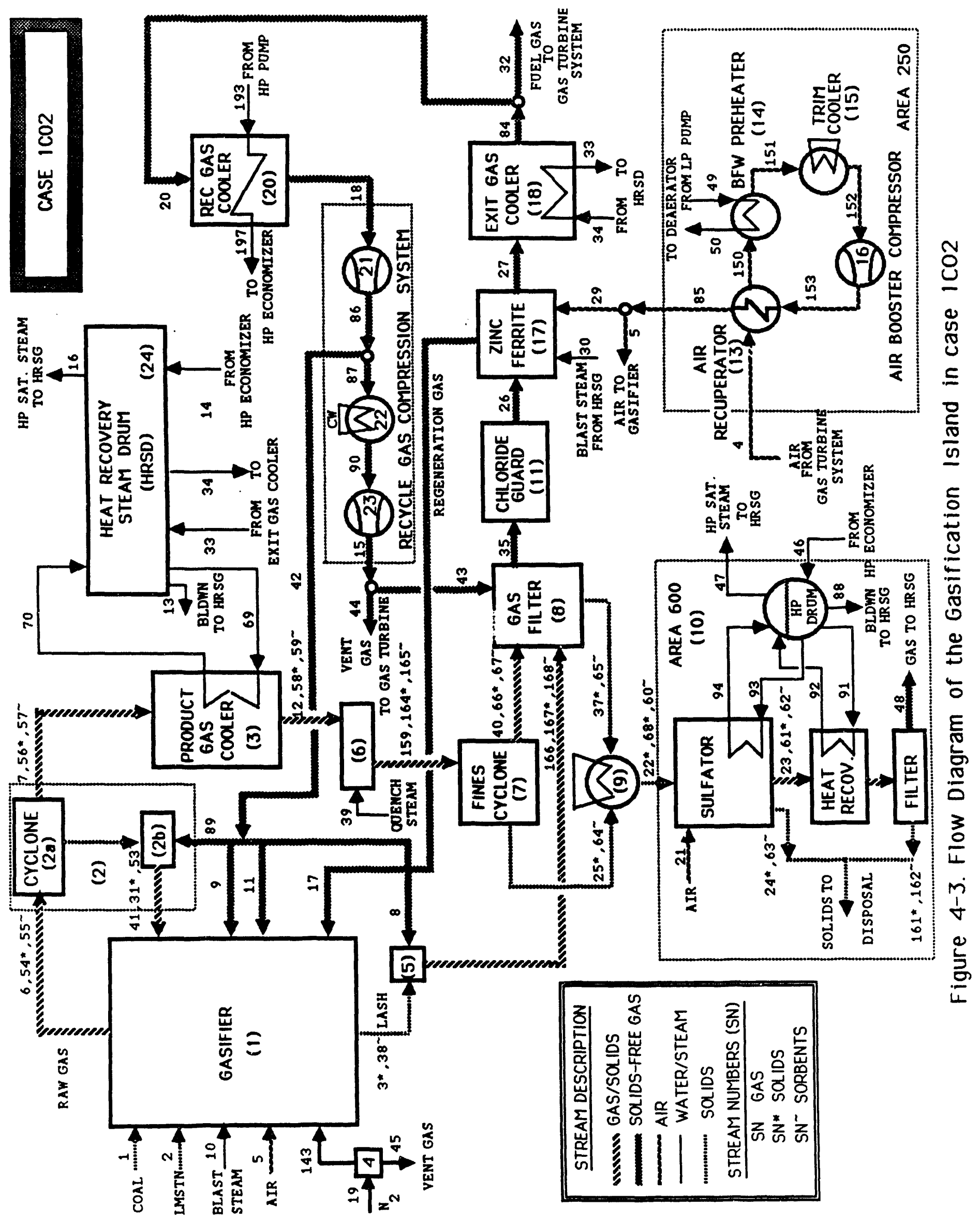




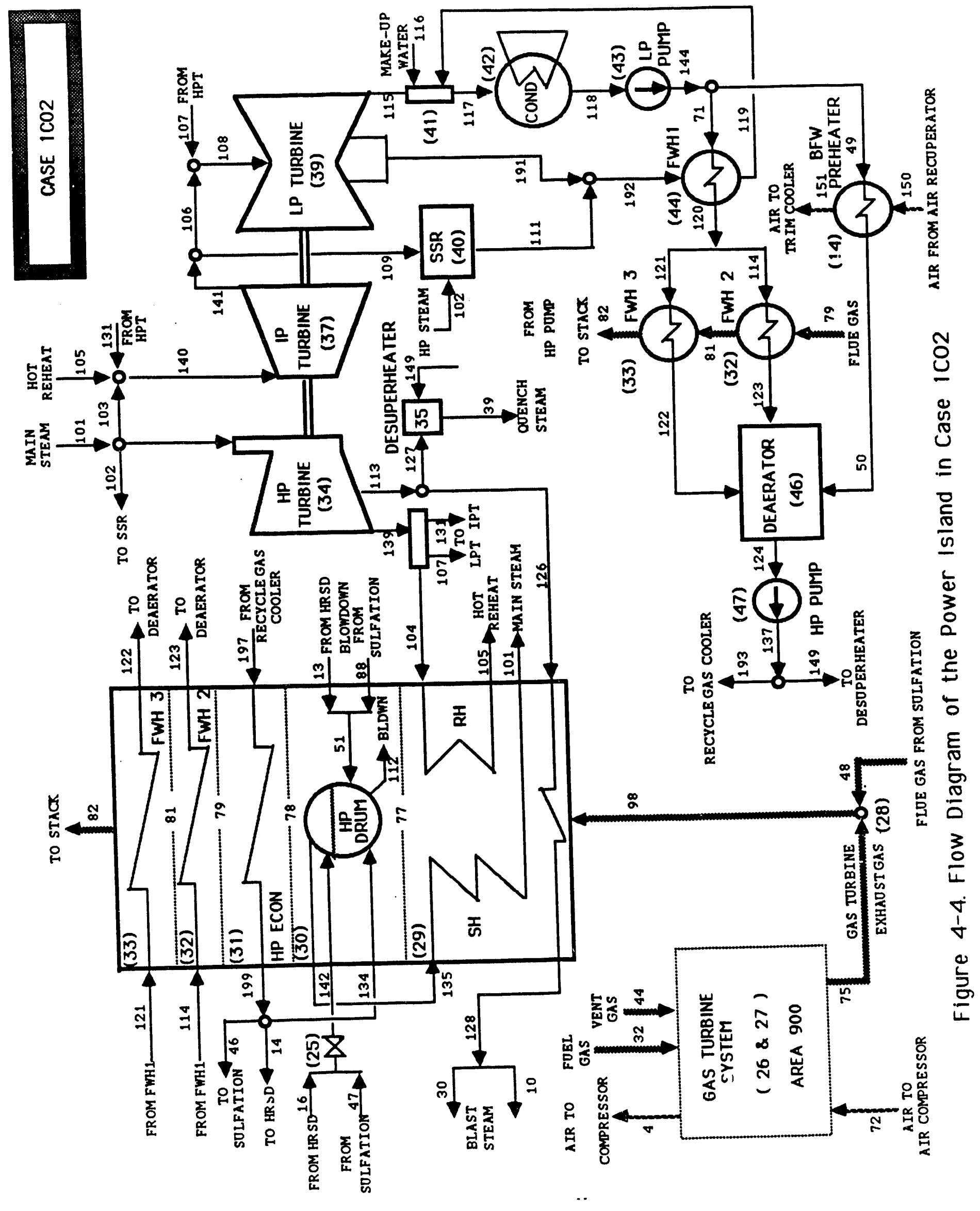


TABLE 4-8

Mass Flow Rate, Temperature, Pressure and Flow Rates of Enthalpy, Entropy and Exergy for Each Stream of Case $1 \mathrm{CO} 2$

\begin{tabular}{|c|c|c|c|c|c|c|}
\hline $\begin{array}{l}\text { Stream } \\
\text { No }\end{array}$ & $\underset{[\mathbf{l b} / \mathbf{h r}]}{\dot{\mathbf{m}}}$ & $\begin{array}{l}\mathbf{T} \\
{[\mathbf{F}]}\end{array}$ & $\underset{\text { [psia] }}{\mathbf{P}}$ & $\frac{\dot{\mathbf{H}}}{[\mathbf{M M B t u} / \mathbf{h r}]}$ & $\stackrel{\dot{\mathbf{S}}}{[\mathrm{MBtu} / \mathrm{hrR}]}$ & $\stackrel{\dot{E}}{[\mathbf{M W}]}$ \\
\hline 1 & 345485 & 90.0 & 14.7 & -503.74 & 134.72 & 1203.80 \\
\hline 2 & 87703 & 90.0 & 14.7 & -456.19 & 18.75 & 0.00 \\
\hline 3 & 28031 & 500.0 & 425.0 & -138.03 & 9.72 & 6.77 \\
\hline 4 & 1140136 & 760.0 & 200.0 & 193.52 & 1896.78 & 52.48 \\
\hline 5 & 1135222 & 650.0 & 450.0 & 160.88 & 1798.16 & 57.50 \\
\hline 6 & 1611124 & 1920.0 & 400.0 & -817.73 & 3361.49 & 1034.86 \\
\hline 7 & 1611124 & 1920.0 & 395.0 & -817.72 & 3363.10 & 1034.60 \\
\hline 8 & 16115 & 411.0 & 430.0 & -32.16 & 30.35 & 7.14 \\
\hline 9 & 36896 & 411.0 & 430.0 & -73.64 & 69.49 & 16.35 \\
\hline 10 & 6897 & 950.0 & 450.0 & -37.16 & 17.74 & 1.11 \\
\hline 11 & 49374 & 411.0 & 430.0 & -98.55 & 92.98 & 21.88 \\
\hline 12 & 1611124 & 1133.7 & 385.0 & -1238.23 & 3152.28 & 945.32 \\
\hline 13 & 10087 & 597.5 & 1515.0 & -63.23 & 16.66 & 0.51 \\
\hline 14 & 1018847 & 597.5 & 1515.0 & -6387.13 & 1682.38 & 51.61 \\
\hline 15 & 16502 & 523.9 & 750.0 & -32.30 & 30.98 & 7.51 \\
\hline 16 & 1008760 & 597.5 & 1515.0 & -5763.15 & 2195.94 & 130.03 \\
\hline 17 & 34075 & 1200.0 & 430.0 & -153.30 & 86.02 & 6.37 \\
\hline 18 & 126280 & 330.0 & 285.3 & -255.48 & 238.07 & 54.89 \\
\hline 19 & 13094 & 500.0 & 450.0 & 1.40 & 20.20 & 0.64 \\
\hline 20 & 126280 & 1000.0 & 295.0 & -225.58 & 265.05 & 59.31 \\
\hline 21 & 197485 & 160.0 & 20.0 & 3.96 & 326.47 & 0.76 \\
\hline 22 & 29504 & 500.0 & 14.7 & -141.46 & 10.34 & 10.52 \\
\hline 23 & 190224 & 1600.0 & 19.8 & -49.48 & 369.53 & 13.10 \\
\hline 24 & 34428 & 150.0 & 14.7 & -181.30 & 7.08 & 0.88 \\
\hline 25 & 13260 & 1015.0 & 14.7 & -29.36 & 8.02 & 32.86 \\
\hline 26 & 2043491 & 1007.2 & 345.0 & -3506.43 & 4320.67 & 998.50 \\
\hline 27 & 2043144 & 1187.6 & 305.0 & -3508.32 & 4373.67 & 987.31 \\
\hline 29 & 4914 & 650.0 & 450.0 & 0.70 & 7.78 & 0.25 \\
\hline 30 & 28935 & 950.0 & 450.0 & -155.89 & 74.42 & 4.65 \\
\hline 31 & 279919 & 1862.0 & 430.0 & -482.45 & 242.08 & 722.28 \\
\hline 32 & 1916864 & 1000.0 & 295.0 & -3424.20 & 4023.26 & 900.29 \\
\hline 33 & 250665 & 597.5 & 1515.0 & -1432.07 & 545.67 & 32.31 \\
\hline 34 & 250665 & 597.5 & 1515.0 & -1571.41 & 413.91 & 12.70 \\
\hline 35 & 2043353 & 1007.2 & 365.0 & -3505.94 & 4310.51 & 1000.06 \\
\hline 37 & 29504 & 494.0 & 14.7 & -141.52 & 10.27 & 10.51 \\
\hline 38 & 50587 & 500.0 & 425.0 & -209.37 & 14.41 & 0.30 \\
\hline 39 & 401759 & 744.7 & 450.0 & -2208.79 & 999.40 & 57.03 \\
\hline 40 & 2012883 & 1015.0 & 385.0 & -3446.07 & 4241.17 & 988.21 \\
\hline 41 & 7393 & 1862.0 & 430.0 & -10.78 & 16.58 & 4.01 \\
\hline
\end{tabular}


TABLE 4-8

Mass Flow Rate, Temperature, Pressure and Flow Rates of Enthalpy, Entropy and Exergy for Each Stream of Case $1 \mathrm{CO}$ (Cont'd)

\begin{tabular}{|c|c|c|c|c|c|c|}
\hline $\begin{array}{l}\text { Stream } \\
\text { No }\end{array}$ & $\underset{[\mathbf{m} / \mathbf{h r}]}{\dot{\mathbf{m}}}$ & $\begin{array}{c}T \\
{[\mathbf{F}]}\end{array}$ & $\underset{\text { [psia] }}{\mathbf{P}}$ & $\frac{\dot{\mathbf{H}}}{[\mathrm{MMBtu} / \mathrm{hr}]}$ & $\begin{array}{c}\dot{\mathbf{S}} \\
\text { [MBtu/hrR] }\end{array}$ & $\stackrel{\dot{\boldsymbol{E}}}{[\mathbf{M W}]}$ \\
\hline 42 & 109778 & 411.0 & 450.0 & -219.12 & 206.30 & 48.70 \\
\hline 43 & 14355 & 524.0 & 750.0 & -28.10 & 26.95 & 6.54 \\
\hline 44 & 2147 & 524.0 & 750.0 & -4.20 & 4.03 & 0.98 \\
\hline 45 & 9215 & 90.0 & 14.7 & 0.03 & 15.15 - & 0.02 \\
\hline 46 & 345775 & 597.5 & 1515.0 & -2167.66 & 570.97 & 17.52 \\
\hline 47 & 342352 & 597.5 & 1515.0 & -1955.89 & 745.26 & 44.13 \\
\hline 48 & 190224 & 1098.0 & 19.6 & -76.01 & 354.91 & 7.68 \\
\hline 49 & 797647 & 120.4 & 23.0 & -5419.51 & 802.74 & 0.45 \\
\hline 50 & 797647 & 228.0 & 20.0 & -5333.51 & 938.73 & 3.75 \\
\hline 51 & 13510 & 596.2 & 1500.0 & -84.69 & 22.31 & 0.68 \\
\hline 53 & 113266 & 1862.0 & 430.0 & -435.63 & 53.56 & 6.95 \\
\hline 54 & 294652 & 1920.0 & 400.0 & -496.46 & 259.67 & 762.85 \\
\hline 55 & 115575 & 1920.0 & 400.0 & -442.97 & 55.31 & 7.44 \\
\hline 56 & 14733 & 1920.0 & 395.0 & -24.82 & 12.98 & 38.14 \\
\hline 57 & 2310 & 1920.0 & 395.0 & -8.85 & 1.11 & 0.15 \\
\hline 58 & 14733 & 1133.7 & 385.0 & -31.74 & 9.49 & 36.68 \\
\hline 59 & 2310 & 1133.7 & 385.0 & -9.26 & 0.90 & 0.06 \\
\hline 60 & 52897 & 500.0 & 14.7 & -218.93 & 15.07 & 0.31 \\
\hline 61 & 68 & 1600.0 & 19.8 & -0.32 & 0.04 & 0.01 \\
\hline 62 & 137 & 1600.0 & 19.8 & -0.59 & 0.07 & 0.01 \\
\hline 63 & 68454 & 150.0 & 14.7 & -320.11 & 13.80 & 0.01 \\
\hline 64 & 2079 & 1015.0 & 14.7 & -8.38 & 0.78 & 0.05 \\
\hline 65 & 50818 & 494.0 & 14.7 & -210.39 & 14.41 & 0.29 \\
\hline 66 & 1473 & 1015.0 & 385.0 & -3.26 & 0.89 & 3.65 \\
\hline 67 & 231 & 1015.0 & 385.0 & -0.93 & 0.09 & 0.01 \\
\hline 68 & 13260 & 500.0 & 14.7 & -32.36 & 5.54 & 32.38 \\
\hline 69 & 758095 & 597.5 & 1515.0 & -4752.49 & 1251.81 & 38.41 \\
\hline 70 & 758095 & 597.5 & 1515.0 & -4331.08 & 1650.28 & 97.72 \\
\hline 71 & 787560 & 120.4 & 23.0 & -5350.97 & 792.59 & 0.45 \\
\hline 72 & 5958123 & 90.0 & 14.7 & 18.91 & 9803.01 & 0.99 \\
\hline 75 & 6736999 & 1098.0 & 15.0 & -4801.56 & 13433.59 & 260.86 \\
\hline 77 & 6927222 & 719.4 & 15.0 & -5620.73 & 13248.63 & 137.73 \\
\hline 78 & 6927222 & 655.1 & 14.9 & -5744.15 & 13141.96 & 118.74 \\
\hline 79 & 6927222 & 318.9 & 14.9 & -6375.24 & 12469.95 & 42.05 \\
\hline 81 & 6927222 & 291.3 & 14.9 & -6426.01 & 12404.52 & 37.70 \\
\hline 82 & 6927222 & 2798 & 14.8 & -6447.11 & 12377.17 & 35.93 \\
\hline 84 & 2043144 & 1000.0 & 295.0 & -3649.78 & 4288.31 & 959.60 \\
\hline 85 & 1140136 & 650.0 & 450.0 & 161.57 & 1805.94 & 57.75 \\
\hline 86 & 126280 & 411.0 & 450.0 & -252.04 & 237.31 & 56.02 \\
\hline
\end{tabular}


TABLE 4-8

Mass Flow Rate, Temperature, Pressure and Flow Rates of Enthalpy, Entropy and Exergy for Each Stream of Case $1 \mathrm{CO}$ (Cont'd)

\begin{tabular}{|c|c|c|c|c|c|c|}
\hline $\begin{array}{l}\text { Stream } \\
\text { No }\end{array}$ & $\underset{[\mathbf{m} / \mathbf{h r}]}{\dot{m}}$ & $\begin{array}{c}\mathbf{T} \\
{[\mathbf{F}]}\end{array}$ & $\underset{\text { [psia] }}{\mathbf{P}}$ & $\underset{\text { [MMBtu/hr] }}{\dot{\mathbf{H}}}$ & $\stackrel{\dot{\mathbf{S}}}{\text { [MBtu/hrR] }}$ & $\underset{[\mathbf{E}}{\dot{E}]}$ \\
\hline 87 & 16502 & 411.0 & 450.0 & -32.94 & 31.01 & 7.32 \\
\hline 88 & 3423 & 597.5 & 1515.0 & -21.46 & 5.65 & 0.17 \\
\hline 89 & 7393 & 411.0 & 430.0 & -14.75 & 13.92 & 3.28 \\
\hline 90 & 16502 . & 365.7 & 450.0 & -33.20 & 30.70 & 7.29 \\
\hline 91 & 47069 & 597.5 & 1515.0 & -295.08 & 77.72 & 2.38 \\
\hline 92 & 47069 & 597.5 & 1515.0 & -268.91 & 102.46 & 6.07 \\
\hline 93 & 295283 & 597.5 & 1515.0 & -1851.12 & 487.59 & 14.96 \\
\hline 94 & 295283 & 597.5 & 1515.0 & -1686.98 & 642.79 & 38.06 \\
\hline 98 & 6927222 & 1098.0 & 15.0 & -4877.58 & 13793.28 & 267.79 \\
\hline 101 & 1569513 & 1000.0 & 1359.3 & -8457.11 & 3852.49 & 281.47 \\
\hline 102 & 663 & 1000.0 & 1359.3 & -3.57 & 1.63 & 0.12 \\
\hline 103 & 2701 & 1000.0 & 1359.3 & -14.55 & 6.63 & 0.48 \\
\hline 104 & 1108245 & 626.6 & 300.0 & -6154.20 & 2750.65 & 140.35 \\
\hline 105 & 1108245 & 1000.0 & 282.0 & -5935.91 & 2930.85 & 175.30 \\
\hline 106 & 1128541 & 838.4 & 150.0 & -6134.38 & 2996.96 & 150.20 \\
\hline 107 & 1970 & 626.6 & 300.0 & -10.94 & 4.89 & 0.25 \\
\hline 108 & 1130511 & 838.0 & 150.0 & -6145.31 & 3002.02 & 150.42 \\
\hline 109 & 748 & 838.4 & 150.0 & -4.07 & 1.99 & 0.10 \\
\hline 111 & 1412 & 881.8 & 150.0 & -7.64 & 3.77 & 0.19 \\
\hline 112 & 15694 & 596.2 & 1500.0 & -98.41 & 25.89 & 0.79 \\
\hline 113 & 437590 & 744.7 & 500.0 & -2406.88 & 1082.77 & 62.72 \\
\hline 114 & 47556 & 138.9 & 22.5 & -322.24 & 49.35 & 0.04 \\
\hline 115 & 1118246 & 120.6 & 1.7 & -6452.94 & 3098.55 & 18.29 \\
\hline 116 & 453284 & 80.0 & 14.5 & -3098.08 & 423.50 & 0.16 \\
\hline 117 & 1585206 & 120.6 & 1.7 & -9643.72 & 3537.38 & 18.27 \\
\hline 118 & 1585206 & 120.4 & 1.7 & -10770.63 & 1595.26 & 0.87 \\
\hline 119 & 13676 & 136.4 & 3.3 & -92.70 & 14.14 & 0.01 \\
\hline 120 & 787560 & 138.9 & 22.5 & -5336.42 & 817.28 & 0.73 \\
\hline 121 & 740003 & 138.9 & 22.5 & -5014.19 & 767.93 & 0.69 \\
\hline 122 & 740003 & 167.0 & 20.0 & -4993.40 & 801.88 & 1.31 \\
\hline 123 & 47556 & 234.4 & 20.0 & -272.22 & 121.91 & 3.01 \\
\hline 124 & 1585206 & 228.0 & 20.0 & -10599.57 & 1865.59 & 7.45 \\
\hline 126 & 35831 & 744.7 & 500.0 & -197.08 & 88.66 & 5.14 \\
\hline 127 & 401759 & 744.7 & 450.0 & -2208.79 & 999.40 & 57.03 \\
\hline 128 & 35831 & 950.0 & 450.0 & -193.05 & 92.15 & 5.75 \\
\hline 131 & 18344 & 626.6 & 300.0 & -101.87 & 45.53 & 2.32 \\
\hline 134 & 220584 & 597.5 & 1515.0 & -1382.84 & 364.24 & 11.17 \\
\hline 135 & 1569513 & 596.2 & 1500.0 & -8966.62 & 3417.97 & 202.14 \\
\hline 137 & 1585206 & 231.5 & 1565.0 & -10588.70 & 1870.32 & 9.88 \\
\hline
\end{tabular}




\section{TABLE 4-8}

Mass Flow Rate, Temperature, Pressure and Flow Rates of Enthalpy, Entropy and Exergy for Each Stream of Case $1 \mathrm{CO} 2$ (Cont'd)

$\begin{array}{lrrrrrr}\begin{array}{l}\text { Stream } \\ \text { No }\end{array} & \begin{array}{r}\mathbf{m} \\ {[\mathbf{m} / \mathbf{h r}]}\end{array} & \begin{array}{c}\mathbf{T} \\ {[\mathbf{F}]}\end{array} & \begin{array}{c}\mathbf{P} \\ \text { [psia] }\end{array} & \begin{array}{c}\dot{\mathbf{H}} \\ \text { [MMBtu/hr] }\end{array} & \begin{array}{c}\dot{\mathbf{S}} \\ \text { [MBtu/hrR] }\end{array} & \begin{array}{r}\dot{\boldsymbol{E}} \\ \text { [MW] }\end{array} \\ 139 & 1128559 & 626.6 & 300.0 & -6267.00 & 2801.07 & 142.92 \\ 140 & 1129290 & 993.8 & 282.0 & -6052.32 & 2983.96 & 177.95 \\ 141 & 1129290 & 838.4 & 150.0 & -6138.44 & 2998.95 & 150.30 \\ 142 & 1351112 & 596.2 & 1500.0 & -7719.05 & 2942.22 & 173.99 \\ 143 & 3879 & 500.0 & 450.0 & 0.41 & 5.98 & 0.19 \\ 144 & 1585206 & 120.4 & 23.0 & -10770.48 & 1595.33 & 0.90 \\ 149 & 0 & - & - & - & - & - \\ 150 & 1140136 & 450.0 & 199.0 & 104.24 & 1812.78 & 39.85 \\ 151 & 1140136 & 138.4 & 198.0 & 16.93 & 1695.79 & 33.10 \\ 152 & 1140136 & 127.7 & 176.0 & 13.98 & 1700.01 & 31.56 \\ 153 & 1140136 & 341.9 & 453.0 & 73.64 & 1712.66 & 47.01 \\ 154 & 1566149 & 1000.0 & 1359.3 & -8438.99 & 3844.24 & 280.87 \\ 159 & 2012883 & 1015.0 & 385.0 & -3446.07 & 4241.17 & 988.21 \\ 161 & 68 & 1098.0 & 19.6 & -0.34 & 0.04 & 0.00 \\ 162 & 137 & 1098.0 & 19.6 & -0.61 & 0.06 & 0.00 \\ 164 & 14733 & 1015.0 & 385.0 & -32.63 & 8.91 & 36.51 \\ 165 & 2310 & 1015.0 & 385.0 & -9.31 & 0.86 & 0.05 \\ 166 & 16115 & 479.7 & 375.0 & -31.78 & 30.97 & 7.15 \\ 167 & 28031 & 479.7 & 375.0 & -138.22 & 9.52 & 6.74 \\ 168 & 50587 & 479.7 & 375.0 & -209.58 & 14.19 & 0.27 \\ 170 & 345485 & 90.0 & 14.7 & -503.74 & 134.72 & 1203.80 \\ 191 & 12265 & 205.8 & 3.7 & -70.29 & 33.75 & 0.38 \\ 192 & 13676 & 277.1 & 3.7 & -77.93 & 38.27 & 0.45 \\ 193 & 1585206 & 231.5 & 1565.0 & -10588.70 & 1870.32 & 9.88 \\ 194 & 218401 & 596.2 & 1500.0 & -1247.58 & 475.76 & 28.15 \\ 197 & 1585206 & 250.0 & 1533.7 & -10559.25 & 1912.60 & 11.70 \\ 199 & 1585206 & 597.5 & 1515.0 & -9937.63 & 2617.59 & 80.31\end{array}$




\section{TABLE 49}

Exergy Flow Rates of Fuel $\left(\dot{E}_{\mathrm{p}}\right)$, Product $\left(\dot{E}_{\mathrm{p}}\right)$, and Exergy Destruction $\left(\dot{E}_{\mathrm{p}}\right)$, Exergy Destruction Ratio $(\theta)$, Exergy Destruction to Total Exergy Input Ratio $\left(\theta^{\circ}\right)$ and Exergetic Efficiency $(\zeta)$ for Each Area and the Total Plant in Case $1 \mathrm{CO}_{2}$

\begin{tabular}{|c|c|c|c|c|c|c|}
\hline Area & ${\stackrel{\boldsymbol{E}_{\mathrm{r}}}{\mathrm{mW}}}$ & $\stackrel{\dot{E}_{\mathrm{P}}}{[\mathrm{MW}]}$ & $\frac{\boldsymbol{E}_{\mathrm{D}}}{\text { [MW] }}$ & [\%] & $1 \% 1$ & {$[\%]$} \\
\hline $\begin{array}{l}\text { Booster Air Compressor } \\
\text { KRW Gasification } \\
\text { Recycle Gas Compression } \\
\text { Gas Conditioning } \\
\text { External Desulfurization } \\
\text { Sulfation } \\
\text { Gas Turbine System } \\
\text { HRSG } \\
\text { Steam Cycle }\end{array}$ & $\begin{array}{r}23.35 \\
1287.90 \\
61.44 \\
200.90 \\
944.09 \\
36.70 \\
641.21 \\
232.61 \\
255.25\end{array}$ & $\begin{array}{r}13.51 \\
1024.25 \\
56.22 \\
182.77 \\
926.27 \\
26.79 \\
363.93 \\
205.57 \\
201.62\end{array}$ & $\begin{array}{r}9.84 \\
263.65 \\
5.22 \\
18.12 \\
17.81 \\
9.92 \\
277.28 \\
27.04 \\
53.63\end{array}$ & $\begin{array}{r}1.35 \\
36.08 \\
0.71 \\
2.48 \\
2.44 \\
1.36 \\
37.94 \\
3.70 \\
7.34\end{array}$ & $\begin{array}{r}0.82 \\
21.86 \\
0.43 \\
1.50 \\
1.48 \\
0.82 \\
22.99 \\
2.24 \\
4.44\end{array}$ & $\begin{array}{l}57.86 \\
79.53 \\
91.50 \\
90.98 \\
98.11 \\
72.98 \\
56.76 \\
88.38 \\
78.99\end{array}$ \\
\hline $\begin{array}{l}\text { Exergy Losses } \\
\text { tion Power } \\
\text { sport Losses }\end{array}$ & & & $\begin{array}{r}36.96 \\
11.20 \\
0.16\end{array}$ & $\begin{array}{l}5.06 \\
1.53 \\
0.02\end{array}$ & $\begin{array}{l}3.06 \\
0.93 \\
0.01\end{array}$ & \\
\hline & 1206.35 & 475.52 & 730.83 & 100.00 & 60.58 & 39.42 \\
\hline
\end{tabular}


TABLE 4-10

Heat Loss, Power Supplied (Generated), Exerpy Destruction Flow Rate, Exergy Destruction Ratio ( $\theta$ ), Exergy Destruction to Total Exergy Input Ratio ( ()$^{\circ}$ and Exe, etic Efriciency ( () for Plant Components in Case 1CO2

\begin{tabular}{|c|c|c|c|c|c|c|c|}
\hline & Component & $\begin{array}{l}\mathbf{Q}_{L O S S} \\
\text { [MW] }\end{array}$ & $\begin{array}{c}\dot{\mathbf{W}} \\
\text { [MW] }\end{array}$ & $\underset{[M W]}{\dot{E}_{D}}$ & [\%] & $\frac{\theta^{*}}{[\%]}$ & ${ }_{[\%]}^{5}$ \\
\hline 1 & Gasifier & 5.51 & 1.10 & 229.50 & 31.40 & 19.02 & 81.85 \\
\hline 2 & Cyclones & 2.44 & 0.00 & 2.29 & 0.31 & 0.19 & 99.02 \\
\hline 3 & Product Gas Cooler & 1.88 & 0.00 & 31.51 & 4.31 & 2.61 & 65.31 \\
\hline 4 & Coal Hopper System & 0.00 & 0.03 & 0.46 & 0.06 & 0.04 & 31.12 \\
\hline 6 & Quench Steam Mixing & 0.00 & 0.00 & 14.32 & 1.96 & 1.19 & 98.62 \\
\hline $7 / 8$ & Fines Cyclone \&Gas Filter & 0.00 & 0.00 & 1.71 & 0.23 & 0.14 & 99.08 \\
\hline 9 & Solids Conveyor \& Cooler & 0.91 & 0.00 & 0.50 & 0.07 & 0.04 & 98.86 \\
\hline 10 & Area 600: Sulfation & 1.10 & 1.31 & 9.92 & 1.36 & 0.82 & 72.98 \\
\hline 11 & Chloride Guard & 0.14 & 0.00 & 1.56 & 0.21 & 0.13 & 99.15 \\
\hline 12 & Air Extraction Cooler & 0.00 & 0.00 & 0.00 & 0.00 & 0.00 & 0.00 \\
\hline 13 & Air Recuperator & 0.39 & 0.00 & 1.89 & 0.26 & 0.16 & 85.06 \\
\hline 14 & BFW Preheater & 0.38 & 0.00 & 3.45 & 0.47 & 0.29 & 48.90 \\
\hline 15 & Trim Cooler & 0.87 & 0.00 & 1.55 & 0.21 & 0.13 & - \\
\hline 16 & Booster Air Compressor & 0.00 & 18.41 & 2.96 & 0.40 & 0.25 & 83.93 \\
\hline 17 & Zinc Ferrite System & 0.00 & 0.00 & 9.72 & 1.33 & 0.81 & 99.03 \\
\hline 18 & Exit Gas Cooler & 0.62 & 0.00 & 8.10 & 1.11 & 0.67 & 70.78 \\
\hline 19 & HP Drum in HRSG & 0.55 & 0.00 & 2.70 & 0.37 & 0.22 & 85.79 \\
\hline 20 & Recycle Gas Cooler & 0.13 & 0.00 & 2.60 & 0.36 & 0.22 & 41.23 \\
\hline 21 & Recycle Gas Compressor I & 0.65 & 1.84 & 0.71 & 0.10 & 0.06 & 61.45 \\
\hline 23 & Recycle Gas Compressor II & 0.00 & 0.29 & 0.07 & 0.01 & 0.01 & 74.71 \\
\hline 25 & Steam Transport Losses & 0.00 & 0.00 & 0.16 & 0.02 & 0.01 & 99.92 \\
\hline 26 & Gas Turbine/Air Compressor & 39.62 & (311.64) & 84.94 & 11.62 & 7.04 & 78.58 \\
\hline 27 & Combustion Chamber & 0.00 & 0.00 & 192.34 & 26.32 & 15.94 & 82.62 \\
\hline 29 & Superheater \& Reheater & 3.30 & 0.00 & 14.93 & 2.04 & 1.24 & 88.44 \\
\hline 30 & Blast Reheater & 0.02 & 0.00 & 0.24 & 0.03 & 0.02 & 72.42 \\
\hline 31 & HP Economizer & 2.77 & 0.00 & 8.09 & 1.11 & 0.67 & 89.46 \\
\hline 32 & Feedwater Heater 1 & 0.22 & 0.00 & 1.37 & 0.19 & 0.11 & 68.39 \\
\hline 33 & Feedwater Heater 2 & 0.09 & 0.00 & 1.16 & 0.16 & 0.10 & 35.06 \\
\hline 34 & HP Turbine & 0.00 & $(67.74)$ & 7.48 & 1.02 & 0.62 & 90.06 \\
\hline 37 & IP Turbine & 0.00 & (24.84) & 2.82 & 0.39 & 0.23 & 89.81 \\
\hline 39 & LP Ty-bine & 0.00 & (108.99) & 22.75 & 3.11 & 1.89 & 82.73 \\
\hline 40 & Steam Seal Regulator & 0.00 & 0.00 & 0.03 & 0.00 & 0.00 & 88.40 \\
\hline 42 & Condenser & 330.26 & 0.00 & 17.40 & 2.38 & 1.44 & - \\
\hline 43 & LP Pump & 0.00 & 0.04 & 0.01 & 0.00 & 0.00 & 67.21 \\
\hline 44 & Feedwater Heater 3 & 0.07 & 0.00 & 0.15 & 0.02 & 0.01 & 64.92 \\
\hline 46 & Deaerator & 0.13 & 0.00 & 0.62 & 0.09 & 0.05 & 92.27 \\
\hline 47 & HP Pump & 0.00 & 3.54 & 1.12 & 0.15 & 0.09 & 68.50 \\
\hline
\end{tabular}




\subsection{DESCRIPTION OF CASE 1TO1}

Development of Case 1TO1 focused on the overall plant thermal efficiency. This case represents the thermodynamically optimal case and demonstrates the potential for increasing the plant efficiency. By issuming (a) a constant carbon conversion ratio in the gasifier, (b) a given minimum temperature difference for steam generation and feedwater preheating, and (c) a given minimum temperature at the HRSG exit, the optimal thermodynamic efficiency of an IGCC power plant design similar to Case 1 is obtained when the following conditions are fulfilled simultaneously:

1. The gasification temperature is equal to the minimum value (here $1800^{\circ} \mathrm{F}$ ) for which a constant carbon conversion ratio is assumed.

2. The coal is supplied to the gasifier with "as received" moisture.

3. The sulfator combustion gas is used to generate HP steam before exiting the sulfation at about the same temperature at which the gas turbine combustion gases exit the gas turbine. The two combustion gas streams are mixed and enter the HRSG together.

4. The steam high pressure $\left(P_{\mathrm{HP}}\right)$ is equal to its "thermodynamically optimum" value, which is obtained when

(a) all HP steam generation occurs exclusively in the gasification island,

(b) the potential for generating HP steam in the gasification island is fully used in all areas (including recycle gas compression and booster air compression) by not allowing any heat transfer across the hightemperature pinch point (PP-1 in Figures 4-7 through 4-10),

(c) the HRSG is used only for steam superheating, steam reheating and feedwater preheating, and

(d) any additional heat required for feedwater preheating is provided through steam extractions from the steam turbine.

This optimal $P_{\mathrm{HP}}$ value is unique for a given design configuration.

(5) The minimum temperature differences during HP steam preheating and steam generation in the HRSG, recycle gas cooler and extraction air co (which was added to the booster air compression area) are about equal to 
assumed minimal values. It is apparent that the overall plant efficiency increases with decreasing minimum temperature differences in these heat exchangers.

All these conditions were taken into account in developing the design for the thermodynamically optimal Case 1TO1, which is shown in Figures 4-5 and 4-6. Tables 4-9 and 4-10 contain the results of the simulation and thermodynamic analyses. The design changes are discussed in the following section. 


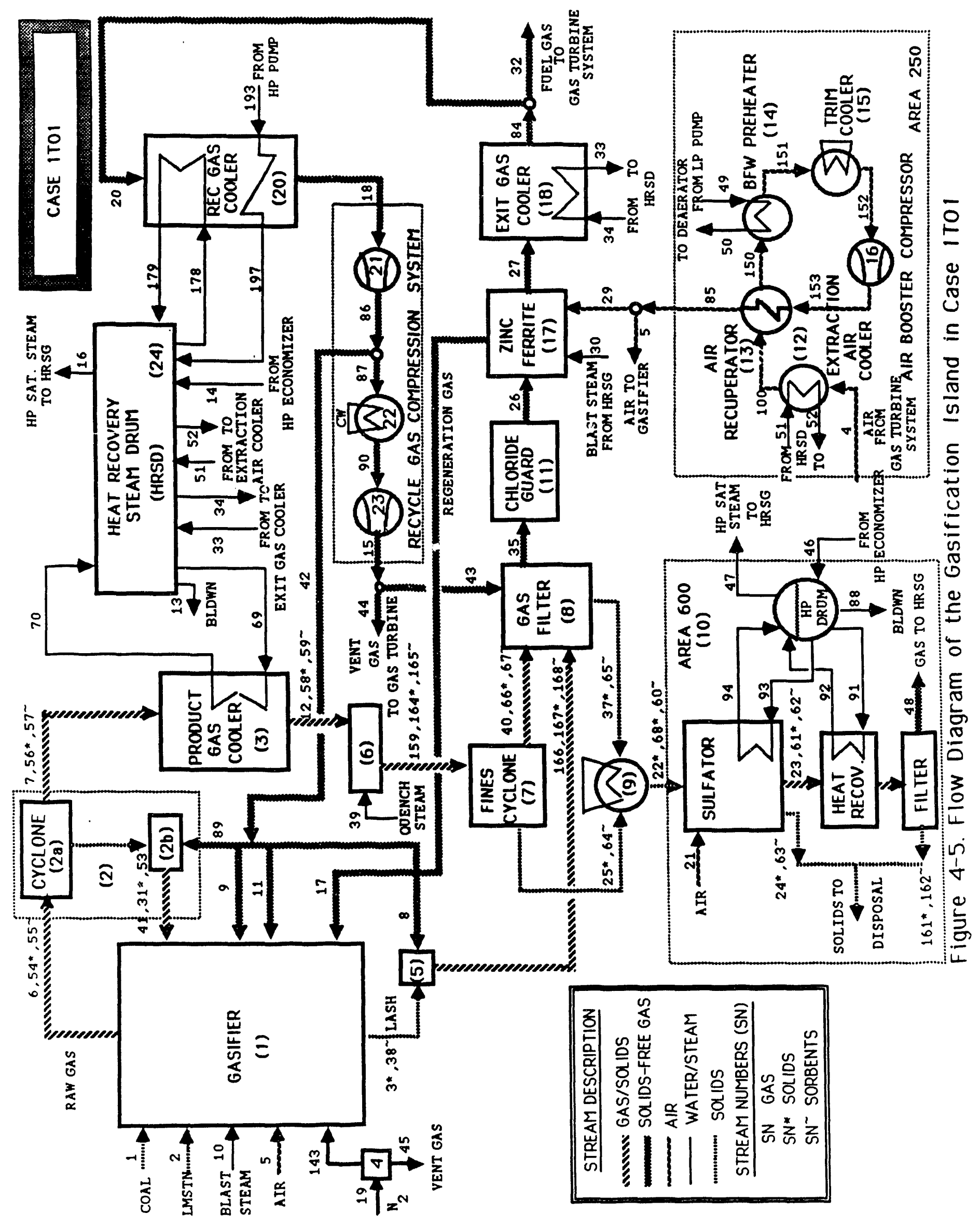




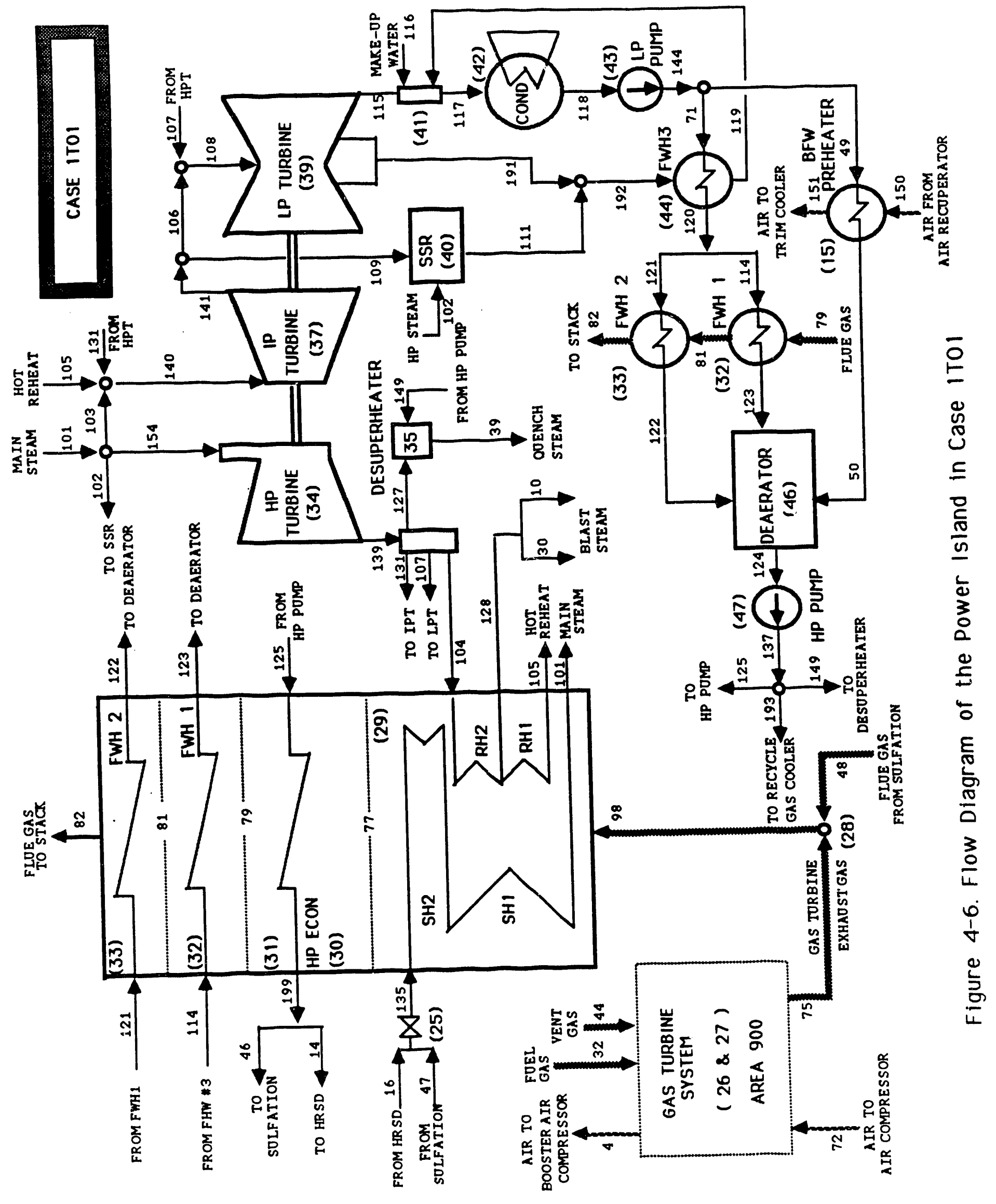


Mass Flow Rate, Temperature, Pressure and Flow Rates of Enthalpy, Entropy and Exergy for Each Stream of Case 1TO1

\begin{tabular}{|c|c|c|c|c|c|c|}
\hline $\begin{array}{l}\text { Stream } \\
\text { No }\end{array}$ & $\underset{\mathbf{m} \mathbf{b} / \mathbf{h r}]}{\mathbf{m}}$ & $\begin{array}{c}\mathbf{T} \\
{[\mathbf{F}]}\end{array}$ & $\underset{\text { [psia] }}{\mathbf{P}}$ & $\stackrel{\dot{\mathbf{H}}}{\text { [MMBtu/hr] }}$ & $\underset{\text { [MBtu/hrR] }}{\dot{\mathbf{S}}}$ & $\stackrel{\dot{E}}{[\mathbf{M W}]}$ \\
\hline 1 & 336224 & 90.0 & 14.7 & -490.24 & 131.11 & 1171.53 \\
\hline 2 & 85352 & 90.0 & 14.7 & -443.96 & 18.25 & 0.00 \\
\hline 3 & 27279 & 500.0 & 425.0 & -134.33 & 9.46 & 6.59 \\
\hline 4 & 1063331 & 760.0 & 200.0 & 180.48 & 1769.01 & 48.94 \\
\hline 5 & 1058549 & 650.0 & 450.0 & 150.01 & 1676.71 & 53.62 \\
\hline 6 & 1534463 & 1800.0 & 400.0 & -826.73 & 3198.90 & 1017.43 \\
\hline 7 & 1534463 & 1800.0 & 395.0 & -826.72 & 3200.46 & 1017.18 \\
\hline 8 & 15683 & 411.0 & 430.0 & -31.66 & 29.75 & 7.26 \\
\hline 9 & 47910 & 411.0 & 430.0 & -96.72 & 90.88 & 22.19 \\
\hline 10 & 6695 & 950.0 & 450.0 & -36.07 & 17.22 & 1.08 \\
\hline 11 & 48542 & 411.0 & 430.0 & -98.00 & 92.08 & 22.48 \\
\hline 12 & 1534463 & 1179.8 & 385.0 & -1144.47 & 3039.42 & 950.00 \\
\hline 13 & 11283 & 649.4 & 2199.8 & -69.79 & 19.45 & 0.72 \\
\hline 14 & 1102110 & 649.4 & 2199.8 & -6817.27 & 1899.90 & 69.86 \\
\hline 15 & 16054 & 524.0 & 750.0 & -31.79 & 30.36 & 7.63 \\
\hline 16 & 1128432 & 649.4 & 2199.8 & -6494.61 & 2379.46 & 143.86 \\
\hline 17 & 33179 & 1200.0 & 430.0 & -149.27 & 83.76 & 6.20 \\
\hline 18 & 135658 & 330.0 & 285.3 & -277.62 & 257.61 & 61.69 \\
\hline 19 & 12743 & 500.0 & 450.0 & 1.36 & 19.66 & 0.62 \\
\hline 20 & 135658 & 1000.0 & 295.0 & -245.18 & 286.88 & 66.48 \\
\hline 21 & 192192 & 160.0 & 20.0 & 3.86 & 317.72 & 0.74 \\
\hline 22 & 28713 & 500.0 & 14.7 & -137.67 & 10.06 & 10.23 \\
\hline 23 & 185125 & 1600.0 & 19.8 & -48.16 & 359.63 & 12.75 \\
\hline 24 & 33505 & 150.0 & 14.7 & -176.44 & 6.89 & 0.86 \\
\hline 25 & 12904 & 1015.0 & 14.7 & -28.58 & 7.80 & 31.98 \\
\hline 26 & 1960011 & 1007.1 & 345.0 & -3400.24 & 4177.39 & 998.58 \\
\hline 27 & 1959673 & 1191.2 & 305.0 & -3402.09 & 4228.43 & 987.76 \\
\hline 29 & 4782 & 650.0 & 450.0 & 0.68 & 7.57 & 0.24 \\
\hline 30 & 28174 & 950.0 & 450.0 & -151.80 & 72.46 & 4.52 \\
\hline 31 & 272416 & 1750.0 & 430.0 & -489.38 & 226.83 & 698.51 \\
\hline 32 & 1824015 & 1000.0 & 295.0 & -3296.56 & 3857.28 & 893.92 \\
\hline 33 & 319726 & 649.4 & 2199.8 & -1840.16 & 674.19 & 40.76 \\
\hline 34 & 319726 & 649.4 & 2199.8 & -1977.71 & 551.17 & 20.27 \\
\hline 35 & 1959878 & 1007.1 & 365.0 & -3399.78 & 4167.54 & 1000.09 \\
\hline 37 & 28713 & 494.0 & 14.7 & -137.72 & 10.00 & 10.23 \\
\hline 38 & 49231 & 500.0 & 425.0 & -203.76 & 14.02 & 0.29 \\
\hline 39 & 395766 & 645.4 & 450.0 & -2197.67 & 965.57 & 52.83 \\
\hline 40 & 1930230 & 1015.0 & 385.0 & -3340.85 & 4099.67 & 987.96 \\
\hline 41 & 7468 & 1750.0 & 430.0 & -11.35 & 16.73 & 4.14 \\
\hline
\end{tabular}


TABLE 4-11

Mass Flow Rate, Temperature, Pressure and Flow Rates of Enthalpy, Entropy and Exergy for Each Stream of Case 1TO1 (Cont'd)

\begin{tabular}{|c|c|c|c|c|c|c|}
\hline $\begin{array}{l}\text { Stream } \\
\text { No }\end{array}$ & $\underset{[\mathbf{l b} / \mathbf{h r}]}{\dot{m}}$ & $\underset{\mathbf{T}]}{\mathbf{T}}$ & $\underset{\text { [psia] }}{\mathbf{P}}$ & $\stackrel{\dot{\mathbf{H}}}{\text { [MMBtu/hr] }}$ & $\underset{\text { [MBtu/hrR] }}{\dot{\mathbf{S}}}$ & $\underset{[\mathbf{M W}]}{\dot{\boldsymbol{E}}}$ \\
\hline 42 & 119603 & 411.0 & 450.0 & -241.47 & 226.40 & 55.47 \\
\hline 43 & 13965 & 524.0 & 750.0 & -27.65 & 26.41 & 6.64 \\
\hline 44 & 2089 & 524.0 & 750.0 & -4.14 & 3.95 & 0.99 \\
\hline 45 & 8968 & 90.0 & 14.7 & 0.03 & 14.74 & 0.02 \\
\hline 46 & 434796 & 649.4 & 2199.8 & -2689.49 & 749.53 & 27.56 \\
\hline 47 & 430491 & 649.4 & 2199.8 & -2477.66 & 907.75 & 54.88 \\
\hline 48 & 185125 & 1098.0 & 19.6 & -73.97 & 345.40 & 7.47 \\
\hline 49 & 498973 & 120.5 & 34.5 & -3390.19 & 502.17 & 0.29 \\
\hline 50 & 498973 & 250.3 & 30.0 & -3325.11 & 603.39 & 3.06 \\
\hline 51 & 35145 & 649.4 & 2199.8 & -217.40 & 60.59 & 2.23 \\
\hline 52 & 35145 & 649.4 & 2199.8 & -202.28 & 74.11 & 4.48 \\
\hline 53 & 110230 & 1750.0 & 430.0 & -426.76 & 50.89 & 6.14 \\
\hline 54 & 286754 & 1800.0 & 400.0 & -505.89 & 242.91 & 737.32 \\
\hline 55 & 112477 & 1800.0 & 400.0 & -434.18 & 52.50 & 6.55 \\
\hline 56 & 14338 & 1800.0 & 395.0 & -25.30 & 12.15 & 36.87 \\
\hline 57 & 2248 & 1800.0 & 395.0 & -8.68 & 1.05 & 0.13 \\
\hline 58 & 14338 & 1179.8 & 385.0 & -30.54 & 9.45 & 35.76 \\
\hline 59 & 2248 & 1179.8 & 385.0 & -8.99 & 0.89 & 0.07 \\
\hline 60 & 51479 & 500.0 & 14.7 & -213.06 & 14.66 & 0.30 \\
\hline 61 & 66 & 1600.0 & 19.8 & -0.31 & 0.04 & 0.01 \\
\hline 62 & 133 & 1600.0 & 19.8 & -0.58 & 0.06 & 0.01 \\
\hline 63 & 66619 & 150.0 & 14.7 & -311.53 & 13.43 & 0.01 \\
\hline 64 & 2023 & 1015.0 & 14.7 & -8.16 & 0.75 & 0.05 \\
\hline 65 & 49456 & 494.0 & 14.7 & -204.75 & 14.02 & 0.28 \\
\hline 66 & 1434 & 1015.0 & 385.0 & -3.18 & 0.87 & 3.55 \\
\hline 67 & 225 & 1015.0 & 385.0 & -0.91 & 0.08 & 0.01 \\
\hline 68 & 12904 & 500.0 & 14.7 & -31.49 & 5.40 & 31.52 \\
\hline 69 & 740216 & 649.4 & 2199.8 & -4578.72 & 1276.04 & 46.92 \\
\hline 70 & 740216 & 649.4 & 2199.8 & -4260.26 & 1560.85 & 94.37 \\
\hline 71 & 1075538 & 120.5 & 34.5 & -7307.55 & 1082.44 & 0.62 \\
\hline 72 & 5974227 & 90.0 & 14.7 & 18.96 & 9829.51 & 0.99 \\
\hline 75 & 6736999 & 1098.0 & 15.0 & -4652.88 & 13427.06 & 259.55 \\
\hline 77 & 6922125 & 702.3 & 14.9 & -5501.10 & 13206.17 & 131.35 \\
\hline 79 & 6922125 & 313.1 & 14.9 & -6231.79 & 12442.50 & 40.23 \\
\hline 81 & 6922125 & 286.9 & 14.9 & -6279.89 & 12380.14 & 36.18 \\
\hline 82 & 6922125 & 279.8 & 14.9 & -6292.81 & 12363.73 & 35.04 \\
\hline 84 & 1959673 & 1000.0 & 295.0 & -3541.73 & 4144.16 & 960.41 \\
\hline 85 & 1063331 & 650.0 & 450.0 & 150.69 & 1684.29 & 53.86 \\
\hline 86 & 135658 & 411.0 & 450.0 & -273.88 & 256.79 & 62.92 \\
\hline
\end{tabular}




\section{TABLE 4-11}

Mass Flow Rate, Temperature, Pressure and Flow Rates of Enthalpy, Entropy and Exergy for Each Stream of Case 1TO1 (Coni'd)

\begin{tabular}{|c|c|c|c|c|c|c|}
\hline $\begin{array}{l}\text { Stream } \\
\text { No }\end{array}$ & $\underset{[\mathbf{m} / \mathbf{h r}]}{\dot{n}}$ & $\underset{[\mathbf{F}]}{\mathbf{T}}$ & $\underset{\text { [psia] }}{\mathbf{P}}$ & $\frac{\dot{\mathbf{H}}}{[\mathrm{MMBtu} / \mathbf{h r}]}$ & $\begin{array}{c}\dot{\mathbf{S}} \\
\text { [MBtu/hrR] }\end{array}$ & $\begin{array}{c}\dot{\boldsymbol{E}} \\
{[\mathbf{M W}]}\end{array}$ \\
\hline 87 & 16054 & 411.0 & 450.0 & -32.41 & 30.39 & 7.45 \\
\hline 88 & 4304 & 649.4 & 2199.8 & -26.63 & 7.42 & 0.27 \\
\hline 89 & 7468 & 411.0 & 430.0 & -15.08 & 14.17 & 3.46 \\
\hline 90 & 16054 & 365.7 & 450.0 & -32.67 & 30.09 & 7.42 \\
\hline 91 & 59187 & 649.4 & 2199.8 & -366.11 & 102.03 & 3.75 \\
\hline 92 & 59187 & 649.4 & 2199.8 & -340.65 & 124.80 & 7.55 \\
\hline 93 & 371304 & 649.4 & 2199.8 & -2296.76 & 640.08 & 23.53 \\
\hline 94 & 371304 & 649.4 & 2199.8 & -2137.01 & 782.95 & 47.34 \\
\hline 95 & 185125 & 4421.9 & 20.0 & 114.53 & 408.66 & 52.53 \\
\hline 96 & 66 & 4421.9 & 20.0 & -0.12 & 0.10 & 0.05 \\
\hline 97 & 133 & 4421.9 & 20.0 & -0.45 & 0.10 & 0.04 \\
\hline 98 & 6922125 & 1098.0 & 15.0 & -4726.86 & 13777.11 & 266.29 \\
\hline 100 & 1063331 & 703.4 & 195.0 & 165.13 & 1757.97 & 46.22 \\
\hline 101 & 1558923 & 1000.0 & 1980.0 & -8430.74 & 3745.79 & 283.58 \\
\hline 102 & 659 & 1000.0 & 1980.0 & -3.56 & 1.58 & 0.12 \\
\hline 103 & 2682 & 1000.0 & 1980.0 & -14.51 & 6.45 & 0.49 \\
\hline 104 & 1139639 & 645.4 & 500.0 & -6332.32 & 2764.46 & 153.54 \\
\hline 105 & 1104770 & 1000.0 & 470.0 & -5923.37 & 2856.34 & 183.49 \\
\hline 106 & 1124929 & 719.7 & 150.0 & -6182.58 & 2932.57 & 138.66 \\
\hline 107 & 1956 & 645.4 & 500.0 & -10.87 & 4.75 & 0.26 \\
\hline 108 & 1126886 & 719.5 & 150.0 & -6193.45 & 2937.57 & 138.89 \\
\hline 109 & 743 & 719.7 & 150.0 & -4.09 & 1.94 & 0.09 \\
\hline 111 & 1402 & 801.1 & 150.0 & -7.65 & 3.70 & 0.18 \\
\hline 114 & 47235 & 195.2 & 33.8 & -317.40 & 53.27 & 0.14 \\
\hline 115 & 1049405 & 120.6 & 1.7 & -6086.65 & 2854.44 & 16.69 \\
\hline 116 & 446223 & 80.0 & 14.5 & -3049.82 & 416.91 & 0.16 \\
\hline 117 & 1574511 & 120.6 & 1.7 & -9666.74 & 3361.72 & 16.79 \\
\hline 118 & 1574511 & 120.4 & 1.7 & -10697.96 & 1584.50 & 0.86 \\
\hline 119 & 78883 & 192.6 & 11.9 & -530.27 & 88.64 & 0.22 \\
\hline 120 & 1075538 & 195.2 & 33.8 & -7227.05 & 1212.96 & 3.19 \\
\hline 121 & 1028302 & 195.2 & 33.8 & -6909.65 & 1159.69 & 3.05 \\
\hline 122 & 1028302 & 207.6 & 30.0 & -6896.93 & 1178.95 & 3.67 \\
\hline 123 & 47235 & 257.3 & 33.8 & -270.01 & 119.55 & 3.35 \\
\hline 124 & 1574511 & 250.3 & 30.0 & -10492.38 & 1904.00 & 9.64 \\
\hline 125 & 1536905 & 255.6 & 2250.0 & -10226.49 & 1864.95 & 12.86 \\
\hline 126 & 1139639 & 950.0 & 475.0 & -6141.07 & 2923.75 & 183.93 \\
\hline 127 & 395766 & 645.4 & 450.0 & -2197.67 & 965.57 & 52.83 \\
\hline 128 & 34869 & 950.0 & 450.0 & -187.87 & 89.68 & 5.60 \\
\hline 131 & 18220 & 645.4 & 500.0 & -101.24 & 44.20 & 2.45 \\
\hline
\end{tabular}


Mass Flow Rate, Temperature, Pressure and Flow Rates of Enthalpy, Entropy and Exergy for Each Stream of Case 1TO1 (Cont'd)

\begin{tabular}{|c|c|c|c|c|c|c|}
\hline $\begin{array}{l}\text { Stream } \\
\text { No }\end{array}$ & $\underset{[\mathbf{m} / \mathbf{h r}]}{\dot{m}}$ & $\begin{array}{c}\mathbf{T} \\
{[\mathbf{F}]}\end{array}$ & $\underset{\text { [psia] }}{\mathbf{P}}$ & $\underset{\text { [MMBtu/hr] }}{\text { H }}$ & $\underset{\text { [MBtu/hrR] }}{\dot{\mathbf{S}}}$ & $\stackrel{\dot{\boldsymbol{E}}}{[\mathbf{M W}]}$ \\
\hline 135 & 1558923 & 648.4 & 2184.8 & -8972.28 & 3288.16 & 198.59 \\
\hline 137 & 1574511 & 255.6 & 2250.0 & -10476.72 & 1910.58 & 13.17 \\
\hline 139 & 1555582 & 645.4 & 500.0 & -8643.48 & 3773.43 & 209.58 \\
\hline 140 & 1125673 & 993.9 & 470.0 & -6039.11 & 2907.86 & 186.29 \\
\hline 141 & 1125673 & 719.7 & 150.0 & -6186.66 & 2934.51 & 138.75 \\
\hline 143 & 3775 & 500.0 & 450.0 & 0.40 & 5.82 & 0.18 \\
\hline 144 & 1574511 & 120.5 & 34.5 & -10697.74 & 1584.61 & 0.91 \\
\hline 149 & 0 & 0.0 & 0.0 & 0.00 & 0.00 & 0.00 \\
\hline 150 & 1063331 & 392.0 & 194.0 & 81.87 & 1675.07 & 35.17 \\
\hline 151 & 1063331 & 138.5 & 193.1 & 15.80 & 1583.41 & 30.58 \\
\hline 152 & 1063331 & 127.7 & 176.0 & 13.04 & 1585.49 & 29.43 \\
\hline 153 & 1063331 & 341.9 & 453.0 & 68.68 & 1597.29 & 43.84 \\
\hline 154 & 1555582 & 1000.0 & 1980.0 & -8412.67 & 3737.76 & 282.97 \\
\hline 159 & 1930230 & 1015.0 & 385.0 & -3340.85 & 4099.67 & 987.96 \\
\hline 161 & 66 & 1098.0 & 19.6 & -0.33 & 0.03 & 0.00 \\
\hline 162 & 133 & 1098.0 & 19.6 & -0.60 & 0.05 & 0.00 \\
\hline 164 & 14338 & 1015.0 & 385.0 & -31.75 & 8.67 & 35.53 \\
\hline 165 & 2248 & 1015.0 & 385.0 & -9.06 & 0.84 & 0.05 \\
\hline 166 & 15683 & 479.6 & 375.0 & -31.28 & 30.36 & 7.28 \\
\hline 167 & 27279 & 479.6 & 375.0 & -134.52 & 9.26 & 6.56 \\
\hline 168 & 49231 & 479.6 & 375.0 & -203.96 & 13.81 & 0.26 \\
\hline 170 & 336224 & 90.0 & 14.7 & -490.24 & 131.11 & 1171.53 \\
\hline 176 & 6922125 & 1054.5 & 15.0 & -4813.43 & 13721.22 & 249.92 \\
\hline 177 & 135658 & 704.4 & 289.1 & -259.74 & 275.97 & 63.97 \\
\hline 178 & 33346 & 649.4 & 2199.8 & -206.27 & 57.48 & 2.11 \\
\hline 179 & 33346 & 649.4 & 2199.8 & -191.92 & 70.31 & 4.25 \\
\hline 191 & 77481 & 299.0 & 13.2 & -440.89 & 206.78 & 4.36 \\
\hline 192 & 78883 & 307.9 & 13.2 & -448.54 & 210.96 & 4.47 \\
\hline 193 & 37605 & 255.6 & 2250.0 & -250.22 & 45.63 & 0.31 \\
\hline 197 & 37605 & 649.4 & 2199.8 & -232.61 & 64.83 & 2.38 \\
\hline 199 & 1536905 & 649.4 & 2199.8 & -9506.76 & 2649.44 & 97.42 \\
\hline
\end{tabular}


TABLE 4-12

Exergy Flow Rates of Fuel, Product, and Exergy Destruction, Exergy Destruction Ratio $(\theta)$, Exergy Destruction to Total Exergy Input Ratio $\left(\theta^{\circ}\right)$ and Exergetic Efficiency $(\zeta)$ for Each Area and the Total Plant in Case 1 TO1

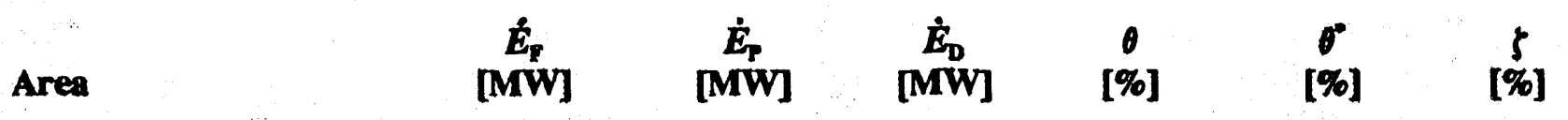

$\begin{array}{lrrrrrr}\text { Area 250: Booster Air Compressor } & 19.52 & 12.29 & 7.23 & 1.05 & 62 & 62.30 \\ \text { Area 300: KRW Gasification } & 1262.38 & 1022.34 & 240.05 & 34.55 & 20.45 & 80.99 \\ \text { Area 380: Recycle Gas Compression } & 69.08 & 63.11 & 5.98 & 0.86 & 0.51 & 91.35 \\ \text { Area 400: Gas Conditioning } & 195.70 & 176.89 & 18.82 & 2.71 & 1.60 & 90.39 \\ \text { Area 500: External Desulfurization } & 936.86 & 920.62 & 16.24 & 2.34 & 1.38 & 98.27 \\ \text { Area 600: Sulfation } & 35.72 & 27.60 & 8.12 & 1.17 & 0.69 & 77.26 \\ \text { Area 900: Gas Turbine System } & 636.19 & 360.41 & 275.78 & 39.70 & 23.49 & 56.65 \\ \text { Area 1000: HRSG } & 231.98 & 208.95 & 23.03 & 3.32 & 1.96 & 90.07 \\ \text { Area 1100: Steam Cycle } & 257.08 & 205.47 & 51.61 & 7.43 & 4.40 & 79.92 \\ \text { Total Plant Exergy Losses } & & & 36.92 & 5.31 & 3.14 & \\ \text { Service Station Power } & & & 10.77 & 1.55 & 0.92 & \\ \text { Steam Transport Losses } & & 0.15 & 0.02 & 0.01 & \\ \text { Total Plant } & & & & & & \\ \end{array}$


TABLE 4-13

Heat Loss, Power Supplied (Generated), Exergy Destruction Flow Rate, Exergy Destruction Ratio $(\theta)$, Exergy Destruction to Total Exergy Input Ratio $\left(\theta^{\circ}\right)$ and Exergetic Efficiency

( $\$$ ) for Plant Components in Case 1 TO2

\section{Component}

Gasifier

Cyclones

Product Gas Cooler

Coal Hopper System

Lash Transport \& Mixing

Quench Steam Mixing

7/8 Fines Cyclone \& Gas Filter

9 Solids Conveyor \& Cooler

10 Area 600: Sulfation

11 Chloride Guard

12 Air Extraction Cooler

13 Air Recuperator

14 BFW Preheater

15 Trim Cooler

16 Booster Air Compressor

17 Zinc Ferrite System

18 Exit Gas Cooler

20 Recycle Gas Cooler

21 Recycle Gas Compressor I

23 Recycle Gas Conipressor II

25 Steam Transport Losses

26 Gas Turbine/Air Compressor

27 Combustion Chamber

29 Superheater \& Reheater

31 HP Economizer

32 Feedwater Heater 1

33 Feedwater Heater 2

34 HP Turbine

37 IP Turbine

39 LP Turbine

40 Steam Seal Regulator

42 Condenser

43 LP Pump

44 Feedwater Heater 3

46 Deaerator

47 HP Pump
$\dot{Q}_{\text {Loss }}$
[MW]

\subsection{2}

1.85

1.42

0.00

0.00

0.00

0.00

0.88

1.07

0.14

0.07

0.37

0.29

0.81

0.00

0.00

0.61

0.14

0.70

0.00

0.00

37.31

0.00

3.41

3.21

0.21

0.06

0.00

0.00

0.00

0.00

302.22

0.00

0.36

0.10

0.00 $\underset{\text { [MW] }}{\dot{\mathbf{w}}}$

$$
1.07
$$

0.00

0.00

0.03

0.00

0.00

0.00

0.00

1.27

0.00

0.00

0.00

0.00

0.00

17.17

0.00

0.00

0.00

2.00

0.29

0.00

(311.64)

0.00

0.00

0.00

0.00

0.00

(66.57)

(42.55)

(96.35)

0.00

0.00

0.07

0.00

0.00

5.10
$\dot{E}_{D}$

[MW]

219.15

1.79

20.90

0.45

0.03

15.12

1.67

0.49

8.12

1.51

0.47

1.03

1.83

1.15

2.76

9.38

6.86

0.59

0.77

0.07

0.15

83.02

192.76

14.37

6.57

0.84

0.52

6.82

4.98

21.48

0.03

15.92

0.02

1.68

0.44

1.57
[\%]

31.55

0.26

3.01

0.07

0.00

2.18

0.24

0.07

1.17

0.22

0.07

0.15

0.26

0.16

0.40

1.35

0.99

0.08

0.11

0.01

0.02

11.95

27.75

2.07

0.95

0.12

0.07

0.98

0.72

3.09

0.00

2.29

0.00

0.24

0.06

0.23
0
$[\%]$

\section{$\zeta$}

[\%]

$18.67 \quad 82.28$

$0.15 \quad 99.15$

1.78

69.42

31.12

$0.00 \quad 99.77$

$1.29 \quad 98.54$

$0.14 \quad 99.07$

$0.04 \quad 98.86$

$0.69 \quad 77.26$

$0.13 \quad 99.15$

0.04

0.09

0.16

0.10

0.23

0.80

0.58

0.05

0.07

0.01

0.01

7.07

16.42

1.22

0.56

0.07

0.04

0.58

0.42

1.83

0.00

1.36

0.00

0.14

0.04

0.13
82.82

90.70

60.19

83.93

99.06

74.93

87.76

61.46

74.71

99.92

78.96

82.55

89.33

92.79

79.18

54.80

90.70

89.52

81.77

86.11

67.31

60.43

95.68

69.21 


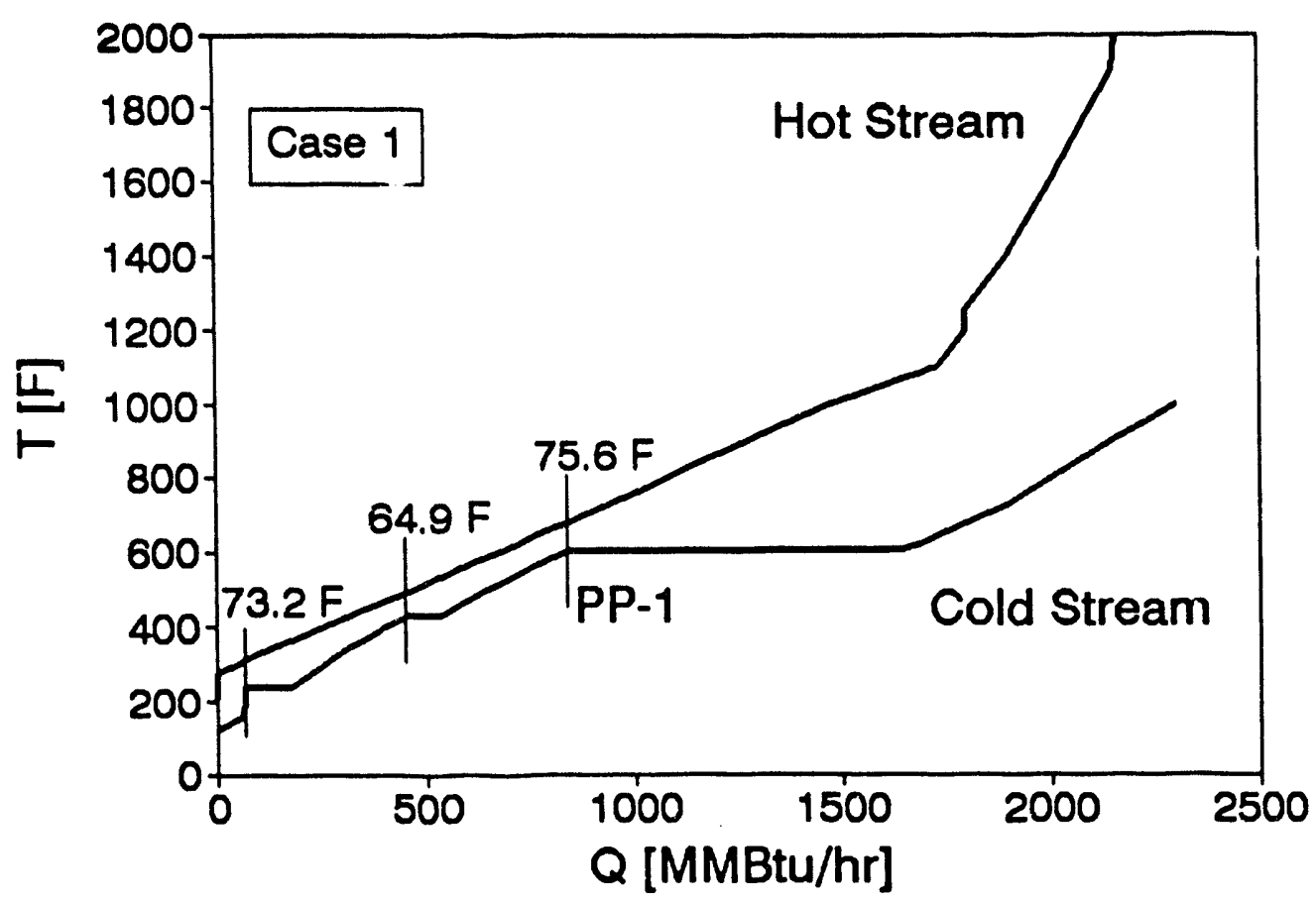

Figure 4-7. Composite Curves for the Heat Exchanger Network of the IGCC Plant in Case 1.

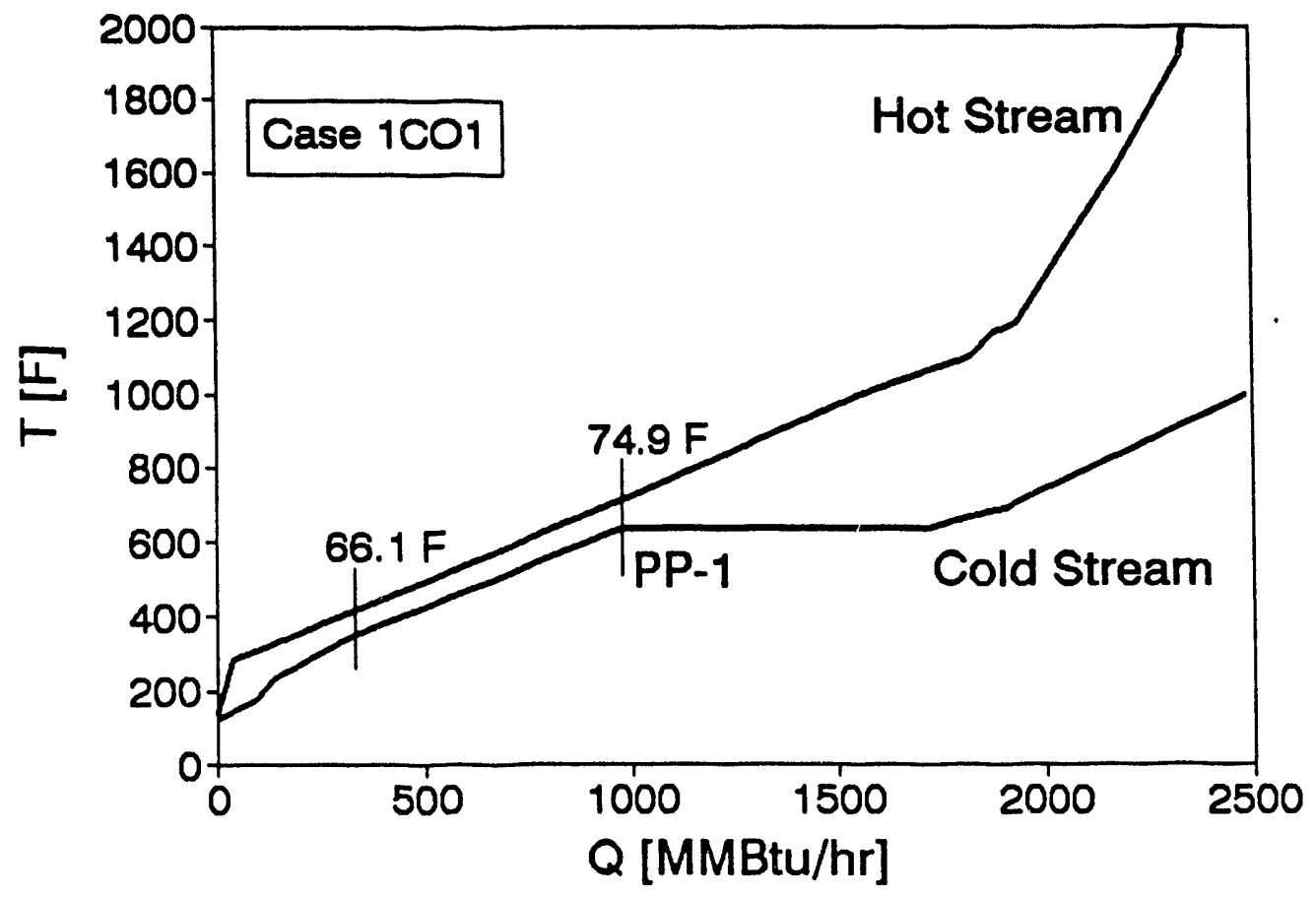

Figure 4-8. Composite Curves for the Heat Exchanger Network of the IGCC Plant in Case $1 \mathrm{CO}$. 


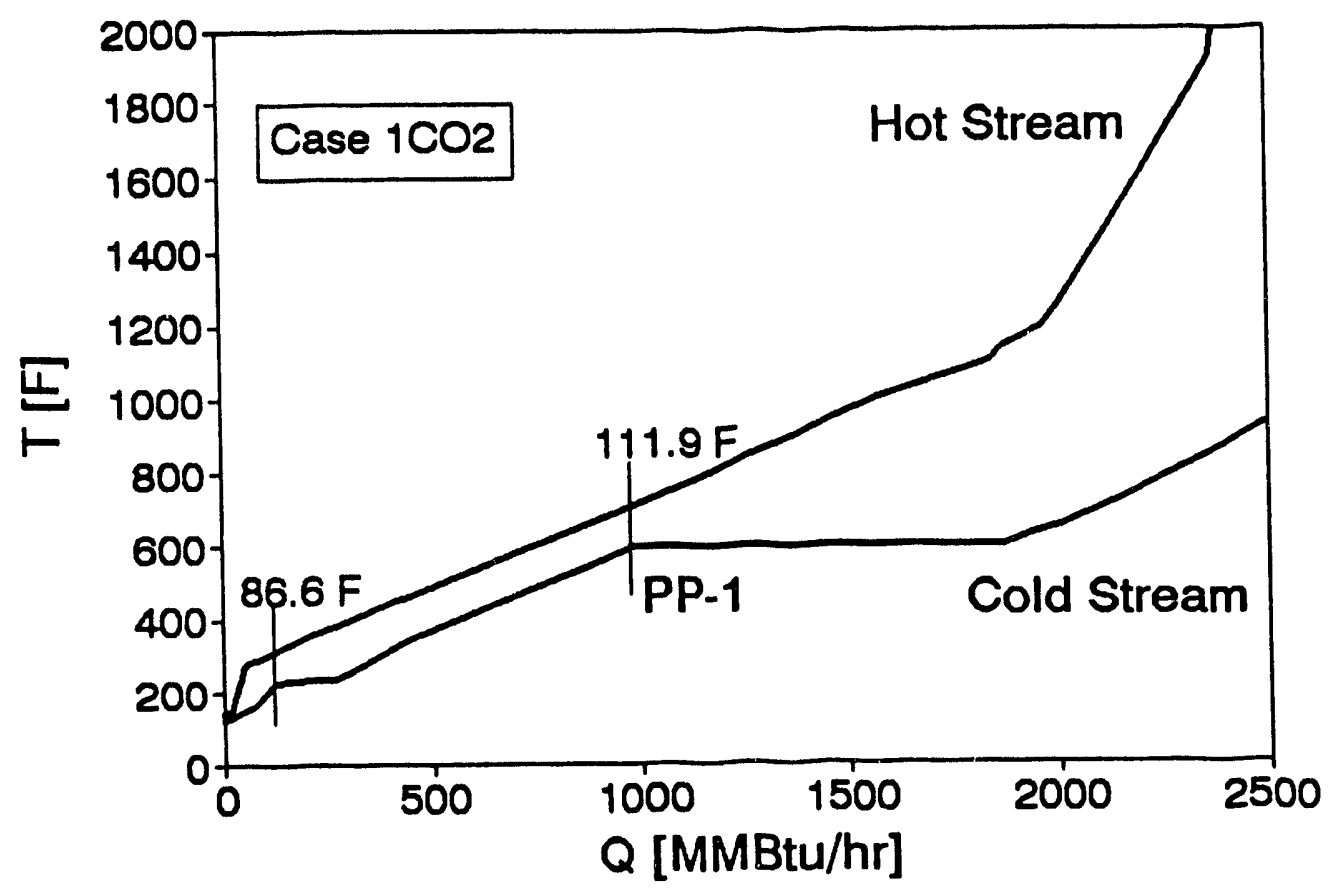

Figure 4-9. Composite Curves for the Heat Exchanger Network of the IGCC Plant in Case 1 CO2.

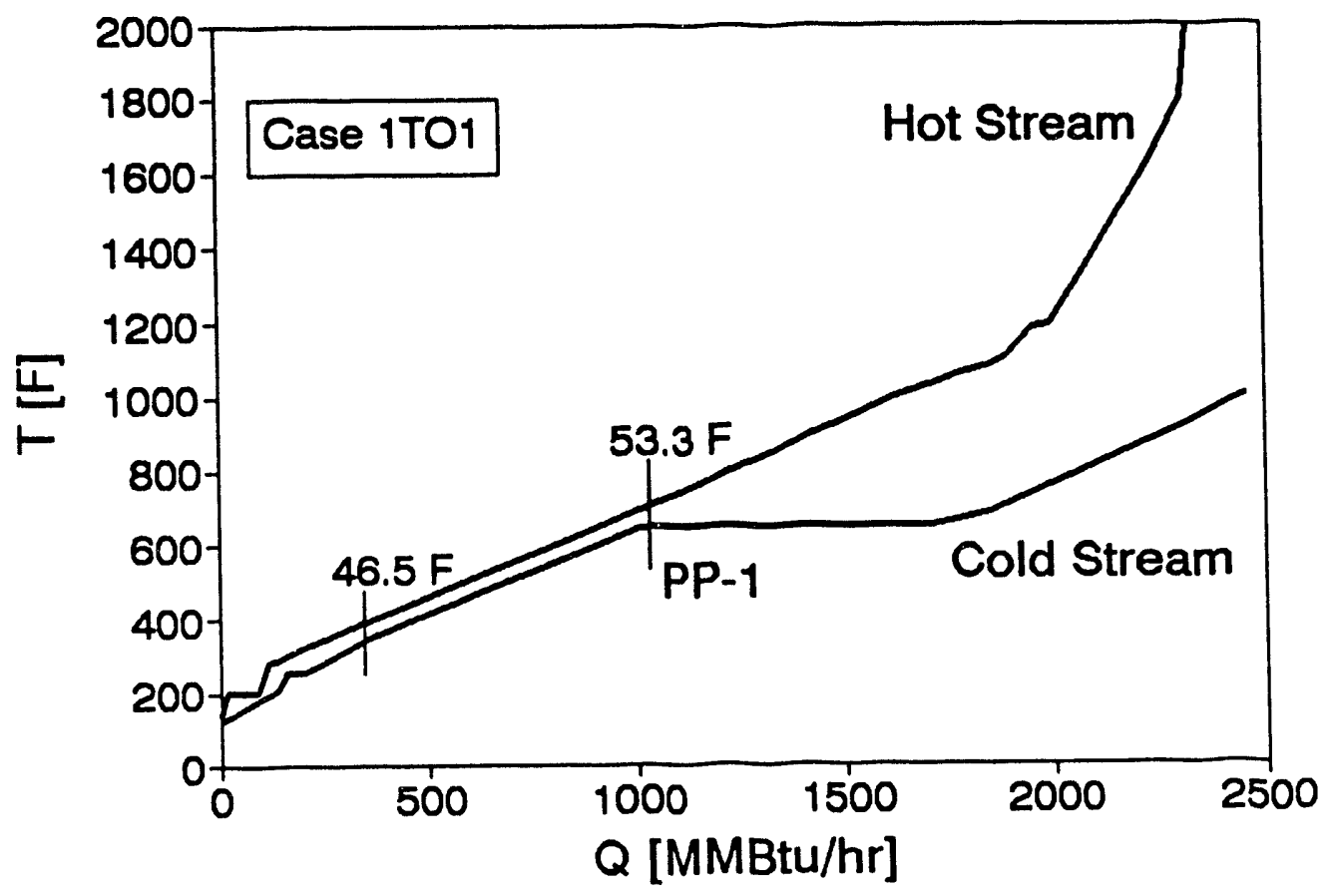

Figure 4-10. Composite Curves for the Heat Exchanger Network of the IGCC Plant in Case 1TO1. 


\subsection{DISCUSSION OF THE DESIGN CHANGES}

This section discusses the major design changes considered in each plant area for the optimized Cases 1CO1, 1CO2 and 1TO1 as compared with the original Case 1. The pinch analysis [10] was used to identify design changes in the heat exchanger network that would improve the overall plant efficiency by avoiding heat transfer across the pinch points in the composite curves (Figures 4-7 through 4-10). Most of the identified design changes were incorporated in the thermodynamically optimal design of Case 1TO1. Some possible process modifications, however, were not incorporated in the designs of Cases $1 \mathrm{CO} 1$ and $1 \mathrm{CO} 2$ because they could not be justified economically. Our studies confirmed that the usefulness of pinch analysis techniques in IGCC power plant design studies is very limited when the objective is minimization of the electricity cost. The exergy analysis and the thermoeconomic evaluation techniques are much more powerful tools for the design optimization of power generating plants than the pinch analysis techniques. The recommendations given in the following refer to design changes to be conducted in the original Case 1 design.

\subsubsection{Area 250 - Air Booster Compression}

Area 250 consists of the air recuperator, BFW preheater, trim cooler and booster air compressor. As indicated in Reference [1], the initial design of this area was close to the thermoeconomic optimum. The only change considered in the cost optimal Cases $1 \mathrm{CO}$ and $1 \mathrm{CO} 2$ compared with the original Case 1 refers to the pressure level of the feedwater, which is preheated in the BFW preheater. By preheating LP (lowtemperature) feedwater (Cases 1CO1, 1CO2, and 1TO1) instead of HP feedwater (original Case 1) both the performance and the cost effectiveness of the plant increase because the amount of heat rejected to the environment in the trim cooler decreases when the temperature difference $T_{49}-T_{151}$ (Figures 2-1, 4-1, 4-3, and 4-5) is assumed constant.

For the thermodynamic optimum, however, an additional change is required in the original Case 1 due to some heat transfer across the pinch point that is formed by the high-pressure vaporization process. This pinch point is indicated as PP-1 in the heat transfer composite curves for Cases 1CO1, 1CO2 and 1TO1, respectively (Figures 4-7 through 4-10). Therefore, in Case $1 \mathrm{TO}$ and in accidance with criterion 4(b) presented in section 4-3, a heat exchanger called "extraction air cooler" was added to this area. This heat exchanger cools the air coming from the gas turbine system down to a temperature $\left(T_{100}\right)$ which corresponds to the temperature $\left(T_{H, P P 1}\right)$ on the hot composite curve at PP-1 in Figure 4-10.

However, the MWK capital cost estimates indicated that using tiis cooler is not cost effective because of the relatively large total surface area required to cool the air in this 
cooler and the subsequent air recuperator. Therefore, the extraction air cooler was used only in the design of the thermodynamically optimal Case 1TO1.

Recommendation for Area 250: Increase the size of the BFW preheater and preheat LP (low-temperature) instead of HP (high-temperature) feedwater.

\subsubsection{Area 300 - KRW Gasification}

Area 300 contains the following components: pressurization air compressor, pressurization air receiver, coal feed vent filter, feed surge drum, ieed pressurization hopper, feed hopper, coal feeder, gasifier, ash feeder and cyclone. In the Case 1 optimization studies significant changes were considered only in the gasifier. The performance of the remaining components was assumed to be constant; only their size was varied with changing mass flow rates. For the optimization we assumed that an increase in the moisture of the coal feed affects the investment costs of the coal feeding system only through the increased coal flow rate. The two major independent parameters of the gasifier considered in the design optimization are the coal moisture content at the gasifier inlet and the gasification temperature. These parameters are discussed below.

\section{Coal Moisture at the Gasifier Inlet}

The high-temperature gas cleanup process used in all cases discussed here requires that the moisture content of the gas supplied to the zinc ferrite system is about 30 percent by volume. This is achieved by extracting steam (stream 39) from the HP turbine and mixing it with the gas exiting the product gas cooler (stream 12). This mixing process has the additional advantage of cooling the gas to a temperature of $1,015^{\circ} \mathrm{F}$.

The undesired effect of the mixing process refers to the extremely high exergy destruction, which is greater than $17 \mathrm{MW}$ in the Original Case $1 .^{*}$ A reduction in the amount of steam mixed with the gas results in (a) a larger mass flow rate to be expanded in the steam turbine, and, consequently, more electric power generated in the steam turbine generator, and (b) a lower temperature of stream 12 (assuming a constant temperature $\left(T_{159}\right)$ after the mixing) with the consequence that more steam can be generated in the product gas cooler.

In addition, the coal, before being fed into the gasifier in the original Case 1, is dried using the high-temperature sensible heat of the combustion gas exiting the sulfation area. This heat, however, could be used elsewhere to generate more HP steam and preheat

*The exergy destruction in the mixing process represents an "energy waste" which is easily detected in an exergy analysis but cannot be identified through an energy balance. 
feedwater. Finally, the quench steam (stream 39) is cooled in the desuperheater before being mixed with the gas (stream 12). This desuperheating process adds unnecessarily to the total exergy destruction.

Thus, the combination of (a) the requirement of the high-temperature desulfurization process for a high moisture content of the gas to be cleaned, and (b) the coal drying process, which removes moisture from the gas exiting the gasifier, results in the following performance penalties in the original Case 1:

- The valuable heat content of the combustion gas exiting the sulfation area (stream 48) is used counterproductively. Instead of being used to generate steam and preheat feedwater, it is used to reduce the moisture content of the gasification gas (stream 6), when, in a subsequent step, moisture is added to this gas at a very high cost.

- A relatively high steam flow rate is extracted from the HP steam turbine and is finally expanded in the gas turbine. Since the pressure ratio in the latter is significantly lower than the combined pressure ratio in the IP and LP steam turbines, this steam extraction decreases the electric power generation in the total plant.

- The potent $d$ for generating steam in the product gas cooler is reduced when the temperature of the quench steam decreases since the condition of stream 159 remains constant.

- The exergy destruction of the quench steam desuperheating and, particularly, the mixing process of streams 12 and 39 is significant.

From the above discussion it becomes apparent that eliminating the coal drying process (a) allows the heat of the sulfation combustion gas to be used in the HRSG, (b) increases the power production in the steam turbines, (c) increases the steam generation in the product gas cooler, and (d) decreases the exergy destruction in the desuperheater and quench steam mixing process. These benefits outweigh the increase in the exergy destruction in the gasifier.

In addition to the positive effects discussed above, increasing the coal moisture at the gasifier inlet results in the two additional advantages: (1) A decreased mass flow rate of blast steam (stream 10) needs to be supplied to the gasifier per coal mass unit. Thus, more steam is left to be expanded in the IP and LP turbines. (2) The reduction in the mass flow rate of the blast steam leads to a higher per pass in-bed sulfur removal in the gasifier. This results in a reduction of the size and the O\&M costs in the zinc ferrite system. 
In the optimization studies, various values of the coal moisture at the gasifier inlet were considered. These studies concluded that both the economic and the thermodynamic optimal points are achieved when the coal is supplied to the gasifier with the as received moisture of 11.12 weight percent. Therefore, the optimized Cases 1CO1, 1CO2 and 1 TO1 do not contain a coal drying step. For optimization purposes it was assumed that the reliability of coal feeding is not affected by this decision.

Recommendation for Coal Moisture: Supply the coal to the gasifier with the highest allowable moisture content which is dictated by the reliability of the coal feeding process. Should the actual coal moisture exceed this value, use a low-temperature flue gas extraction from the HRSG to dry the coal to the specified maximum moisture value. Some changes in the plant layout will be required to accommodate these recommendations.

\section{Gasification Temperature}

With increasing gasification temperature, the exergy destruction in the gasification system increases (thus, the exergetic efficiencies of the gasifier and the product gas cooler decrease) while the amount of steam generated in the product gas cooler also increases. The economically optimal gasification temperature depends on the overall plant design and is affected by the interaction between gasification island and power island. The thermoeconomic optimization has shown that the best gasification temperature is about $1920^{\circ} \mathrm{F}$ (Cases $1 \mathrm{CO} 1$ and $1 \mathrm{CO} 2$ ).

The thermoeconomic evaluation reported in Reference [1] concluded, based on the average cost per product exergy unit for the gasifier $\left(c_{P}\right)$, that the cost optimal gasification temperature for Case 1 is between $1850^{\circ} \mathrm{F}$ and $1900^{\circ} \mathrm{F}$. If the relative cost difference d, Equation 3-7, for the gasifier had been used instead of $c_{p}$ to predict the cost optimal gasification temperature, the recommendation would have been in the range of $1900^{\circ} \mathrm{F}$ $1950^{\circ} \mathrm{F}$, i.e., much closer to the optimal value of $1920^{\circ} \mathrm{F}$. This effect is shown in the Appendix, Figure A-2. The current work has indicated that in general the relative cost difference (d) calculated for the gasifier accurately predicts the cost optimal gasification temperature for various design configurations.

The thermodynamically optimal gasification temperature is apparently equal to the lowest temperature for which a constant carbon conversion ratio may be assumed. This temperature was set to $1800^{\circ} \mathrm{F}$ in the present study. Case 1TO1, therefore, assumes this gasification temperature.

Recommendation for the Gasification Temperature: The economically optimal value depends on the overall plant design. The relative cost difference d, Equation 3-7, for the 
gasifier should be used to obtain a good and fast estimate of the cost optimal value of the gasification temperature.

\subsubsection{Areas 360/380 - Heat Recovery and Recycle Gas Compression}

These areas consist of the product gas cooler, heat recovery steam drum, recycle gas cooler, recycle gas compressor and recycle gas receiver. In the optimization, changes were considered in the product gas cooler and the recycle gas cooler. These changes are discussed below.

\section{Product Gas Cooler}

The product gas cooler cannot be optimized independently because its main operating parameters depend on decisions made with respect to other plant parameters. The inlet gas temperature depends on the gasification temperature $\left(T_{6}\right)$; the gas temperature at the outlet is a function of the mass flow rate $\left(\dot{m}_{39}\right)$ and temperature $\left(T_{39}\right)$ of the quench steam used to provide a gas mixture (stream 159) with 30 percent by volume moisture content $\left(\mathrm{x}_{\left.\mathrm{H}_{2} \mathrm{O}, 159\right)}\right)$ at $\mathrm{T}_{159}=1015^{\circ} \mathrm{F}$; the temperature on the steam side depends on the value of the steam high pressure $\left(\mathrm{P}_{\mathrm{HP}}\right)$.

The thermoeconomic optimization indicated that it is always thermodynamically efficient and cost effective to adjust the performance and size of the product gas cooler in this way. In all cases considered here, the minimum temperature difference in this cooler was above $520^{\circ} \mathrm{F}$.

Recommendation for the Product Gas Cooler: Adjust its size and effectiveness based on the following variables: $T_{6}, T_{39}, \dot{m}_{39}, T_{159}, x_{H_{2}, 0,159}$, and $\mathrm{P}_{H P}$.

\section{Recycle Gas Cooler}

The following options were considered for the recycle gas cooler (RGC):

1. RGC preheats the high-temperature feedwater that is supplied to the heat recovery steam drum (HRSD).

2. RGC preheats the low-temperature feedwater that subsequently enters the HP economizer.

3. Part of RGC generates HP steam, and the remaining part preheats the hightemperature feedwater that is supplied to the HRSD. 
4. The cooling of the recycle gas is obtained through spraying liquid water into the gas.

5. Cooling water is used exclusively to cool the recycle gas from $T_{20}$ to $T_{18}$.

Among all heat exchangers, the recycle gas cooler has the highest value of investment cost to product exergy ratio, $r_{k}$, Equation 3-9. The relatively high investment cost associated with the RGC explains why the economically best options were found to be 5 and 4 above. ${ }^{*}$ Both options, however, were rejected because of operating reasons: option 5 would cause undesirable water condensation in the recycle gas; option 4 was rejected because the additional water supplied to the recycle gas would disturb the gasifier operation.

Option 3 represents the thermodynamic optimum and was therefore used in Case 1TO1. This option avoids heat transfer across the pinch point PP-1 in Figures 4-7 through 4-10 and is in accordance with the criterion 4(b) in section 4-3.

The cost optimal Cases 1CO1 and 1CO2 employ option 2, whereas the original Case 1 uses option 1. A design configuration based on option 3, which would allow little heat transfer across the pinch point 1 , could also be acceptable from the thermoeconomic viewpoint.

Recommendation for the Recycle Gas Cooler: Decrease the cooler surface area by preheating the relatively low-temperature feedwater.

The gas recycling process increases the total plant investment cost and decreases the overall plant efficiency. The recycle gas is mainly used to assure proper fluidization in the gasifier bed. The size of the recycle system was selected by MWK to maintain proper fluidization at reduced plant capacity. Future optimization studies for Case 1 should consider options which would allow for either elimination or reduction of the recycle gas flow rate. These options might be more cost effective than the design considered here. Consideration of these options in the present study would exceed the scope of work.

General Recommendation for the Gas Recycling Process: In future optimization studies, investigate the economic feasibility of design options allowing elimination or equipment size reduction for this process.

*This is an interesting example in the analysis of the total heat exchanger network where the economically optimal solution is obtained when in a heat exchanger all heat is transferred across the pinch point. Solutions such as this cannot be predicted by the pinch analysis techniques discussed in Reference [10]. 


\subsubsection{Area 400 - Gas Conditioning}

This area contains the following plant components: Fines cyclone, cyclone fines lockhopper, cyclone fines depressurization lockhopper, cyclone lockhopper filter, gas filter, filter depressurization lockhopper, solids conveyor and chloride guard drums. Only changes in the size of these components were considered in the optimization process. Thus, no specific recommendations are made.

\subsubsection{Area 500 - External Desulfurization}

This area consists of the zinc ferrite reactors, guard cyclone, guard drum and exit gas cooler. Performance changes were considered only for the exit gas cooler. Since the gas temperatures at the inlet and outlet of this cooler are almost constant, the performance and investment cost of the cooler are mainly affected by the steam high-pressure value $\left(\mathrm{P}_{\mathrm{HP}}\right)$.

The value of the investment cost to product exergy ratio, $r_{k}$ (Equation 3-9) is lower for the exit gas cooler than for the recycle gas cooler. Therefore, in all optimal cases, the recycle gas (stream 20) was extracted at the exit gas cooler outlet instead of the zinc ferrite outlet. If the recycle gas cooler is used only for feedwater preheating, this change in the design structure allows more steam to be generated in the gasification island.

Recommendation for the Exit Gas Cooler: Let the entire clean gas which exits the zinc ferrite unit, flow through the exit gas cooler, and then extract the recycle gas stream.

The decrease in the flow rate of the blast steam supplied to the gasifier leads to an increase in the sulfur removal in the gasifier from 86.5 percent in the original Case 1 to 91.4 percent in all optimized Cases 1CO1, 1CO2 and 1TO1. Since the investment and $O \& M$ costs and the performance penalties associated with the operation of the zinc ferrite unit are significant, the economic feasibility of design options permitting elimination of the external desulfurization step should be investigated. Consideration of these options in the present study would exceed the scope of work. The general design of Case 1 without an external desulfurization step would be similar to the design of Case 6 in Reference [1].

The use of zinc titanate instead of zinc ferrite in the external desulfurization area could improve the efficiency and cost effectiveness of the total plant. The zinc titanate does not require addition of steam. Thus, the heat content of the fuel gas to the gas turbine would be increased and the steam flow rate to be expanded in the steam turbines would increase. At present, however, more test data are required to study the economic feasibility of zinc titanate. 
General Recommendation for the External Desulfurization: In future optimization studies, investigate the economic feasibility of design changes aimed at either making redundant the external desulfurization step in Case 1 or using an external bed sorbent which does not require addition of steam.

\subsubsection{Area 600 - Sulfation}

The sulfation area contains the LASH receiver, screw feeder, sulfation air compressor, sulfator, sulfator solids screw cooler, solids disengager, sulfator heat recovery and sulfator steam drum. In the optimization, the performance of all components in this area except the sulfator heat recovery was assumed to remain constant. The surface area of the heat recovery was varied with varying combustion gas temperature $\left(T_{48}\right)$ at the sulfation exit. The following options were considered for this gas after leaving the sulfation area:

1. The gas is used to dry the coal to a residual moisture content in the range of 4.98-9.50 weight percent.

2. The gas is filtered and mixed with the gas turbine exhaust gas. The mixture is sent to the HRSG.

3. The gas is supplied to the HRSG and mixed with the gas turbine exhaust gas at an intermediate HRSG position (e.g., between the superheater/reheater and the vaporization section, or between the vaporization and the HP economizer section).

Both the thermodynamic and the economic optima are achieved when option 2 is used. When the gas streams from the gas turbine and the sulfation are mixed (regardless of the position at which this occurs) both streams should have about the same temperature to avoid unnecessary exergy destruction in the mixing. This can be achieved by adjusting the combustion gas temperature $\left(\mathrm{T}_{48}\right)$ at the sulfation exit.

Recommendation for the Sulfation Area: Increase the heat recovery surface area to cool the combustion gas to about the temperature of the gas turbine exhaust gas. Add a filter to remove the solids from the combustion gas exiting the sulfation and mix this gas with the gas exiting the gas turbine system.

\subsubsection{Area 900 - Gas Turbine System}

In all optimization runs, the same gas turbine system with constant performance was assumed. Therefore, no recommendation, in addition to the one included in Reference 
[1], which is repeated below, can be made here. The performance of the GE MS7001F gas turbine assumed in Reference [1] and in the optimization studies here corresponds to the MS700 $: F$ capabilities in October 1989. GE also supplied cost and performance data referring the MS7001F capabilities in October 1991. The effect of this change in the gas turbine performance on $\mathrm{COE}$ and plant efficiency is significant and is discussed in section 5.4. An increase in the gas turbine firing temperature leads in general to an increase in the efficiency of the gas turbine system. An associated benefit is the increase in the gas turbine exhaust temperature which results in higher temperature pinches in the HRSG. This represents a significant advantage for the HRSG operation when the gas turbines operate at partial load.

Recommendation for the Gas Turbine System: Study the economic feasibility of developing and using a gas turbine system with a reheat stage. Improve the gas turbine design to permit higher firing temperatures and higher system efficiencies.

\subsubsection{Area 1000 - Heat Recovery Steam Generator System}

In the original Case 1, the HRSG uses the heat of the exhaust flow from the combustion turbine to produce steam for both power production in the steam turbine and for process steam use in the gasification island. In all optimal cases, the HRSG also uses the heat of the exhaust flow from the sulfation system.

In the optimization studies, the HRSG design was adjusted according to the steam generation in the gasification island to provide steam superheating and reheating as well as feedwater preheating. HRSG designs with and without a steam drum were studied. At relatively low values of steam high pressure $\left(\mathrm{P}_{\mathrm{HP}}\right)$, a steam drum is required in the HRSG. At $P_{\mathrm{HP}}$ values above 1800-1900 psia, steam generation is not necessary or possible in the HRSG and, thus, the steam drum becomes redundant. Reducing the number of steam drums in the total IGCC plant has a positive effect on the total investment costs without any associated efficiency penalties. These considerations are reflected in the designs of Cases $1 \mathrm{CO} 1\left(\mathrm{P}_{\mathrm{HP}}=2055\right.$ psia; no drum in the HRSG), $1 \mathrm{CO} 2$ $\left(\mathrm{P}_{\mathrm{HP}}=1515\right.$ psia; only an HP steam drum is considered in the HRSG) and 1 TO1 $\left(\mathrm{P}_{\mathrm{HP}}\right.$ $=2200$ psia; no drum in the HRSG).

The steam high pressure value $\left(\mathrm{P}_{\mathrm{HP}}\right)$ is a very important parameter for the optimization of an IGCC power plant. This variable determines the flow rate of steam generated in the gasification island and the pinch temperatures in several heat exchangers (including the HRSG). As Cases $1 \mathrm{CO} 1$ and $1 \mathrm{CO} 2$ indicate, economically attractive solutions can be found at both relatively high and low $\mathrm{P}_{\mathrm{HP}}$ values. The thermodynamic optimum will always be at high $P_{\mathrm{HP}}$ values. Generation of IP steam in the HRSG is not cost effective for the IGCC plants considered here. 
Recommendation for the HRSG: Adjust the HRSG design to optimize the interaction between the gasification and power islands by keeping the steam high pressure $\left(\mathrm{P}_{\mathrm{HP}}\right)$ value variable. If the $\mathrm{P}_{\mathrm{HP}}$ value is relatively high, do not consider steam generation in the HRSG. Avoid any IP or LP steam generation in the HRSG.

\subsubsection{Area 1100 - Steam Turbine System}

In the optimization procedure, the design of this system was continuously adjusted to reflect changes in both the gasification island and the HRSG. When the steam high pressure $\left(\mathrm{P}_{\mathrm{HP}}\right)$ value is relatively high, the design of the HP turbine section should be modified so that the HP exhaust steam conditions allow this steam to be used as quench steam (stream 39) and blast steam (streams 10 and 30). Then, no steam extraction in the HP turbine is necessary. This change was made in Cases 1CO1 and 1TO1.

In general, a decrease in the pressure at the outlet of the LP pump (i.e., a decrease in the deaerator operating pressure) leads to an increase in the overall plant efficiency and to a decrease in the COE. Therefore, this pressure should be kept at its lowest permissible value. Cases $1 \mathrm{CO} 1$ and $1 \mathrm{CO} 2$ use a deaerator operating pressure of 20 psia.

The design of the feedwater heaters 1,2 and 3 is adjusted to accomplish, together with the BFW preheater in the air booster compression area, feedwater preheating up to the deaerator operating pressure. Case $1 \mathrm{CO} 1$ uses only one feedwater heater (located in the HRSG) compared with two feedwater heaters in the original Case 1 and Cases 1CO2 and 1TO1. All optimized cases use one LP steam extraction to preheat feedwater. This extraction is used directly in the deaerator in Case $1 \mathrm{CO} 1$ whereas a third feedwater heater is used in Cases $1 \mathrm{CO} 2$ and 1TO1.

\section{Recommendations for the Steam Turbine System:}

1. If the $\mathrm{P}_{\mathrm{HP}}$ value permits, adjust the pressure at the HP turbine exhaust to supply quench steam to the gasification island directly.

2. Keep the deaerator operating pressure as low as possible.

3. In an optimal IGCC design, at least one LP steam extraction might be required to preheat feedwater.

\subsection{COMPARISON OF CASES 1, 1CO1, 1CO2 AND 1TO1}

Tables 4-14 through 4-21 summarize the major results of the material, performance and cost comparisons of Cases 1, 1CO1, 1CO2 and 1TO1. Among these cases, Case 
1TO1 has the smallest coal flow rate (as received) and the highest cold gas efficiency whereas Cases $1 \mathrm{CO} 1$ and $1 \mathrm{CO} 2$ have the largest as received coal flow rate and the lowest cold gas efficiency. The differences in the cold gas efficiency can be explained by the differences in the gasification temperature. The sulfur removal in the gasifier is 91.4 percent for the three optimized cases and 86.5 percent for the original Case 1 . The sulfur removal in the gasification island is the same, 99.4 percent, for all four cases.

Case 1CO1 has the largest net power output $(482.5 \mathrm{MW})$ while the original Case 1 has the smallest output (458.4 MW). As expected, Case 1TO1 possesses the lowest net plant heat rate $(8,181 \mathrm{Btu} / \mathrm{kWh})$. Case $1 \mathrm{CO}$ is the next lowest $(8,351 \mathrm{Btu} / \mathrm{kWh})$ whereas the original Case 1 has the highest net plant heat rate $(8,595 \mathrm{Btu} / \mathrm{kWh})$. The difference in the overe plant thermal efficiency between Cases $1 \mathrm{CO} 1$ and $1 \mathrm{CO} 2$ is mainly caused by the difference in the steam high pressure value.

Figure 4-11 compares the temperature differences in the composite curves for Cases $1,1 \mathrm{CO} 1$ and 1TO1. These temperature differences determine the costs associated with the total heat exchanger network. As expected Case 1TO1 has the smallest temperature differences in the heat exchanger network while the original Case 1 has the largest differences. The temperature differences in Cases $1 \mathrm{CO} 1$ and $1 \mathrm{CO} 2$ are very close to each other.

Because of the net power output differences among the cases, the capital cost network comparison (Tables 4-19 and 4-20) is made in terms of $\$ / \mathrm{kW}$. The differences in the total capital requirement (TCR) among Cases 1, 1 CO1 and 1 CO2 (1335-1346 \$/kW) are small (less than one percent). The highest TCR is for Case 1TO1 at $1421 \$ / \mathrm{kW}$, primarily the result of the optimization according to overall plant efficiency criteria.

The cost of electricity results are summarized in Table 4-21. The values are shown as 10-year levelized costs based on a 65 percent capacity factor (set I values) and as 30year levelized costs based on a 85 percent capacity factor (set II values). The latter values were used for optimization purposes. The COE values are given in both current and constant dollars. The comparisons discussed below are made on a constant dollar basis for the set II values.

Case $1 \mathrm{CO} 1$ possesses the lowest COE with 38.3 mills/kWh, 1.83 percent lower than the COE of the original Case $1(39.0$ mills $/ \mathrm{kWh})$. Case $1 \mathrm{CO} 2$ is the next lowest with a COE of $38.4 \mathrm{mills} / \mathrm{kWh}$, which is 1.61 percent lower than the COE of the original Case 1. The highest COE is for Case 1 TO1 at $39.2 \mathrm{mills} / \mathrm{kWh}, 2.30$ percent greater than for Case $1 \mathrm{CO} 1$, but only 0.44 percent greater than the COE for the original Case 1 . 
The difference in COE between Case $1 \mathrm{CO} 1(1 \mathrm{CO})$ and the original Case 1 results in savings of over 2.4 (2.2) million constant (mid-1990) dollars per year of plant operation. Compared with the original Case 1, the 30-year pre-tax present value of the cost savings in Cases $1 \mathrm{CO} 1$ and $1 \mathrm{CO} 2$ are 30.0 and 27.7 million constant mid-1990 dollars, respectively.

As we go from set II values to set I values in Table 4-21, the relative differences in COE among the original Case 1 and Cases $1 \mathrm{CO} 1$ and $1 \mathrm{CO} 2$ are reduced, whereas the differences in COE between Case 1 TO1 and the remaining cases increase.

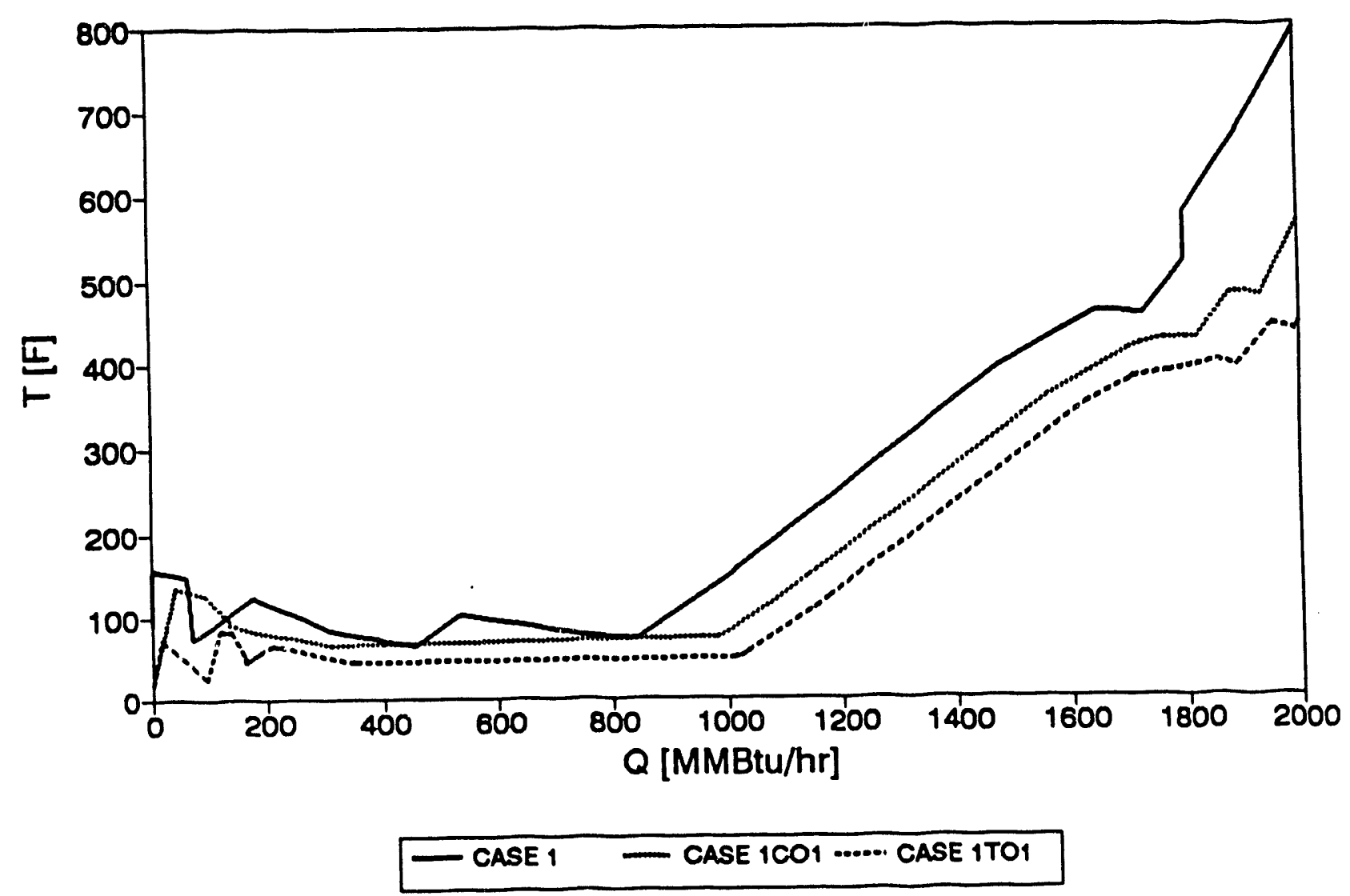

Figure 4-11 Comparison of the Temperature Differences in the Composite Curves (Figures 47, 48 and 4-10) for Cases 1, 1CO1, 1TO1. The Case $1 \mathrm{CO} 2$ values are very close to the Case $1 \mathrm{CO1}$ curve. 
TABLE 4-14

Comparison of Overall Material Balances

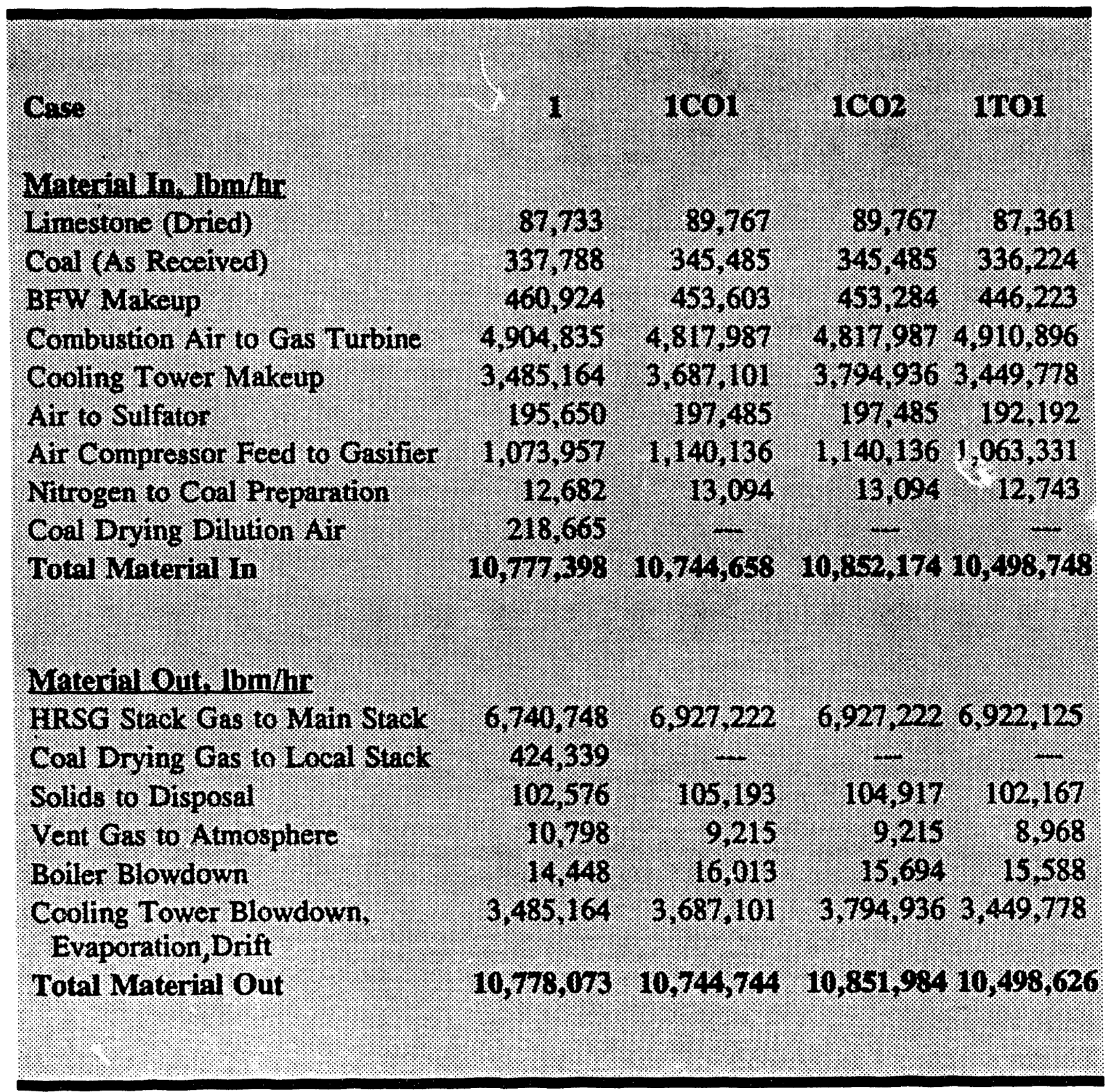


TABLE 4-15

Gasification Island Design Basis Performance Comparison

\begin{tabular}{|c|c|c|c|c|}
\hline gase & 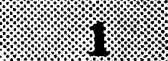 & 108 & 1002 & 88 \\
\hline D.4. & & & & \\
\hline 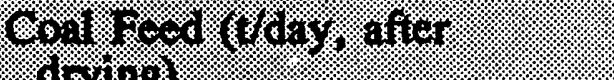 & 3, 192 : & 4.146 & $4.6 \%$ & 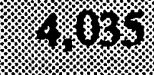 \\
\hline 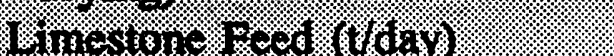 & $10058:$ & 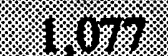 & $\sqrt{12}(7)$ & 0.048 \\
\hline Ar Sugely (uday) & 12,888 & 18.680 & 18.680 & $1,8,80$ \\
\hline Stern (GMinbmiday) & 10774 & 10.5139 & 10500 & 10.386 \\
\hline Praniters. & & & & \\
\hline Ful Gas (IIV. WMBruday) & 63,386 & 63.300 & 63,30 & 68,300 \\
\hline 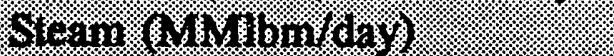 & 24,894 & 38.836 & $82,2,126$ & $37,4,4$ \\
\hline 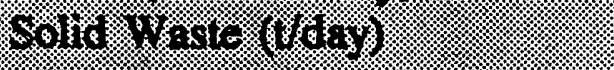 & 1.231 & 1.250 & 1.258 & 1226 \\
\hline Pencomances & & & & \\
\hline Cold Gus ETficency-WIV (8) & 697 & 6800 & 680 & 6989 \\
\hline Carbon domersion (7) & & & & \\
\hline Casinicr Only & 96.5 & 9635 & 96.5 & 9.8 .5 \\
\hline 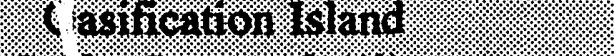 & 999 & 99.9 & 9999 & 999 \\
\hline 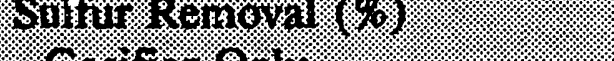 & & 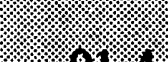 & $T_{2}$ & \\
\hline gasinger ony. & $\begin{array}{ll}80.3 \\
80.8\end{array}$ & $\begin{array}{ll}5 \pi \\
0.89\end{array}$ & $\begin{array}{ll}9129 \\
0.82\end{array}$ & 80.4 \\
\hline ens & & & & \\
\hline
\end{tabular}


TABLE 4-16

Comparison of Steam Turbine Performance Data

\begin{tabular}{|c|c|c|c|c|}
\hline 4 & . & (2) & 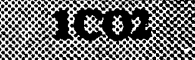 & 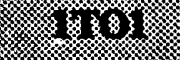 \\
\hline 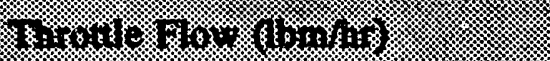 & 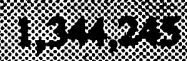 & (6) & 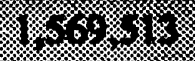 & 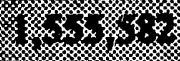 \\
\hline 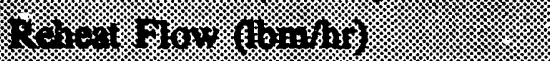 & (1) & 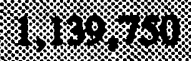 & 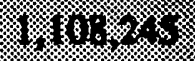 & 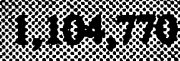 \\
\hline 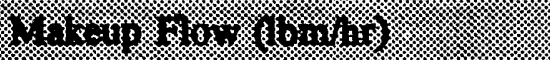 & 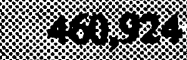 & 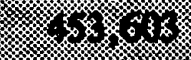 & 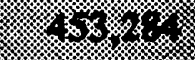 & 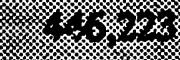 \\
\hline 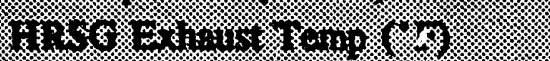 & $4 x$ & $\frac{1}{2}$ & 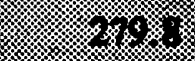 & sing \\
\hline 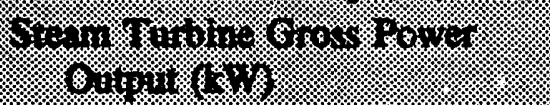 & 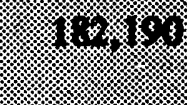 & 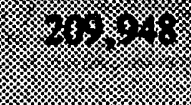 & 36. & $2,3.0 \%$ \\
\hline 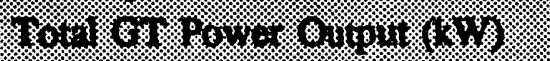 & 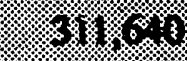 & 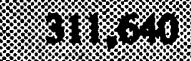 & $\frac{1}{6}$ & 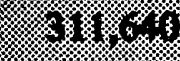 \\
\hline 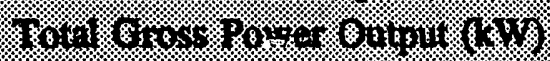 & $8,8 \% 6$ & 2.9.8. & 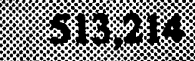 & (3) \\
\hline
\end{tabular}

TABLE 4-17

Comparison of Overall Plant Pxrformance

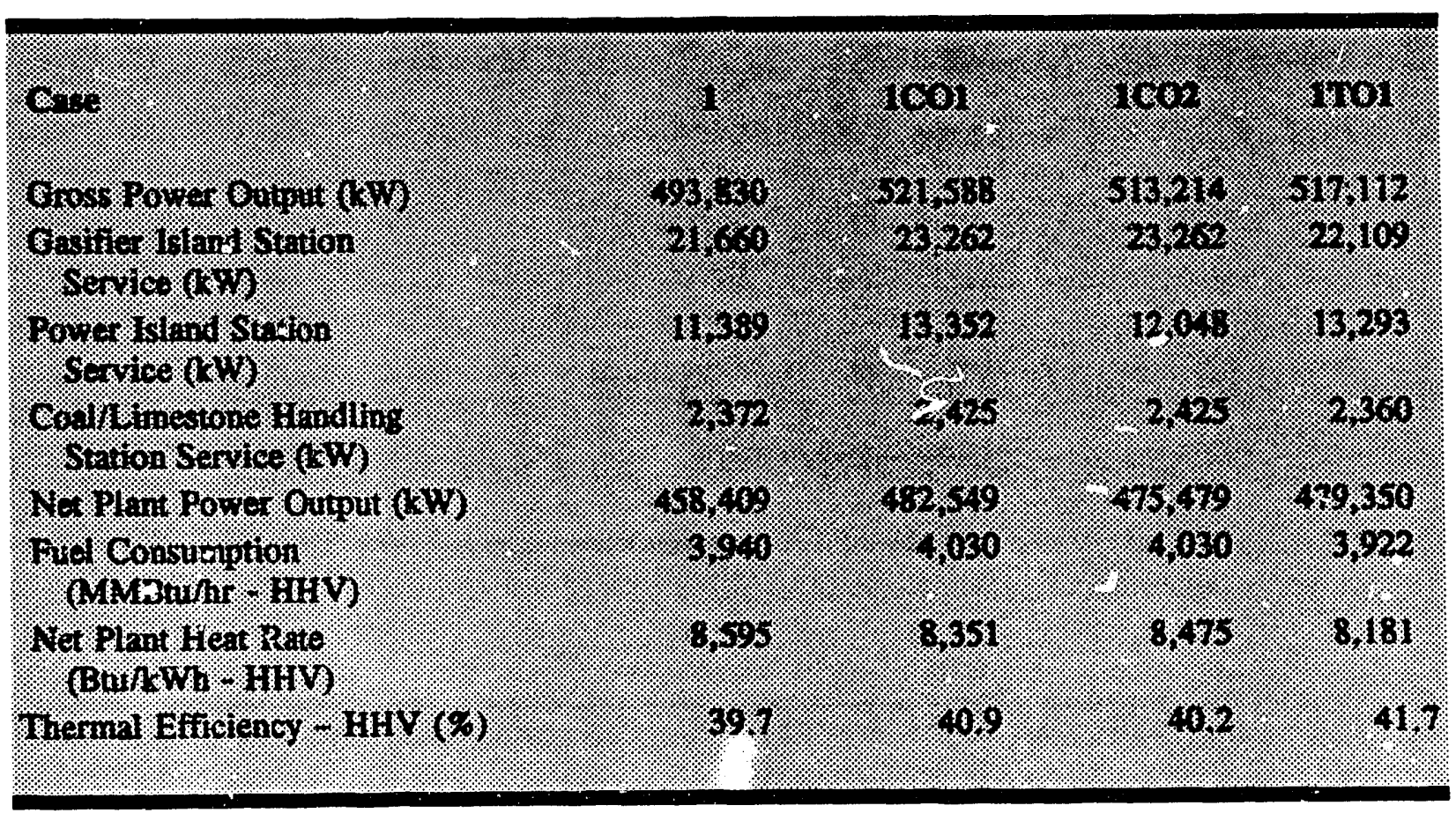


TABLE 4-18

Detailed Plant Station Service Values (All Values in Kilowatts)

\begin{tabular}{|c|c|c|c|c|}
\hline$(x)$ & ; & 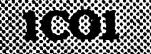 & 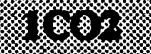 & $3 x^{3}$ \\
\hline \multicolumn{5}{|l|}{ 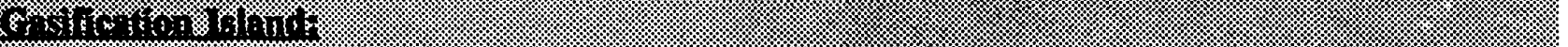 } \\
\hline 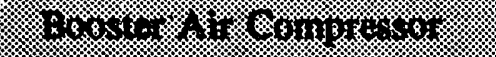 & 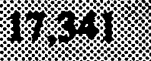 & 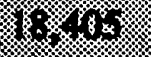 & $(3,498)$ & 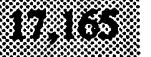 \\
\hline 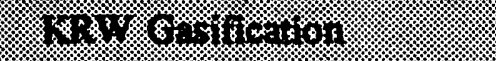 & 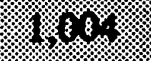 & 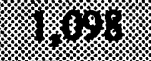 & 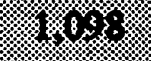 & 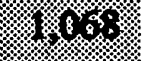 \\
\hline 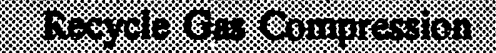 & 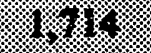 & 4 & (x) & 48 \\
\hline (3) & 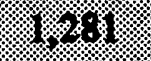 & 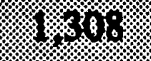 & 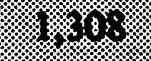 & 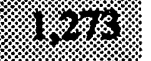 \\
\hline (1) & 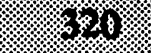 & 60,8 & $4 y$ & 23 \\
\hline 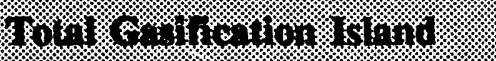 & 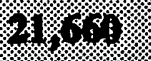 & 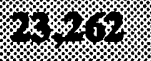 & 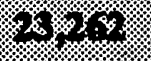 & 40 \\
\hline \multicolumn{5}{|l|}{ 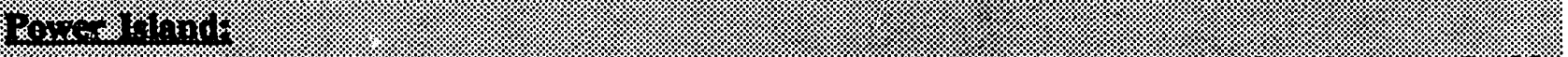 } \\
\hline 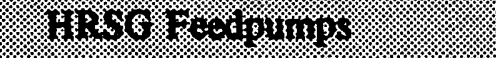 & 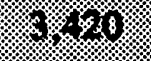 & 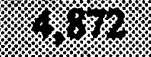 & 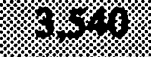 & 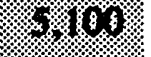 \\
\hline (6) & 4 & 6) & 9 & \%) \\
\hline (6) & 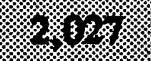 & 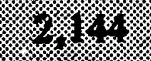 & (\%) & $28.8 \%$ \\
\hline 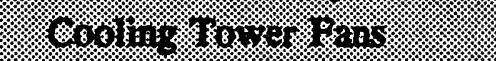 & $6.38 \%$ & 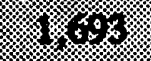 & $\left(\frac{1}{x}\right)$ & 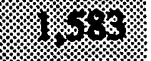 \\
\hline 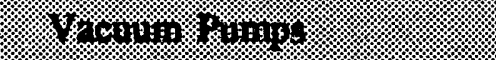 & $6 \%$ & 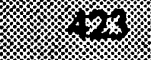 & 36 & 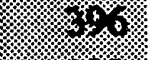 \\
\hline 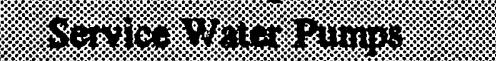 & 4 & $8 x$ & 48 & 2, \\
\hline 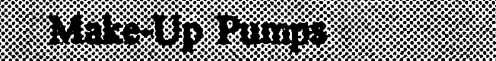 & (y) & \%: & 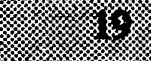 & ?. \\
\hline 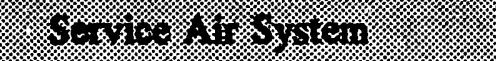 & 40 & 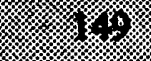 & $(3)$ & 49 \\
\hline 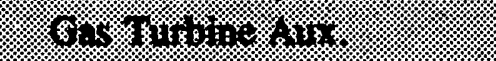 & 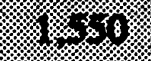 & 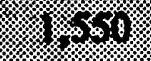 & (4) & $x^{2}+3$ \\
\hline (5) & 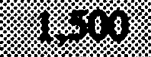 & 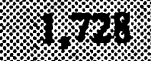 & (3. & 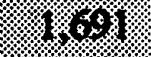 \\
\hline 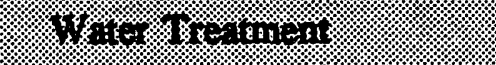 & 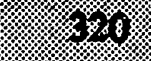 & 920 & 28 & 80 \\
\hline 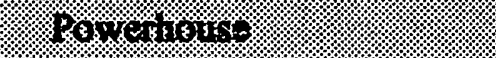 & 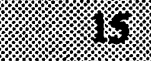 & /6. & 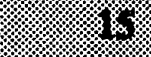 & (6) \\
\hline 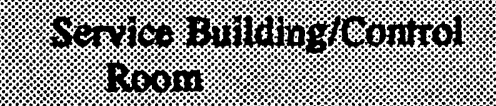 & $\xi$ & 48. & $x ;$ & \%? \\
\hline 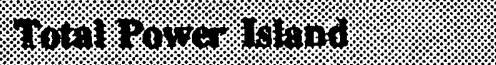 & $1 \%$ & $136 x^{2}$ & 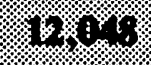 & 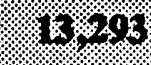 \\
\hline 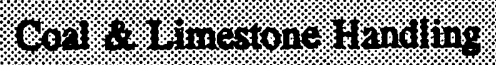 & 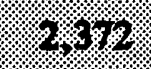 & 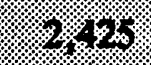 & 2.4 .8$. & 3,860 \\
\hline woris: & 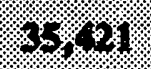 & $6 \% 139$ & 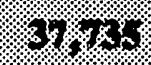 & $39 \% 6 \%$ \\
\hline
\end{tabular}




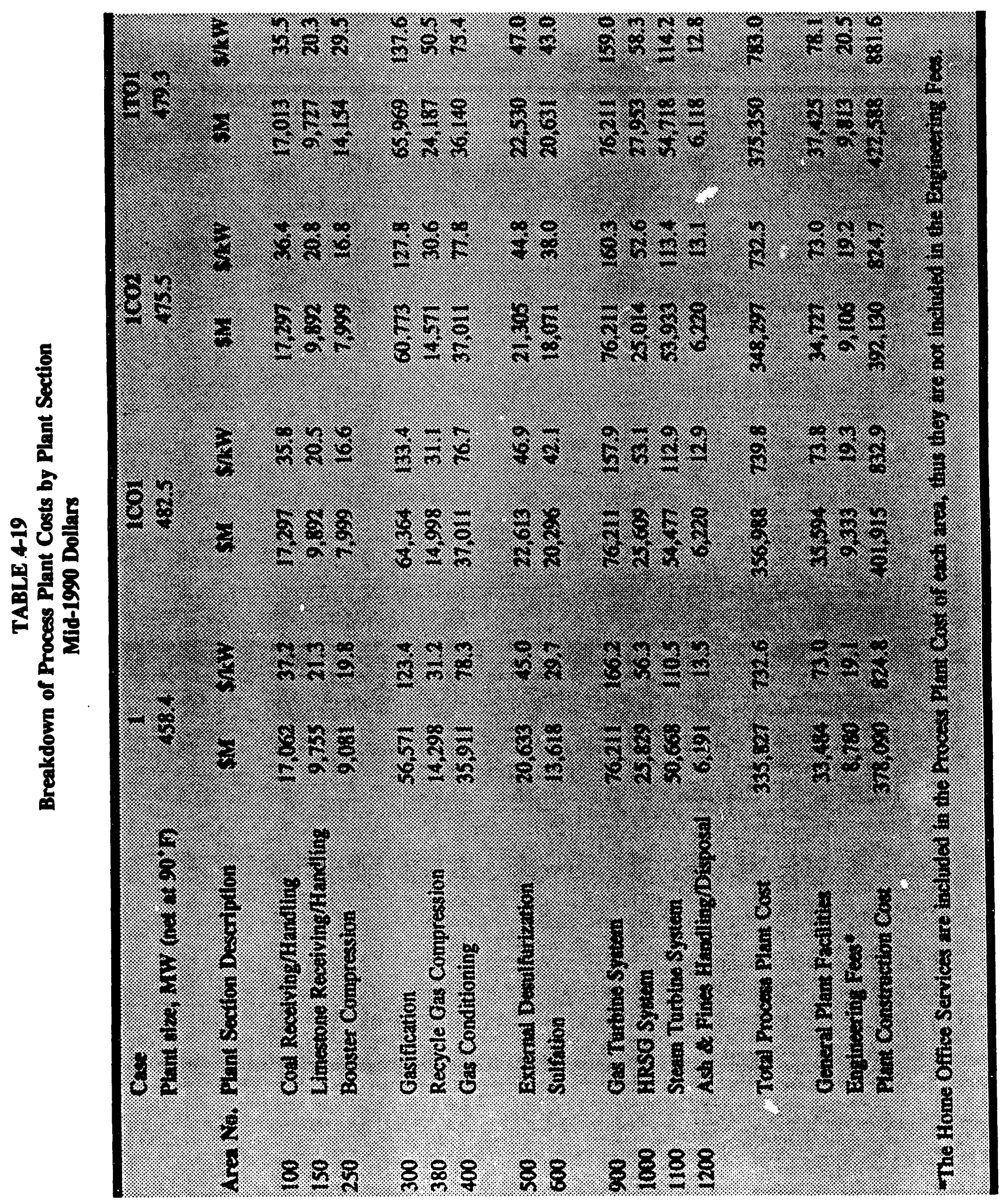


TABLE 4-20

\section{Comparison of Capital Costs \\ Mid-1990 Dollars}

\begin{tabular}{|c|c|c|c|c|c|c|c|c|}
\hline$(2.8)$ & \multicolumn{2}{|c|}{ 8. } & \multicolumn{2}{|c|}{$(2801)$} & \multicolumn{2}{|c|}{ (6) } & \multicolumn{2}{|l|}{ Wus } \\
\hline \% & $4 \%$ & 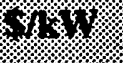 & $4=$ & M1 & 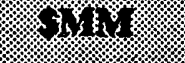 & $4 \%$ & $\because \%$ & $\%$ \\
\hline 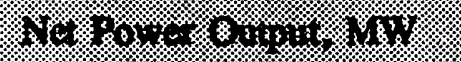 & \multicolumn{2}{|c|}{$688 \%$} & \multicolumn{2}{|c|}{$4 x$} & \multicolumn{2}{|c|}{ 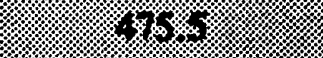 } & \multicolumn{2}{|c|}{ 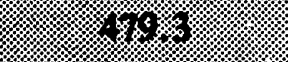 } \\
\hline 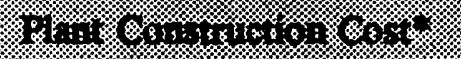 & (2) & 6.96 & 43 & $8.8 x$ & 1098. & 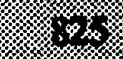 & 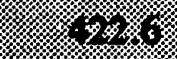 & 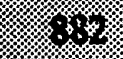 \\
\hline 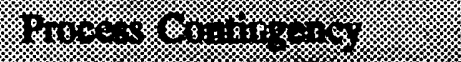 & 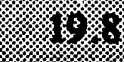 & 8 & 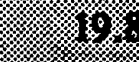 & 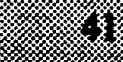 & $4 \%$ & r. & 好 & \% \\
\hline 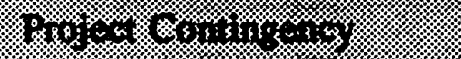 & 13.8 & 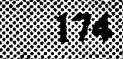 & 8 & $\sqrt[3]{60}$ & 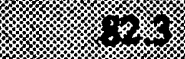 & 䋺俢 & 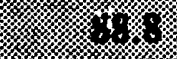 & 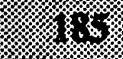 \\
\hline 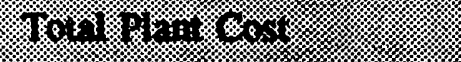 & $8 \%$ & 8 & $x^{2}+x^{8}$ & 8 & 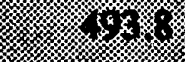 & 30 & 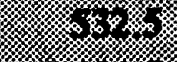 & 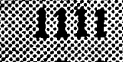 \\
\hline 3ity & 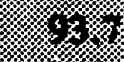 & (3.8\% & 3 & 3 & 40 & $4.8,1$ & 4 & 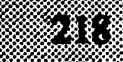 \\
\hline 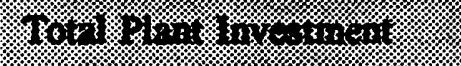 & 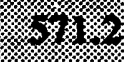 & 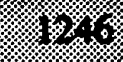 & $(x+\infty)$ & 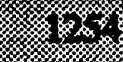 & 80968 & \% & $6 x y$ & 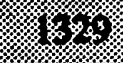 \\
\hline 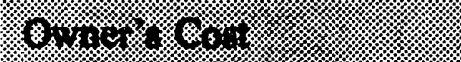 & 8,8 & 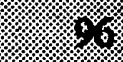 & 18 & 3 & 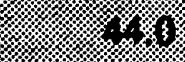 & $4 x$ & s. & 8 \\
\hline 164) & 6 & 3 & 8.8 & 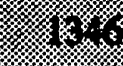 & 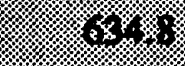 & 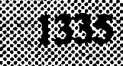 & 3 & 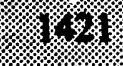 \\
\hline 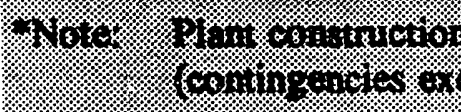 & 18 & $2 x+2)$ & 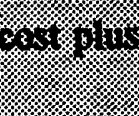 & 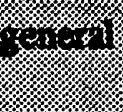 & 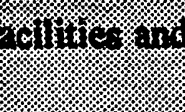 & 4. & $y=$ & \\
\hline
\end{tabular}


TABLE 4-21

COST OF ELEC:O "IMYY COMPARISONS

\begin{tabular}{|c|c|c|c|c|c|c|c|c|}
\hline \multicolumn{9}{|l|}{ Set I } \\
\hline Case & \multicolumn{2}{|c|}{1} & \multicolumn{2}{|c|}{$\mathrm{CO1}$} & \multicolumn{2}{|c|}{$\mathrm{CO2}$} & \multicolumn{2}{|c|}{ T01 } \\
\hline Capital Charges & 26.7 & $(39.8)$ & 26.8 & (39.9) & 26.6 & (39.6) & 28.3 & (42.1) \\
\hline Fuel Costs & 13.2 & $(16.3)$ & 12.8 & $(15.8)$ & 13.0 & (16.1) & 12.6 & (15.5) \\
\hline O\&M Costs & 9.1 & $(11.3)$ & 8.8 & $(10.8)$ & 8.8 & $(10.8)$ & 9.0 & $(11.0)$ \\
\hline Cost of Electricity & 49.1 & $(67.4)$ & 48.4 & $(66.6)$ & 48.4 & $(66.5)$ & 49.9 & $(68.8)$ \\
\hline
\end{tabular}

Set II

30-Year Levelized Costs (mills/kWh) at 85\% Capacity Factor Constant mid-1990 Dollars (Current Dollars)

\begin{tabular}{||l|r|r|r|r|r|r|r|r||}
\hline Case & \multicolumn{2}{|c|}{1} & \multicolumn{2}{c|}{ CO1 } & \multicolumn{2}{c|}{ CO2 } & \multicolumn{2}{c|}{ TO1 } \\
\hline Capital Charges & 16.7 & $(26.3)$ & 16.7 & $(26.4)$ & 16.6 & $(26.2)$ & 17.7 & $(27.8)$ \\
\hline Fuel Costs & 13.6 & $(20.7)$ & 13.2 & $(20.1)$ & 13.4 & $(20.4)$ & 13.0 & $(19.7)$ \\
\hline O\&M Costs & 8.7 & $(13.3)$ & 8.4 & $(12.7)$ & 8.4 & $(12.7)$ & 8.6 & $(13.0)$ \\
\hline Cost of Electricity & 39.0 & $(60.3)$ & 38.3 & $(59.2)$ & 38.4 & $(59.3)$ & 39.2 & $(60.6)$ \\
\hline
\end{tabular}




\subsection{PARAMETRIC STUDIES}

This section discusses the effect of some important design parameters on the efficiency and cost of electricity (30 year levelized costs in constant mid-1990 dollars at 85 percent capacity factor). This effect is shown for the design configurations of the original Case 1 and Cases 1CO1, 1CO2 and 1TO1. When one parameter is varied, the plant configuration and the values of the remaining important parameters are kept constant. In the following, the effect of a design parameter is shown sometimes only for a portion of the total parameter variation range. This means that this parameter cannot be further varied without significant changes in the configuration being considered.

\subsection{THE EFFECT OF GASIFICATION TEMPERATURE}

Figures 5-1a and 5-2a illustrate the effect of the gasification temperature on the overall plant thermal efficiency and COE, respectively. In general, the plant efiiciency decreases with increasing gasification temperature (e.g., for Cases 1 and $1 \mathrm{CO} 2$ as well as for the thermodynamically optimal values at a given gasification temperature). However, the decrease in efficiency in these cases is accompanied by a decrease in the total plant investment costs. The configuration of Case 1CO1 shows the opposite behavior: In the gasification temperature range of $1900^{\circ} \mathrm{F}-1940^{\circ} \mathrm{F}$, both the overall plant efficiency and the total plant investment costs increase with increasing gasification temperature.

The cost of electricity is lowest in the gasification temperature range of $1880^{\circ} \mathrm{F}$ to $1940^{\circ} \mathrm{F}$ in the configurations of the original Case 1 and Cases $1 \mathrm{CO} 1$ and $1 \mathrm{CO} 2$. These minimal COE values express the best trade-off between investment costs and fuel costs when the gasification temperature is varied.

\subsection{THE EFFECT OF COAL MOIST URE}

The effect of coal moisture on plant efficiency and COE is demonstrated in Figures $5-1 b$ and 5-2b. With increasing coal moisture, the total plant efficiency increases in Case 1TO1, whereas it slightly decreases in Cases $1 \mathrm{CO} 1$ and 1CO2. The COE, however, continually decreases in all cases with increasing coal moisture at the gasifier inlet. This effect can be explained by (a) the more effective use of the heat of the sulfation area combustion gas, and (b) the decrease in the investment and O\&M costs of the zinc ferrite unit with increasing coal moisture.

\subsection{THE EFFECT OF HP STEAM PRESSURE}

As indicated previously, the steam high pressure value $\left(\mathrm{P}_{\mathrm{HP}}\right)$ has a significant 
impact on the interaction between the gasification and power islands and, thus, the efficiency and cost of electricity of the IGCC power plant. Figures 5-1c and 5-2c present the effect of $\mathbf{P}_{\mathrm{HP}}$ on these parameters. In general, the overall plant efficiency increases with increasing $P_{\mathrm{HP}}$ value. This value, however, cannot be meaningfully varied in a wider range than the one shown in Figures 5-1 and 5-2 without important changes in the design configuration.

The COE values as a function of $\mathbf{P}_{\mathrm{HP}}$ are lowest at the $\mathbf{P}_{\mathrm{HP}}$ design values for each case (2055 psia and 1515 psia for Cases $1 \mathrm{CO} 1$ and 1CO2, respectively). In Case 1TO1 the COE decreases with decreasing $P_{H P}$, but then this case no longer represents the thermodynamic optimum. The relatively high slope of the curves in Figures 5-1c and 5$2 \mathrm{c}$ indicates the importance of this pressure value on the final results.

The increased plant efficiency achieved with higher pressure steam needs to be balanced against the effect of capacity turndown on the HRSG performance. Operation of the gas turbine at a capacity factor below $80 \%$ might require a disproportional reduction in the fuel supplied to the gas turbine. In this case, both the inlet and outlet temperatures of the gas turbine are reduced. This reduction can affect significantly the temperature pinches in the HRSG, and, consequently, the HRSG operation at partial load. 


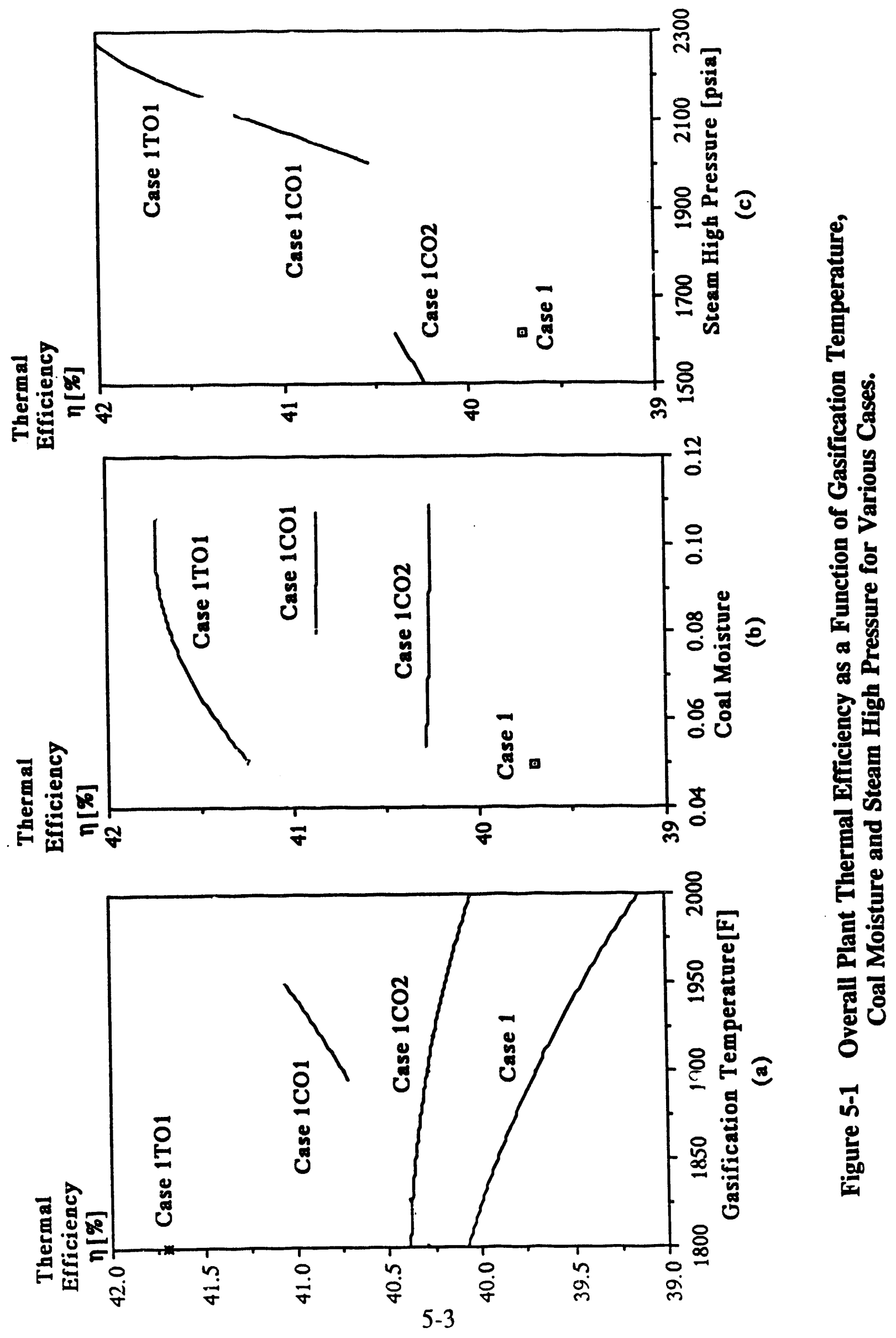



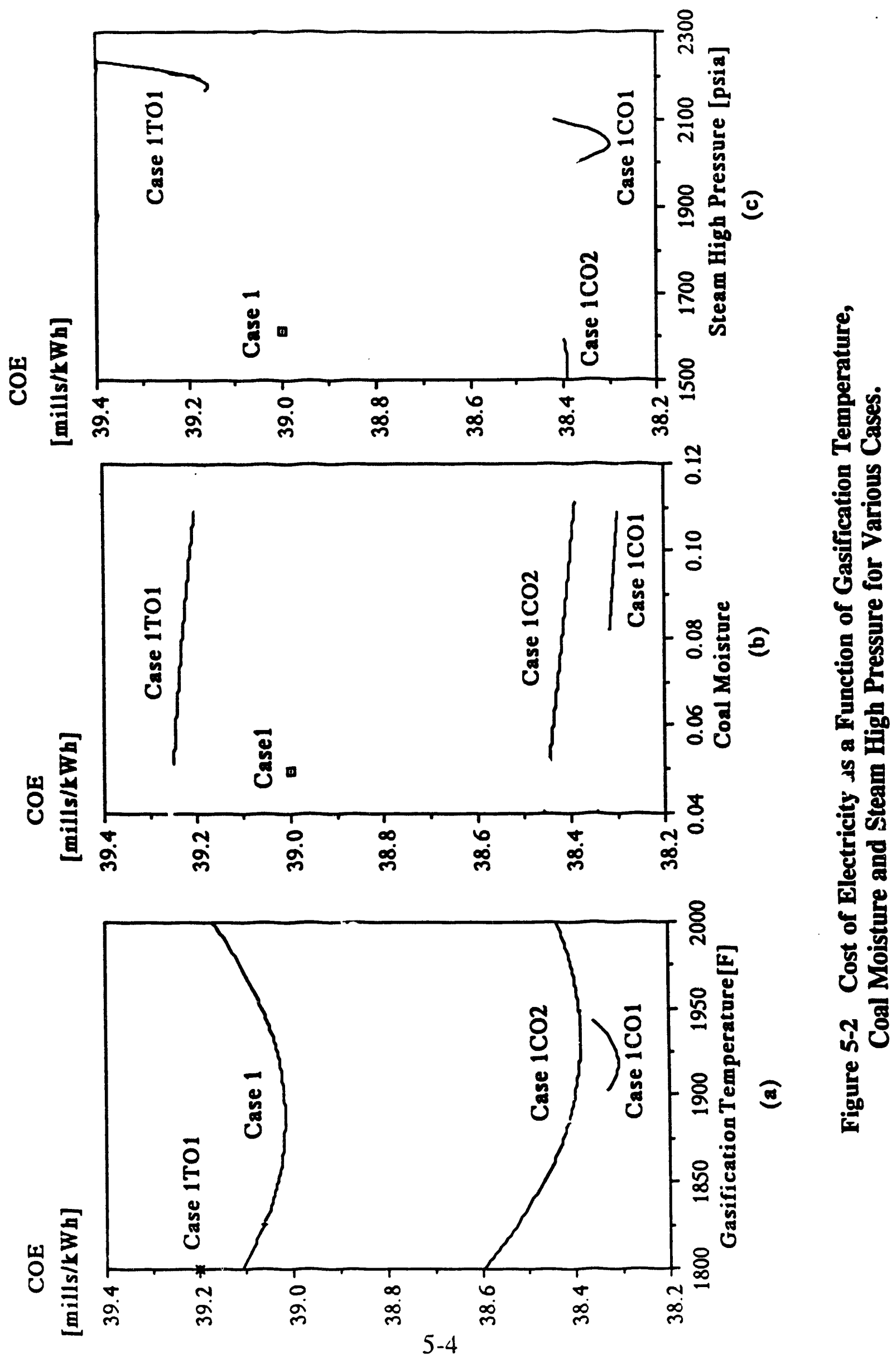


\subsection{THE EFFECT OF GAS TURBINE PERFORMANCE}

Factory prototype evaluations and engineering tests performed on the Virginia Power (Chesterfield) MS7001F gas turbine have enabled GE to refine the computer model used for gas turbine performance predictions and to relax some of the application restrictions. The torque limit in the gas turbine was raised to the equivalent of $192 \mathrm{MW}$ electric power between October 1989 and October 1991. This, combined with the increase in air flow and effective firing temperature, increased the generator output by 9.2 MW for Case 1C, as shown in Table 5-1. When the ambient temperature is $59^{\circ} \mathrm{F}$, instead of the $90^{\circ} \mathrm{F}$ assumed in this study, the increase in the generator output for Case $1 \mathrm{C}$ is $21.6 \mathrm{MW}$ (from 163.3 MW to 184.9 MW). Case $1 \mathrm{C}$ has a coal moisture of 11.12 weight percent and the same gasifier island configuration as Cases $1 \mathrm{CO} 1$ and $1 \mathrm{CO} 2$. The only difference is in the gasification temperature, which is $1800^{\circ} \mathrm{F}$ in Case $1 \mathrm{C}$ and $1920^{\circ} \mathrm{F}$ in Cases $1 \mathrm{CO} 1$ and $1 \mathrm{CO} 2$.

After GE supplied the new data, an attempt was made to estimate the effect of the new performance data on the overall plant efficiency and COE for the Cases 1, 1CO1, $1 \mathrm{CO} 2$ and 1TO1. Since the new gas turbine exhaust temperature is higher than the old, some design changes in the HRSG, steam high pressure $\left(\mathrm{P}_{\mathrm{HP}}\right)$, and steam cycle configuration were required. The results are summarized in Table 5-2.

The new gas turbine performance data have significant impact on the overall efficiency and the cost of electricity. Use of the new data results in (a) an increase in thirmal efficiency by 0.7-0.8 percentage points in the optimized cases, and (b) a decrease in the cost of electricity by more than 2.5 percent. Among the cases compared in Table $5-2$, Cases $1 \mathrm{CO} 1$ and $1 \mathrm{CO} 2$ are close to the corresponding optimal cases with the new gas turbine performance data. Case 1TO1, however, no longer represents the thermodynamically optimal case. This case would have a different design configuration, a higher $P_{H P}$ value than Case 1TO1, and an efficiency above 42.5 percent.

The results presented in this section confirm that the efficiency of the gas turbine system significantly affects the performance and COE in IGCC power plants. Gas turbine design improvements permitting higher firing temperatures are very desirable in IGCC applications provided that the increase in cooling air requirements does not offset most of the increase in power generation. 
TABLE 5-1

GE MS7001F Gas Turbine Performance Comparisons

\begin{tabular}{|c|c|c|c|}
\hline & \multicolumn{2}{|c|}{$9.80,1939$} & 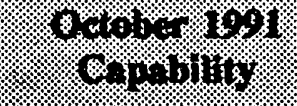 \\
\hline 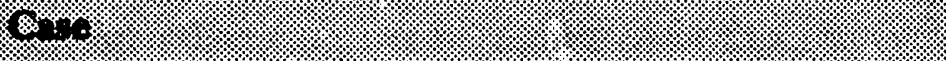 & 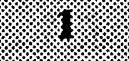 & 18. & \%) \\
\hline 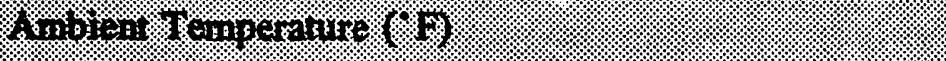 & 8\%. & \%. & \%. \\
\hline 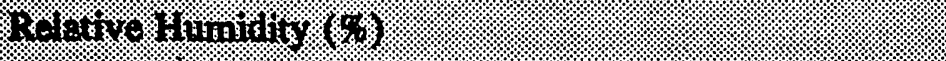 & 8.1. & 6.8. & 6. \\
\hline 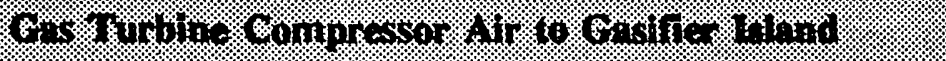 & & & ?. \\
\hline 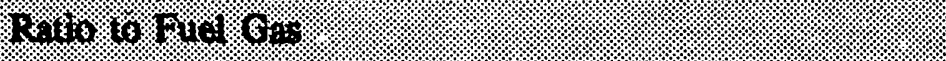 & 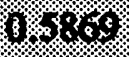 & 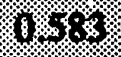 & 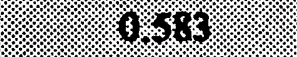 \\
\hline $4,855 \%$ \% & 349. & (n) & 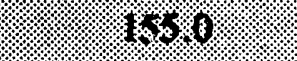 \\
\hline Heniperano $(1)$ : & $\% 0$ & 6. & 760. \\
\hline 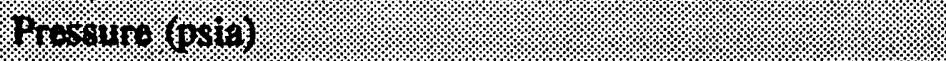 & 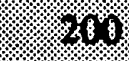 & $\%$ & (95) \\
\hline 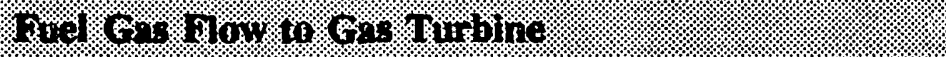 & & & \\
\hline 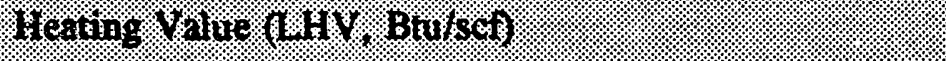 & $6 \%$ & 6.9. & $89 \%$ \\
\hline 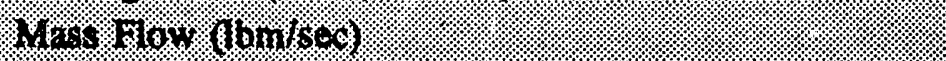 & 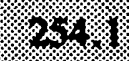 & 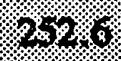 & $265 \%$ \\
\hline 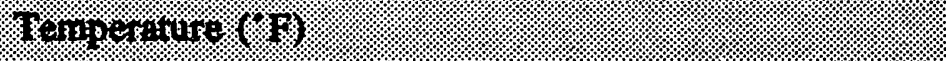 & 1883 & 188.8 & \%61. \\
\hline 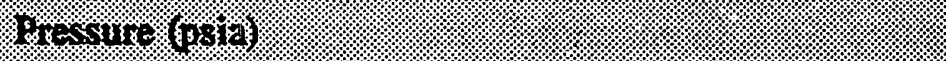 & 20. & 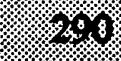 & 300 \\
\hline 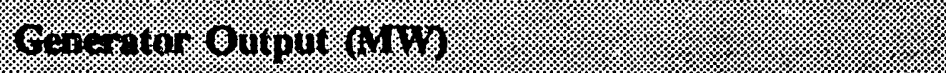 & 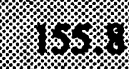 & 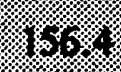 & $166 \%$ \\
\hline 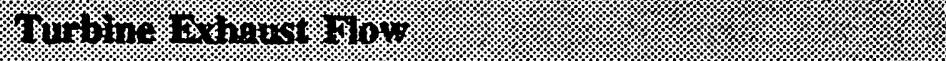 & & & \\
\hline 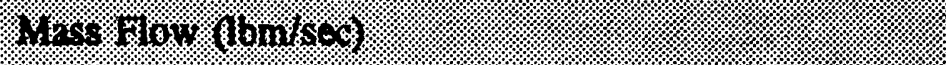 & 36 & 8.868 & (3) \\
\hline 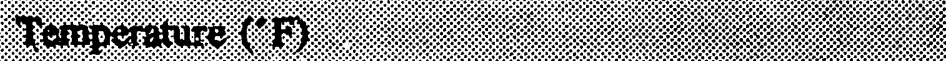 & $18 \%$ & 1305 & (3) \\
\hline 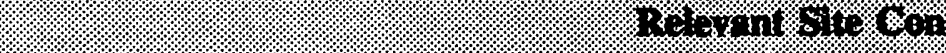 & 1018 & & \\
\hline $418 \%$ tovatron. & & & $4 \%=0$ \\
\hline 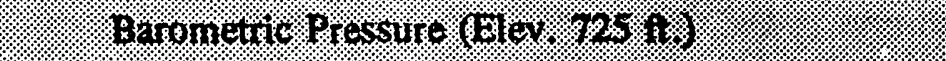 & & & \%: \\
\hline Yhiet wir pressure ross. & & & 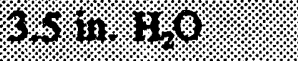 \\
\hline 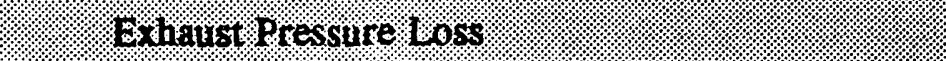 & & & 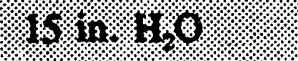 \\
\hline Steara linjection for No, Gontrol. & & & (3019: \\
\hline Supplementary fuel: & & & 10818: \\
\hline Generator Power Factor. & & & $0 \% 9$. \\
\hline 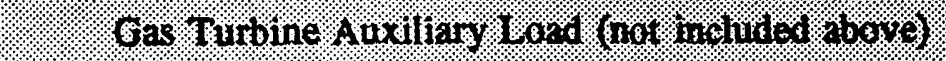 & & & $7 \%$ \\
\hline
\end{tabular}




\section{$10 \mathrm{BDH}: 5 \% 2$}

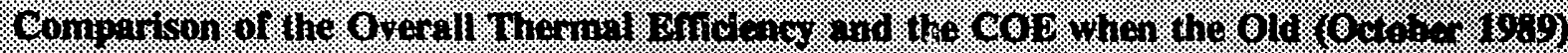

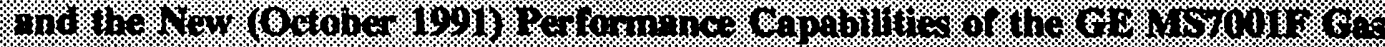

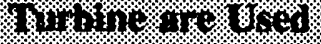

\begin{tabular}{|c|c|c|c|c|c|}
\hline \multirow[b]{2}{*}{ engere } & \multirow[b]{2}{*}{ imessuriti? } & \multicolumn{2}{|c|}{ 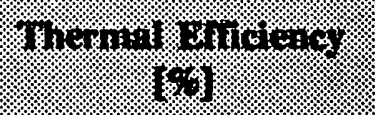 } & \multicolumn{2}{|c|}{ (9. } \\
\hline & & 1819 & 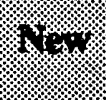 & 8010 & 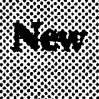 \\
\hline 8 & $1600 \%$ & $39.1 \%$ & 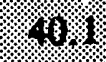 & 1960 & 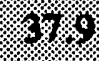 \\
\hline $180 \%$ & 21.5. & 100 & 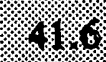 & 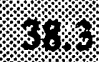 & $1 \%$ \\
\hline 108 & (1515: & $.10 \%$ & 4.40 & 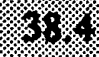 & 3) \\
\hline 1401 & 2250 & 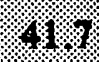 & 42.1. & 898 & $.9 \%$ \\
\hline
\end{tabular}

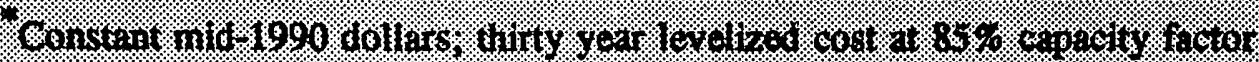

\subsection{COST OF ELECTRICITY SENSITIVITY STUDIES}

Simple sensitivity analyses for the cost of electricity were conducted to evaluate the effect of some uncertainties associated with the COE estimation process. Figures 5-3 through 5-5 show the sensitivity of COE (expressed in current dollars) to total plant cost, real escalation rate for coal cost, and plant capacity factor, respectively. The sensitivity is presented for two sets of values. Set I refers to ten-year levelized costs at 65 percent capacity factor. Set II represents thirty-year levelized costs at 85 percent capacity factor. In these figures the cost differences between Cases 1CO1 and 1CO2 are small.

Most of the uncertainty in capital cost estimation is associated with the gasification island because the major processes therein have little or no commercial history. An overrun in estimated total plant cost affects Case 1TO1 more than the remaining cases, particularly in set $I$. The effect of total plant cost on COE is larger in set I than in set II while the effect of real escalation rate for coal cost is stronger in set II. The plant capacity factor has a dominant influence on COE, as shown in Figure 5-3. When the capacity factor changes from 65 percent to 85 percent, the savings in the COE are more than 15 percent in set I and more than 20 percent in set II. The results shown in Figure 5-5 assume that the plant will operate between 65 and 85 percent of the time at 100 percent capacity. If the given capacity factor value is obtained through plant operation at reduced capacity, the effect of capacity factor on the COE is more pronounced. 


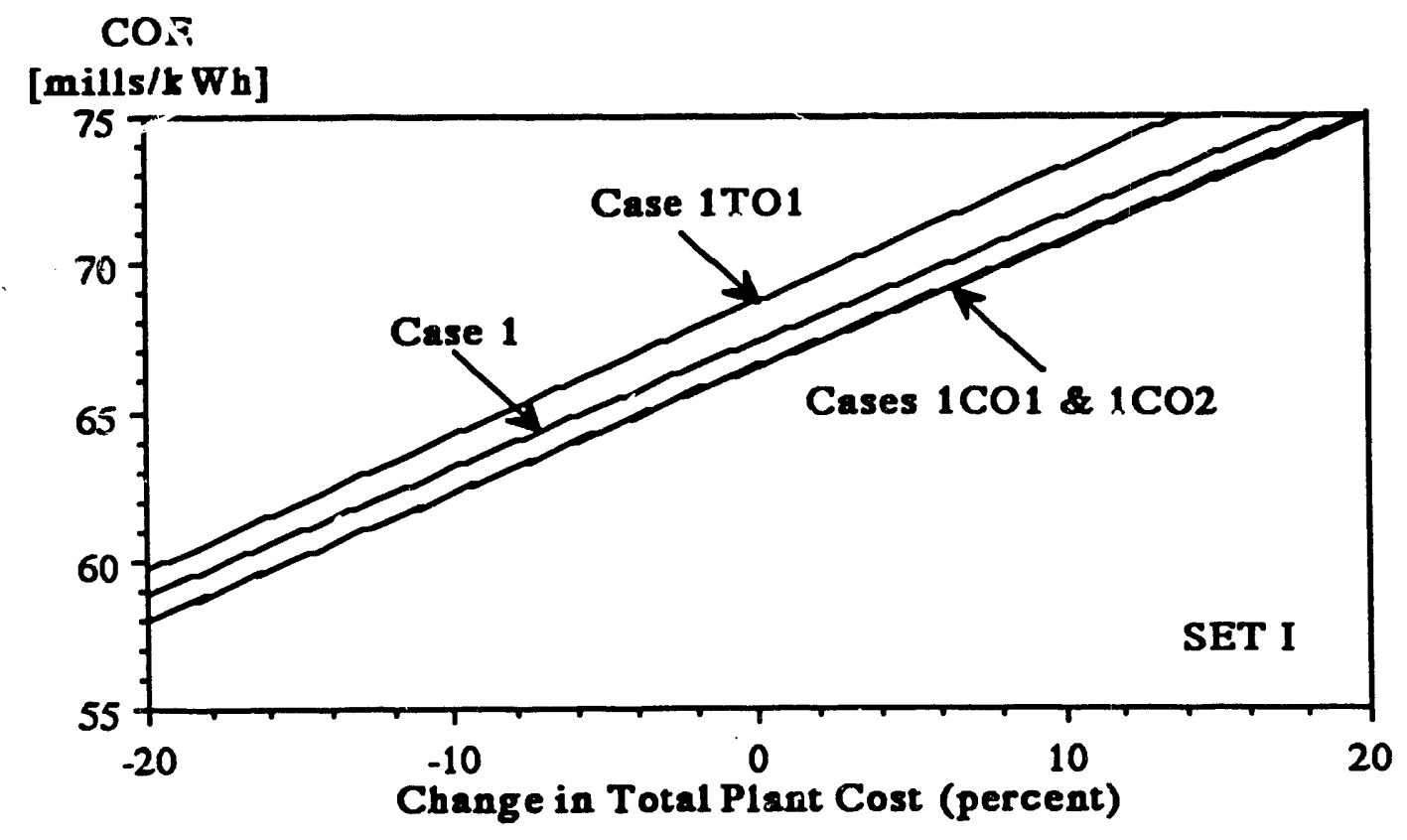

COE

[mills/kWh]

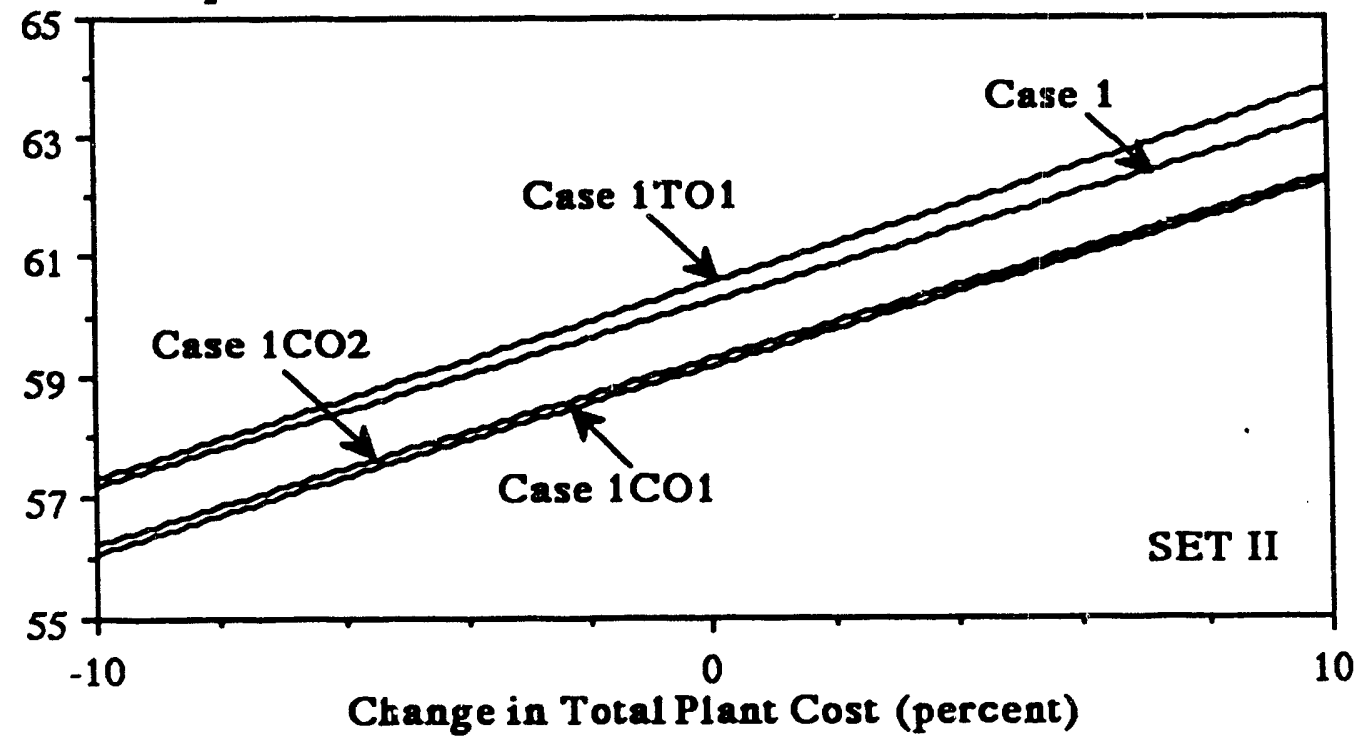

Figure 5-3 Sensitivity of COE (Current Doilars) to Changes in Total Plant Cost Set I: Ten-Year Levelized Cost; 65\% Capacity Factor

Set II: Thirty-Year Levelized Cost; 85\% Capacity Factor 

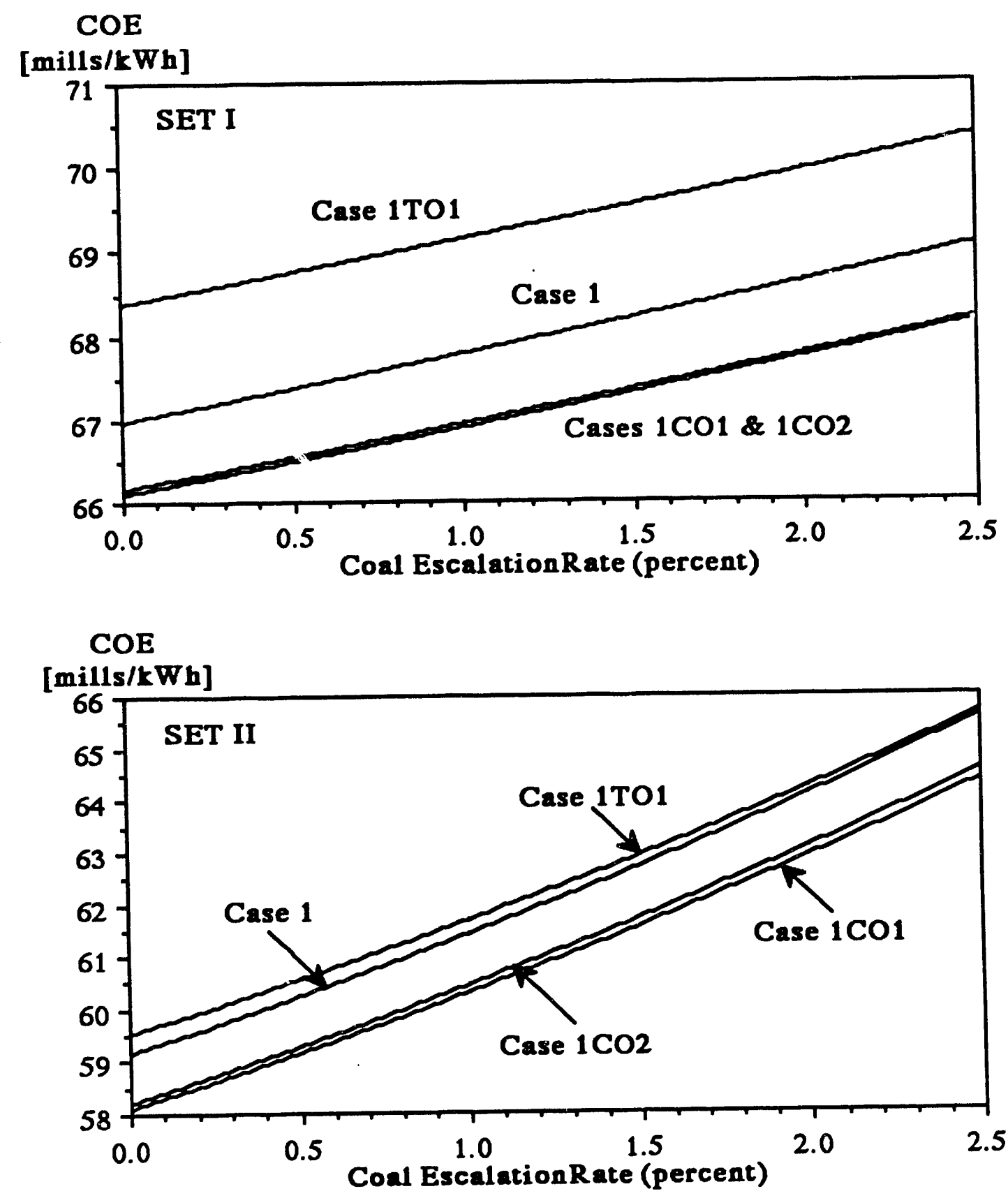

Figure 5-4 Sensitivity of COE (Current Dollars) to Changes in Real Escalation Rate of Coal Cost

Set I: Ten-Year Levelized Cost; 65\% Capacity Factor

Set II: Thirty-Year Levelized Cost; 85\% Capacity Factor 

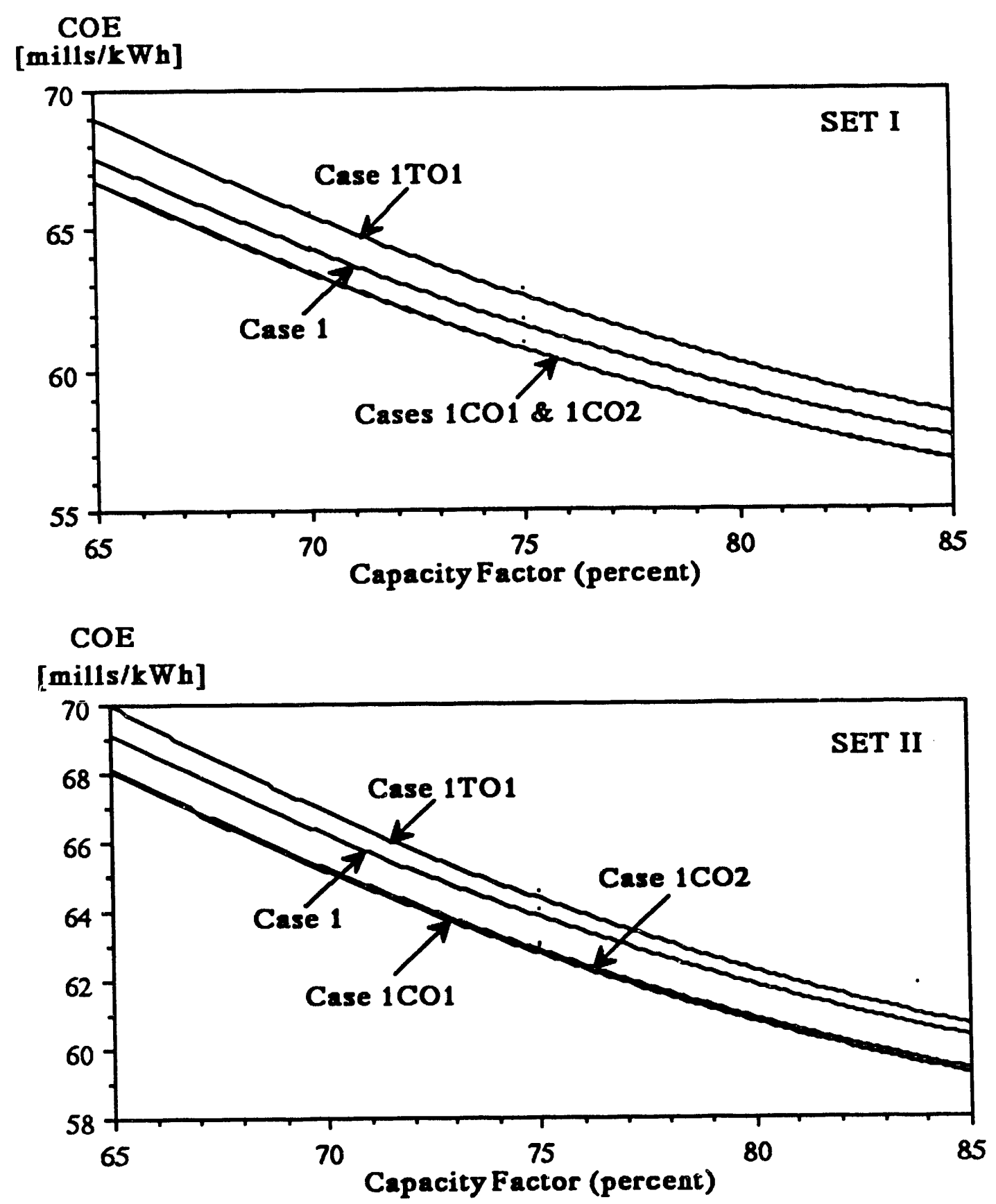

Figure 5-5 Sensitivity of COE (Current Dollars) to Changes in Plant Capacity Factor

Set I: Ten-Year Levelized Cost; 65\% Capacity Factor

Set II: Thirty-Year Levelized Cost; 85\% Capacity Factor 


\subsection{CONCLUSIONS AND RECOMMENDATIONS}

Several IGCC power plant concepts based on air-blown gasification with hot gas cleanup were investigated in this study. The results were compared on the basis of efficiency and cost of electricity. The primary motivations for the study were to develop cost optimal design configurations and to understand the effects of important design parameters on efficiency and cost of electricity.

In addition to the original Case 1, which was developed in a previous study [1], three cases are discussed in this report. Two of them were optimized from the cost viewpoint and the third from the thermodynamic viewpoint. The comparisons among these cases are considered to be accurate when compared to each other since they were based on the same underlying assumptions. In evaluating the results from similar studies we should keep in mind that, in general, the results of performance predictions are more accurate than the results of cost estimates.

Table 6-1 compares the performance of the four cases discussed here. Table 6-2 provides a summary of estimated capital costs, O\&M costs and cost of electricity. The major difference between the cost optimal Cases 1CO1 and 1CO2 is in the steam high pressure values which are 2055 psia and 1515 psia, respectively. Case 1 CO1 has a lower heat rate $(8351 \mathrm{Btu} / \mathrm{kWh})$ but a slightly higher total capital requirement $(1346 \$ / \mathrm{kW})$ than Case 1CO2. Assuming thirty-year levelized costs at 85 percent capacity factor, Case $1 \mathrm{CO} 1$ possesses the lowest cost of electricity $(38.3 \mathrm{mills} / \mathrm{kWh}$ in constant mid-1990 dollars) among all four cases. When ten-year levelized costs at 65 percent capacity factor are assumed, both Cases 1CO1 and 1CO2 have practically the same cost of electricity. The performance and cost advantages of these cases over the original Case 1 are attributable to the optimization of the steam high pressure, gasification temperature, coal moisture at the gasifier inlet, steam turbine, and overall heat exchanger network.

Case 1TO1 represents the thermodynamically optimal case and was included here to demonstrate the potential for improving the overall plant efficiency. The thermal efficiency of this case is 41.7 percent, an improvement of about 5.0 percent compared with the original Case 1 (39.7 percent). This improvement is achieved with an increase of only about 0.5 percent in the cost of electricity. It should be noted that other cases not presented in this report with slightly lower efficiencies than Case 1TO1 have lower cost of electricity than the original Case 1 . The three optimized cases present a lower environmental impact than the original Case 1, primarily due to their higher overall thermodynamic efficiency.

The difference in the cost of electricity between Case $1 \mathrm{CO}(1 \mathrm{CO})$ and the original Case 1 results in savings of over 2.4 (2.2) million constant (mid-1990) dollars 
TABLE 6-1

\section{Summary of Gasification Power Plant Performance}

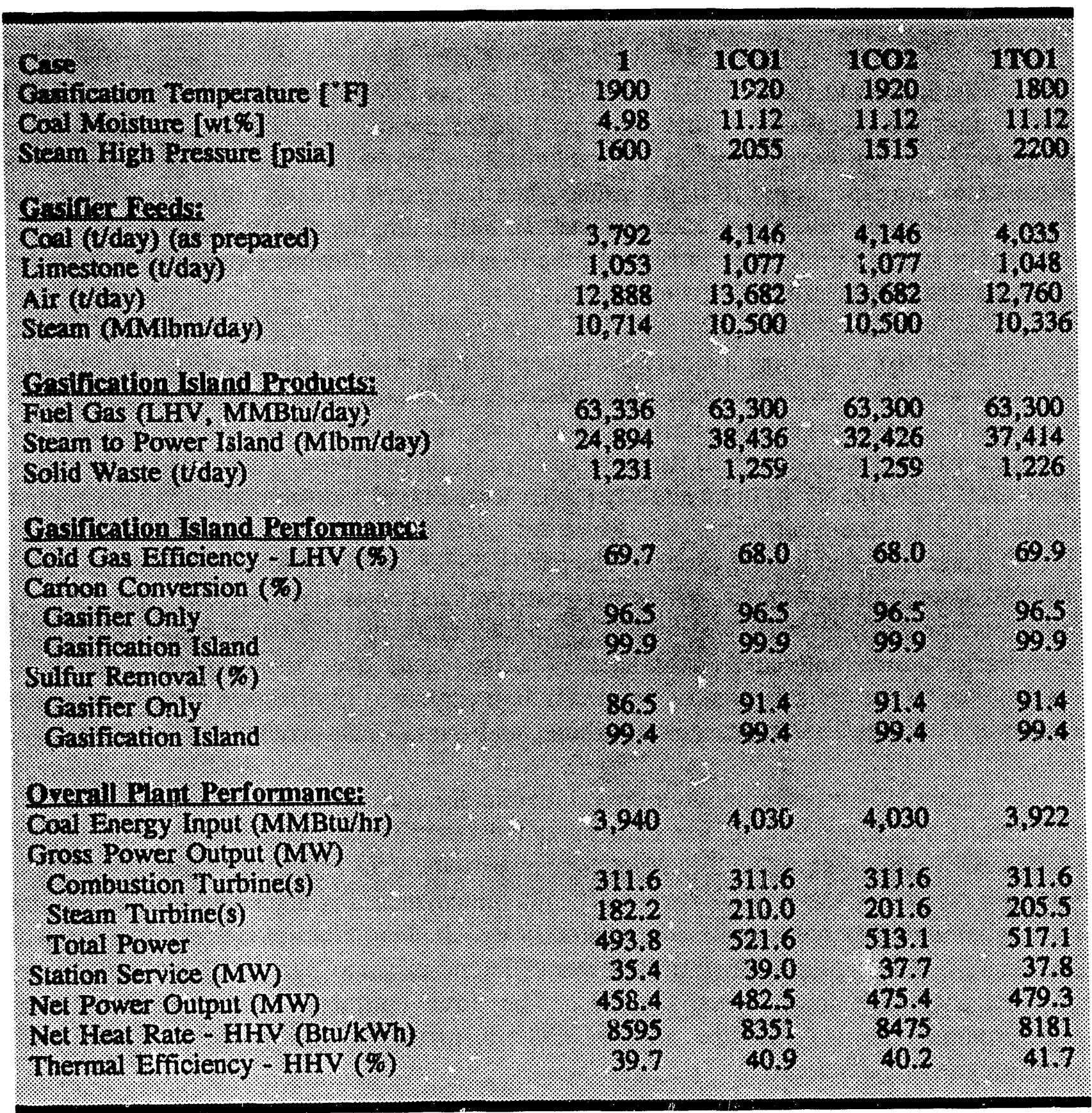


TABLE 6-2

Summary of Gasification Power Plant Costs

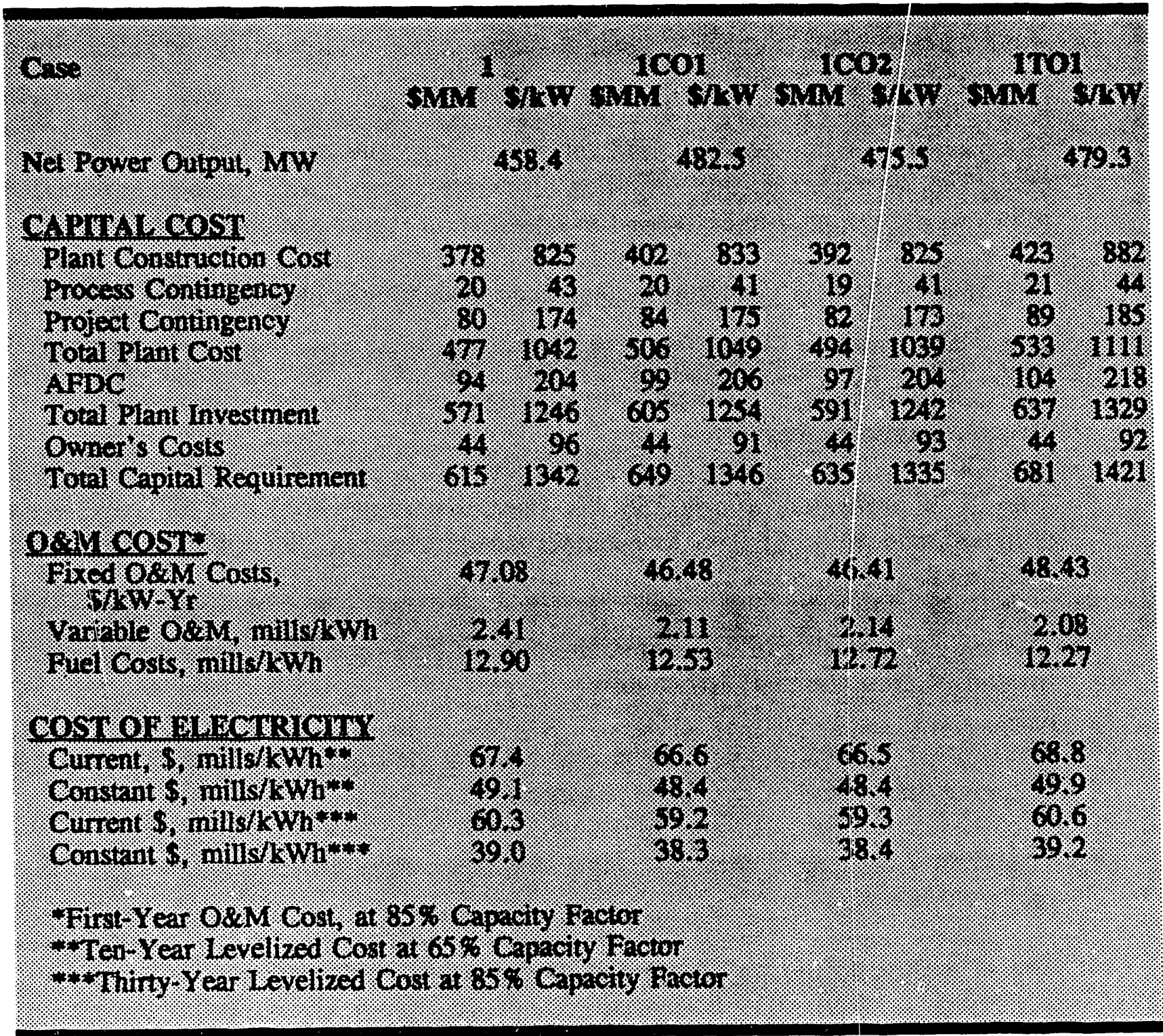


per year of plant operation. Compared with the original Case 1, the thirty-year pre-tax present values of the cost savings in Cases $1 \mathrm{CO} 1$ and $1 \mathrm{CO} 2$ are 30.0 and 27.7 million constant mid-1990 dollars, respectively.

This study identified several design changes which improve the cost effectiveness of the Case 1 IGCC concept. These changes include the following:

- The coal should be supplied to the gasifier with the as received moisture of 11.12 weight percent, or with the highest moisture content allowed by the reliability of the coal feeding process.

- The gasification temperature and the steam high pressure should be optimized using the thermoeconomic variables discussed in section 3. This optimization refers to the interaction between the gasification island and the power island.

- The heat of the flue gas from the sulfation area should be used in the HRSG.

- The mass flow rate of the quench steam should be decreased and its temperature increased through adjustments in the steam turbine and elimination of the desuperheating process.

- The BFW preheater in area 250 (air booster compression) and the recycle gas cooler should preheat LP (or low-temperature) instead of HP (or high-temperature) feedwater.

- The recycle gas should be extracted from the clean gas after the exit gas cooler instead of after the zinc-ferrite unit.

- The size of the product gas cooler and the exit gas cooler should be increased to accommodate some of the above changes.

- The design of the HP steam turbine should be adjusted to the new steam high pressure values.

- The deaerator should be operated at the lowest possible pressure.

- At least one LP steam extraction should be used to preheat feedwater.

These recommendations refer only to the design of Case 1 and should not be used automatically in conjunction with other IGCC concepts. The cost uptimal Cases 1 CO1 
and $1 \mathrm{CO} 2$ are certainly not unique. Other design configurations can be found with comparable cost of electricity values.

Future studies should include investigation of the economic feasibility of design options aimed at eliminating or modifying the external desulfurization step and the gas recycling process. Significant performance and cost benefits should be expected from the elimination or modification of these processes.

The thermoeconomic analysis and optimization techniques were very useful tools in conducting this study. Some optimization techniques were refined during the investigations and will be applied to future design optimizations of IGCC plants and other energy systems.

The parametric study conducted to investigate the impact of major design parameters on the efficiency and cost of electricity established the importance of the gas turbine performance, the steam high pressure, and the gasification temperature for the cost optimization process. The cost sensitivity studies confirmed that the plant capacity factor is the most important variable for cost-effective plant operation. 


\subsection{REFERENCES}

1. Southern Company Services, "Assessment of Coal Gasification/Hot Gas Cleanup Based Advanced Gas Turbine Systems," Final Report prepared for the U.S. Department of Energy, Morgantown Energy Technology Center, Contract No. DE-FC21-89MC26019, December 1990.

2. Gallaspy, D. T., Johnson, T. W. and Sears, R. E., "Southern Company Services Study of a KRW-Based GCC Power Plant, " EPRI GS-6876, RP 2773-5, Final Report, Electric Power Research Institute, Palo Alto, CA, July 1990.

3. Tsatsaronis, G. and Tawfik, T., "Study of a Revised KRW-Based GCC Power Plant for Plant Wazsley," Final Report prepared for Southern Company Services (Contract No. SS90-1384) and EPRI (RP 2773-5), Tennessee Technological University, Center for Electric Power, December 1990.

4. Eisermann, W., Hasberg, W. and Tsatsaronis, G., "THESIS - A Computer Program for the Simulation and Design of Energy-Conversion Plants, " BrennstoffWärme-Kraft, 36 (1984) No. 1-2, pp. 45-51.

5. Tsatsaronis, G. and Winhold M., "Thermoeconomic Analysis of Power Plants," EPRI AP-3651, RP 2029-8, Final Report, Electric Power Research Institute, Palo Alto, CA, August 1984.

6. Tsatsaronis, G., Winhold, M. and Stojanoff, C. G., "Thermoeconoi:" Analysis of Gasification-Combined-Cycle Power Plants, " EPRI AP-4734, RP 2029-8, Final Report, Electric Power Research Institute, Palo Alto, CA, August 1986.

7. Tsatsaronis, G., "Thermoeconomic Analysis and Optimization of Energy Systems," Progress in Energy and Combustion Science, to be published, 1992.

8. Tsatsaronis, G. and Valero, A., "Thermodynamics Meets Economics, " Mechanical Engineering, August 1989, pp. 84-86.

9. Electric Power Research Institute, TAG ${ }^{\text {Th }}$ - Technical Assessment Guide, Vols. 14, EPRI P-4463-SR, 1986.

10. Linnhoff, B., et al., A User Guide on Process Integration for the Efficient Use of Energy, The Institution of Chemical Engineers, England, 1983. 
APPENDIX 


\begin{abstract}
APPENDIX
This Appendix presents some detailed results of the thermoeconomic analysis of Cases 1 and 1CO1. The variables shown here were used in the thermoeconomic evaluation and optimization of the cases discussed in this report.
\end{abstract}




\section{TABLE A-1}

Cost of Fuel (c $)$, Cost of Product ( $\left.c_{p}\right)$, Relative Cost Difference (d), Investment Cost Rate (Z), Cost Rate of Exergy Destruction (D), and Thermoeconomic Factor (f)

for each Area in the Original Case 1

Area

Area 250 Booster Compression

Area 300 KRW Gasification

Area 380 Recycle Gas Compression

Area 400 Gas Conditioning

Area 500 External Desulfurization

Area 600 Sulfation

Area 900 Gas Turbine System

Area 1000 Heat Recovery Steam Generator

Area 1100 Steam Cycle

Gasification Island

Power Island

Total Plant

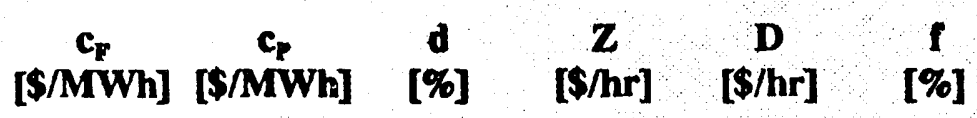

17.94

7.32

10.53

12.49

10.21

7.31

9.62

14.83

20.78

38.11

112.36

135.4

889.7

234.5

15.49

36.21

47.03

16.92

14.60

607.8

10.42

2.07

22.17

203.20

330.8

20.26

$110.54 \quad 1190.6$

19.61

$32.21 \quad 403.6$

33.38648 .8

7.40

11.69

11.31

$52.89 \quad 2431.7$

$94.70 \quad 2242.9$

4214.6

5.72

39.02

$582.20 \quad 4674.6$

4125.5

53.12 


\section{TABLE A-2}

Cost of Fuel ( $\left.c_{F}\right)$, Cost of Product $\left(c_{\mathrm{P}}\right)$, Relative Cost Difference (d), Investment Cost Rate (i்), Cost Rate of Exergy Destruction (D), and Thermoeconomic Factor (I) for each Area in Case $1 \mathrm{CO1}$

\author{
Area \\ Area 250 Booster Compression \\ Area 300 KRW Gasification \\ Area 380 Recycle Gas Compression \\ Area 400 Gas Conditioning \\ Area 500 External Desulfurization \\ Area 600 Sulfation \\ Area 900 Gas Turbine System \\ Area 1000 Heat Recovery Steam Generator \\ Area 1100 Steam Cycle \\ Gasification Island \\ Power Isiand \\ Total Plant
}

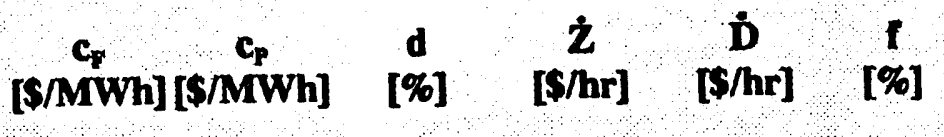

18.47

7.32

$40.75 \quad 120.63$

10.14

15.28

10.44

12.39

10.16

5.82

9.72

14.49

19.96

14.24

10.38

19.57

20.40

18.19

38.63

46.43

14.91

2.12

235.97

109.84

25.49

27.08

35.69

$\begin{array}{lll}119.3 & 181.7 & 39.63\end{array}$

$\begin{array}{lll}1005.3 & 1902.8 & 34.57\end{array}$

$\begin{array}{lll}246.0 & 35.3 & 87.46\end{array}$

$\begin{array}{llll}626.4 & 233.2 & 72.87\end{array}$

$\begin{array}{lll}229.4 & 171.8 & 57.18\end{array}$

$\begin{array}{lll}331.1 & 50.6 & 86.75\end{array}$

$1190.6 \quad 2695.9 \quad 30.63$

$\begin{array}{lll}400.1 & 365.2 & 52.28\end{array}$

$705.81086 .9 \quad 39.37$

$\begin{array}{llllllll}7.35 & 11.47 & 56.15 & 2687.3 & 2334.0 & 53.52\end{array}$

$\begin{array}{llllllll}11.94 & 22.85 & 91.38 & 2296.5 & 4260.9 & 35.02\end{array}$

$\begin{array}{llllll}5.72 & 38.31 & 569.42 & 4983.8 & 4142.2 & 54.61\end{array}$ 


\section{TABLE A-3}

Cost of Fuel ( $\left.c_{\mathrm{p}}\right)$, Cost of Product $\left(c_{\mathrm{p}}\right)$, Relative Cost Difference (d), Investment Cost Rate (i்), Cost Rate of Exergy Destruction (D), and Thermoeconomic Factor (I) for the Major Components in the Original Case 1

Area

\section{Gasifier}

2 Cyclones

3 Product Gas Cooler

6 Quench Steam Mixing

7.9 Cyclones \& Gas Filter

10 Area 600: Sulfation

11 Chloride Guard

12 Air Recuperator

13 BFW Preheater

15 Booster Air Compressor

16 Zinc Ferrite Unit

18 Exit Gas Cooler

20 Recycle Gas Cooler

21 Recycle Gas Compressor I

23 Recycle Gas Compressor II

26 Gas Turbine \& Air Compressor

27 Combustion Chamber

29 Superheater-Reheater-Blast RH

30 HP Drum

31 IP Superheater

32 IP Drum

33 HP2 Economizer

34 IP Economizer

35 HP1 Economizer

36 Feedwater Heater 1

37 Feedwater Heater 2

39 HP Turbine

43 Desuperheater

45 IP Turbine

48 LP Turbine

49 Seal Steam Regulator

52 LP Pump

54 Gland Seal Condenser

55 Deaerator

57 HP Pump

58 IP Pump

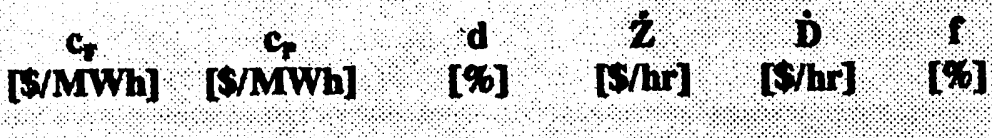

\begin{tabular}{|c|c|c|c|c|c|}
\hline 7.03 & 9.08 & 29.03 & 545.1 & 1436.7 & 27.50 \\
\hline 9.09 & 9.13 & 0.52 & 31.6 & 15.8 & 66.72 \\
\hline 9.14 & 18.72 & 104.76 & 222.3 & 225.0 & 49.70 \\
\hline 9.55 & 9.72 & 1.73 & 0.0 & 167.8 & 0.00 \\
\hline 9.97 & 9.97 & 0.00 & 479.6 & 23.4 & 95.35 \\
\hline 7.31 & 22.17 & 203.20 & 233.5 & 89.0 & 72.42 \\
\hline 9.97 & 10.11 & 1.44 & 128.2 & 14.9 & 89.62 \\
\hline 22.07 & 27.47 & 24.47 & 15.5 & 39.2 & 28.27 \\
\hline 22.19 & 31.43 & 41.67 & 30.3 & 9.3 & 76.46 \\
\hline 22.86 & 38.13 & 66.76 & 83.8 & 63.7 & 56.81 \\
\hline 10.20 & 10.20 & 0.00 & 209.8 & 100.3 & 67.67 \\
\hline 15.87 & 28.72 & 81.01 & 120.9 & 119.0 & 50.40 \\
\hline 15.93 & 46.75 & 193.43 & 83.2 & 25.5 & 76.58 \\
\hline 22.86 & 153.75 & 572.45 & 105.1 & 12.1 . & 89.71 \\
\hline 22.86 & 250.07 & 993.73 & 46.2 & $1.7 \%$ & 96.47 \\
\hline 12.91 & 19.96 & 54.63 & 1131.1 & 1066.9 & 51.46 \\
\hline 13.02 & 15.83 & 21.61 & 59.5 & 2364.1 & 2.46 \\
\hline 14.83 & 17.69 & 19.28 & 99.7 & 191.7 & 34.21 \\
\hline 14.80 & 19.45 & 31.42 & 98.7 & 512 . & 6587 \\
\hline 14.10 & 21.04 & 49.16 & 3.2 & $6.8 \%$ & 31.91 \\
\hline 14.72 & 21.05 & 42.93 & 18.3 & 41.5 & 30.63 \\
\hline 14.78 & 20.96 & 41.79 & 116.4 & 20.6 & 84.96 \\
\hline 14.18 & 23.67 & 66.99 & 1.9 & 11.1. & 14.80 \\
\hline 14.77 & 21.17 & 43.34 & 38.9 & 59.6 & 39.49 \\
\hline 14.71 & 24.27 & 64,96 & 6.4 & 61.5 & 9.48 \\
\hline 14.53 & 63.39 & 336.27 & 19.9 & 46.7 & 29.90 \\
\hline 21.76 & 26.53 & 21.92 & 133.4 & 133.2 & 50.05 \\
\hline 21.82 & 22.60 & 3.55 & 0.0 & 36.5 & 0.00 \\
\hline 21.36 & 26.19 & 22.60 & 67.2 & 68.7 & 49.47 \\
\hline 21.82 & 28.82 & 32.10 & 234.3 & 452.9 & 34.09 \\
\hline 21.48 & 35.81 & 66.69 & 1.9 & 0.5 & 79.85 \\
\hline 22.86 & 207.39 & 807.09 & 5.6 & 0.3 & 94.58 \\
\hline 35.98 & 269.53 & 649.07 & 1.9 & 4.7 & 28.47 \\
\hline 29.19 & 36.03 & 23.46 & 9.3 & 44.4 & 17.34 \\
\hline 22.86 & 40.11 & 75.42 & 14.4 & 24.9 & 36.69 \\
\hline 22.87 & 204.68 & 795.07 & 5.6 & 0.4 & 93.16 \\
\hline
\end{tabular}


TABLE A-4

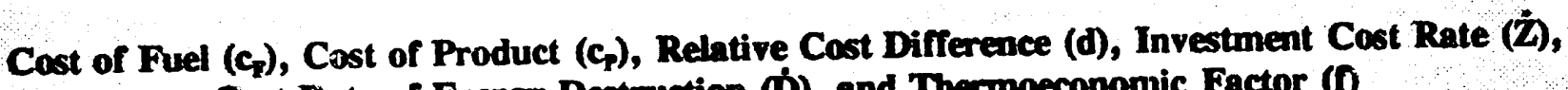
Cost Rate of Exergy Destruction (D), and Thermoeconomic Factor (f)

for the Major Components in Case $1 \mathrm{CO}$

Area
1 Gasifier
2 Cyclones
3 Product Gas Cooler
6 Quench Steam Mixing
$7-9$ Cyclones \& Gas Filter
10 Area 600: Sulfation
11 Chloride Guard
13 Air Recuperator
14 BFW Preheater
16 Booster Air Compressor
17 Zinc Ferrite Unit
18 Exit Gas Cooler
20 Recycle Gas Cooler
21 Recycle Gas Compressor I
23 Recycle Gas Compressor II
26 Gas Turbine \& Air Compressor
27 Combustion Chamber
29 Superheater I - Reheater I
Superheater I - Reheater II
Superheater II
31 HP1 Economizer
32 Feedwater 1/2
34 HP Turbine
37 IP Turbine
39 LP Turbine
40 Seal Steam Regulator
43 LP Pump
46 Deaerator
47 HP Pump

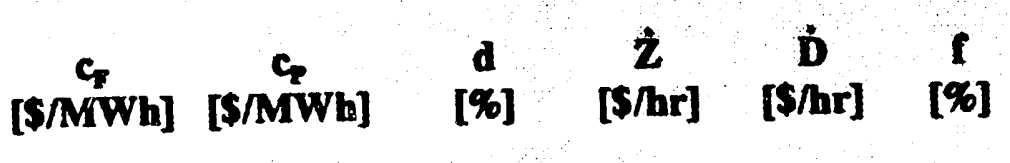

7.04

9.13

9.18

9.58

9.96

5.82

9.96

22.20

22.31

22.93

10.16

14.75

14.77

22.93

22.93

12.93

13.03

14.53

14.55

14.512

14.55

14.26

20.51

9.12

29.54

539.

1520.3

26.19

9.18

18.64

9.72

9.96

19.57

10.11

27.60

49.92

35.32

10.16

26.85

76.30

148.39

244.88

20.08

15.84

18.15

17.12

18.60

18.65

46.62

20.62

24.97

21.98

25.36

29.22

20.31

22.97

34.48

35.18

211.34

38.64

22.93
0.55

102.94

1.47

0.00

235.97

1.48

24.31

123.73

54.06

0.00

82.06

416.45

547.20

968.02

55.33

21.53

24.96

17.66

28.17

28.21

226.83

21.73

22.95

32.93

69.79

820.01

9.82

71.60
31.6

305.5

0.0

493.9

331.1

132.5

16.1

14.1

87.1

216.9

142.3

75.4

125.5

45.2

1131.1

59.5

16.7

96.7

39.8

240.7

6.2

152.2

101.9

233.1

2.1

5.3

9.7

19.6
20.960 .21

$256.3 \quad 54.37$

$143.80 .0 \mathrm{~J}$

22.495 .66

$50.6 \quad 86.75$

$15.6 \quad 89.50$

$41.9 \cdot 27.72$

$76.9 \quad 15.50$

67.856 .23

$98.8 \quad 68.71$

$106.0 \quad 57.30$

$38.0 \quad 66.45$

$16.3 \quad 88.53$

$1.7 \quad 96.37$

$1098.1 \quad 50.74$

$2360.4 \quad 2.46$

$34.7 \quad 32.50$

$118.4 \quad 44.96$

$53.8 \quad 42.52$

$109.4 \quad 68.76$

$35.8 \quad 14.65$

$140.0 \quad 52.09$

$106.0 \quad 49.01$

494.1 32.06

$0.6 \quad 77.86$

$0.3 \quad 94.34$

$16.6 \quad 36.72$

$35.2 \quad 35.81$ 


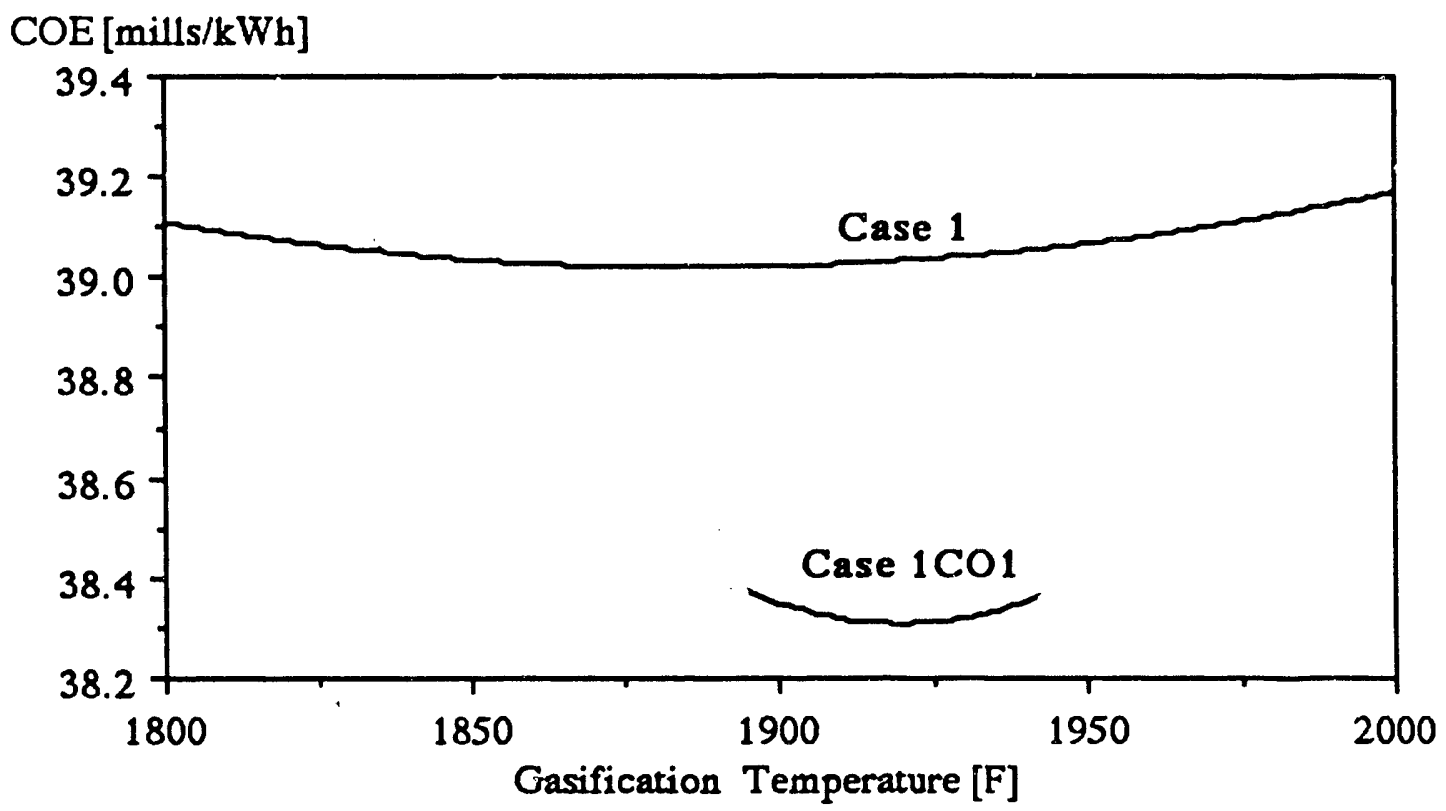

Figure A-1 Cost of Electricity as a Function of the Gasification Temperature for the Original Case 1 and Case $1 \mathrm{CO1}$

Note: If the gasification temperature is the only variable in an otherwise fixed design configuration, then the minimum cost of electricity is obtained in the temperature range of $1850^{\circ} \mathrm{F}-1900^{\circ} \mathrm{F}$ in the configuration of the original Case 1 (as predicted in Reference [1]), and in the range of $1900^{\circ} \mathrm{F}-1940^{\circ} \mathrm{F}$ in the configuration of Case 1CO1. The cost of electricity in the configuration of Case $1 \mathrm{CO} 1$ is more sensitive to changes in the gasification temperature than in the configuration of the original Case 1. This figure demonstrates the effect of different configurations and other design variables on the optimum value of an important design parameter. 


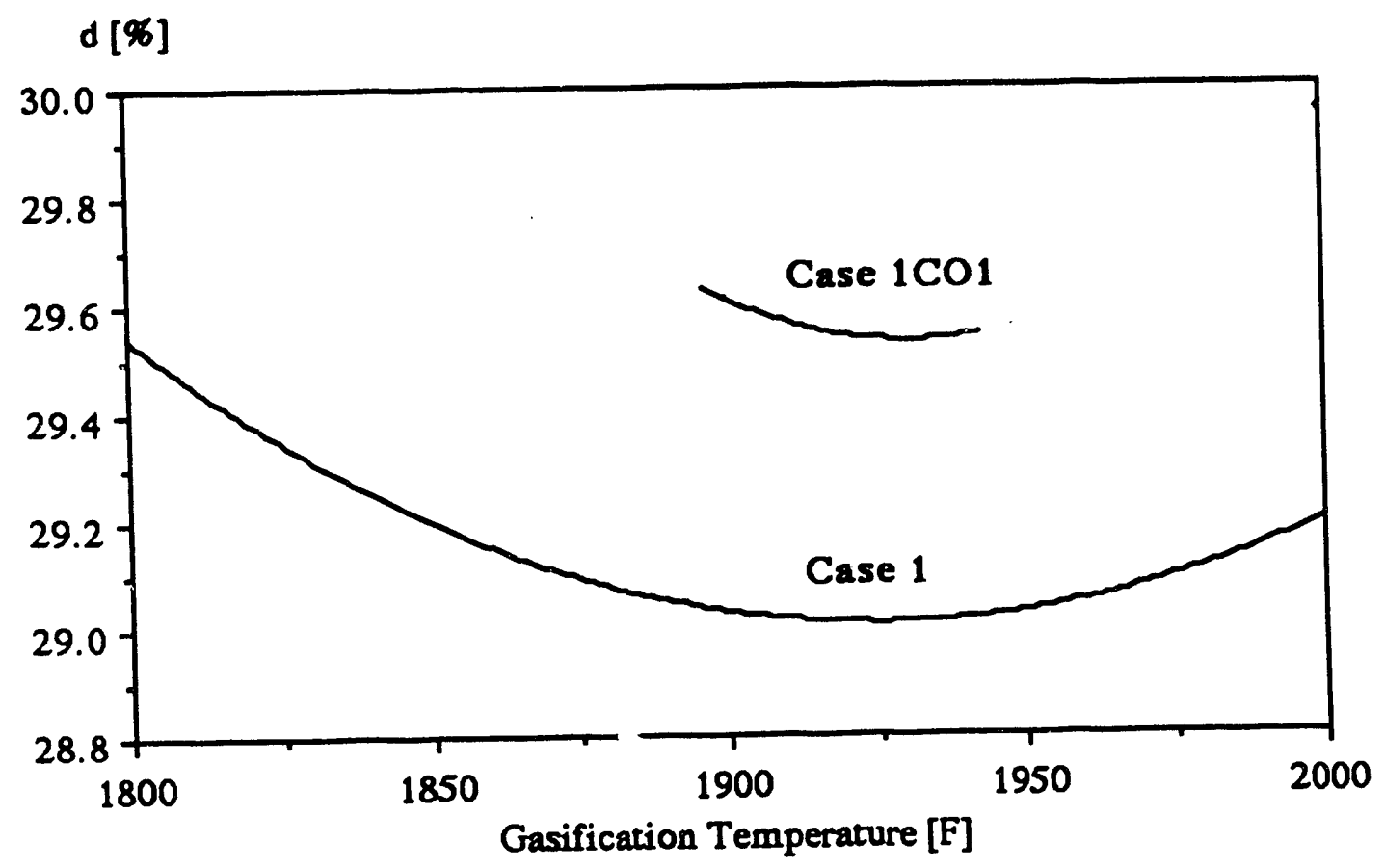

Figure A-2 Relative Cost Difference d for the Gasifier as a Function of the Gasification Temperature for the Original Case 1 and Case 1CO1

Note: The relative cost difference $d$ (Equation 3-6) predicts a cost optimal gasification temperature in the range of $1900^{\circ} \mathrm{F}-1950^{\circ} \mathrm{F}$ for both the design configuration of Case 1 and Case $1 \mathrm{CO} 1$ in spite of the design differences in these cases. Thus, the relative cost difference $d$ could be used in the beginning of the design process to estimate the optimal gasification temperature even before the design of the remaining areas in the plant is completed. This finding could result in significant savings in engineering time during the development of a "good" IGCC power plant design. 


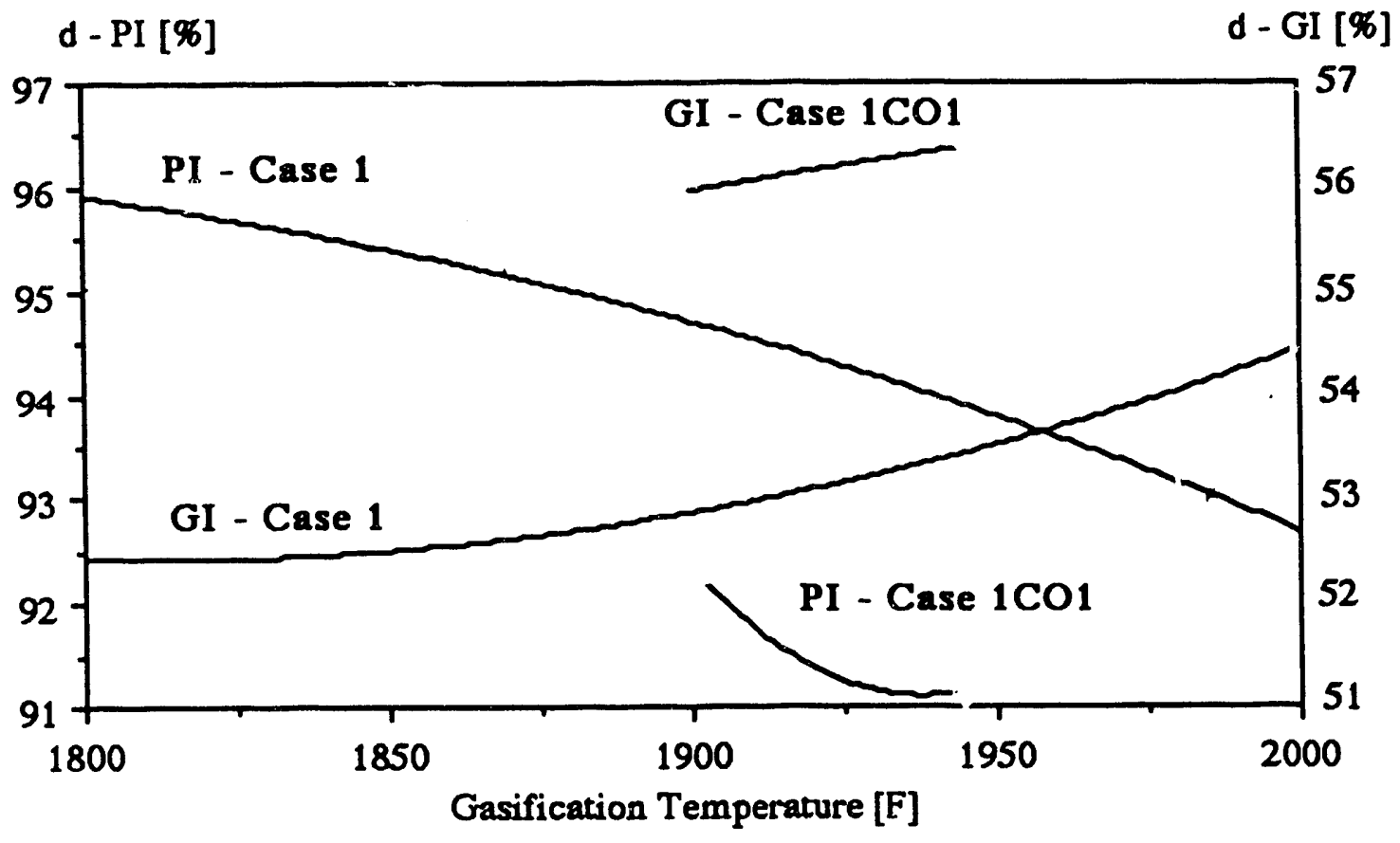

Figure A-3 Comparison of the relative cost difference d calculated for the Gasification Island (GI) and the Power Island (PI) for Cases 1 and 1CO1. The $d$ values are given on the left axis for PI and on the right axis for GI.

Note: With increasing gasification temperature, the $d$ value for the gasification island increases while it decreases for the power island. Compared with Case $1 \mathrm{CO} 1$, the original Case 1 has lower $d$ values for the gasification island but higher values for the power island. The trends expressed in the above curves help to understand the development of the curves shown in Figure A-1. 

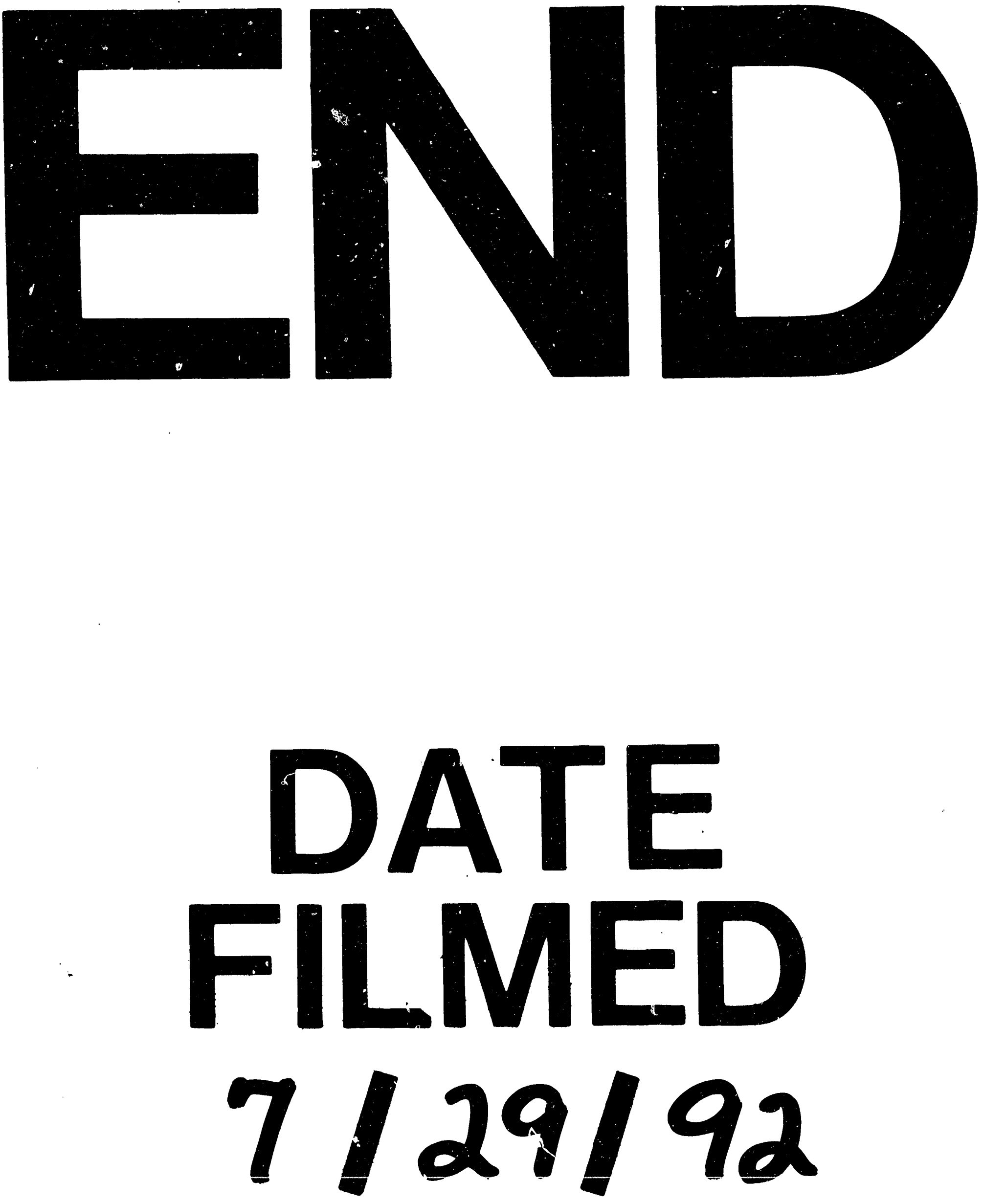
